VŠB - Technical University of Ostrava FACULTy of EleCtrical ENGINEERING AND COMPUTER SCIENCE

\title{
Analysis of Biological Data
}

\author{
DOCTORAL THESIS
}

Ostrava 2015

Tomáš Novosád 

VŠB - TeChNicAl University OF Ostrava FaCUlty of EleCtrical EngineERING AND COMPUTER SCIENCE

Department of Computer Science

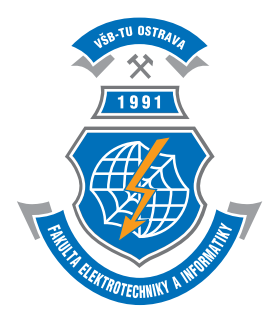

\title{
Analysis of Biological Data
}

\author{
by \\ Mgr. Tomáš Novosád \\ Supervisor: Prof. RNDr. Václav Snášel, CSc.
}

Dissertation submitted to the Faculty of Electrical Engineering and Computer Science, Department of Computer Sciences of VŠB - Technical University of Ostrava in partial fulfillment of the requirements for the degree of

Doctor of Philosophy

in the branch of study

Computer Science

May 2015 
To my dear Pavlínka. To my family. To my friends. 


\section{Preface}

This thesis deals with an analysis of biological data and it is focused mainly on protein molecules and micro RNA molecules which play an important role in the process of the regulation of protein creation. The thesis is divided into three main parts. The first part presents the theoretical background and it is focused on the biological aspects and computer science structures, models and methods used in data analysis. The second part of this work presents our algorithms for the analysis of protein three dimensional structures and protein sequences. The last part of the thesis represents our experiments with micro RNA and its influence on a disease called sarcoidosis. These experiments deal with real data collected in a clinical environment from patients with the sarcoidosis. In this part we applied various statistical and computer science methods for the evaluation of this data and identified biological signaling pathways which affects the course of the disease.

First of all I would like to express my gratitude to my supervisor Prof. Václav Snášel who is a great specialist in the field of data mining and analysis and who steered me through this research. My thanks also to Dr. Miloš Kudělka with whom we developed algorithms for protein sequence analysis. I would also like to thank Dr. Eva Kriegová and Mgr. Tereza Dýšková for letting me be a part of their team solving various molecular biology problems and allowing me to help them with the analysis of micro RNA and Next Generation Sequencing data.

My deepest obligation comes to my family, friends and all my loved ones.

Concerning the financial arrangements, this work was supported by the European Regional Development Fund in the IT4Innovations Center of Excellence project (CZ.1.05/1.1.00/02.0070) and by the SGS, VŠB-Technical University of Ostrava, under grant no. SP2014/110 and by the Internal Grant Agency of the Ministry of Health of the Czech Republic under grant no. NT/11117-6 and by the Internal Grant Agency under grant no. LF_2013_13.

Tomáš Novosád

VŠB - Technical University of Ostrava

Ostrava, May 2015 


\title{
Analysis of Biological Data
}

\author{
Mgr. Tomáš Novosád \\ VŠB - Technical University of Ostrava, Ostrava, May 2015 \\ Supervisor: Prof. RNDr. Václav Snášel, CSc.
}

The thesis deals with computer analysis of biological data. It is mainly focused on protein structures and sequences as well as on small micro RNA (miRNA) molecules which play a crucial role in the regulation of the translation process of the messenger RNA (mRNA) molecules. Analyzing three dimensional protein structures is a very important task in molecular biology. Nowadays, the solution for protein structures often stems from the use of the state-of-the-art technologies such as nuclear magnetic resonance (NMR) spectroscopy techniques, or X-Ray crystallography, etc. as seen in the increasing number of Protein Data Bank (PDB) entries. The Protein Data Bank is a database of 3D structural data of large biological molecules, such as proteins and nucleic acids. It was proved that structurally similar proteins tend to have similar functions even if their amino acid sequences are not similar to one another. Thus, it is very important to find proteins with similar structures (even in part) from the growing database to analyze protein functions. However, technologies like NMR cannot handle the ever increasing speed at which new proteins are sequenced, since protein sequencing is much more simple and cheaper then these methods. Thus it is important to have methods that can predict the protein structure directly from the sequence of amino acid residues. One of the very important and often used modeling methods is based on knowledge of a protein sequence with a known structure as a template. Such methods, however, require fast and accurate sequence analysis tools. It has been proven that proteins with a certain sequence similarity calculated by pairwise alignments tend to have similar structural and functional properties even if their sequences of amino acid residues are not very similar. It has been found that $30 \%$ 
of sequence similarity over aligned regions is sufficient to find similar functional and structural properties of protein molecules. Therefore there is an effort in the development and refinement of the methods and tools which deal with the protein sequence similarity on the level of the protein primary structure i.e. protein sequence.

This thesis has three main parts. The first part presents the theoretical background which is needed in the following parts of this thesis. It is aimed at both biological and computer science background. We briefly describe protein, RNA and micro RNA molecules and protein databases. We also bring the description of information retrieval models, methods and structures used for the analysis of the biological data.

The second part of this thesis presents our novel approaches for the analysis of protein molecules in a sense of 3D structure and sequence similarity. For this purpose we utilize information retrieval models such a vector space model, inverted lists and term weighting schemes. Since the protein molecules are presented as sequences of amino acid residues, we use a fast sequence comparison structure suffix tree. With the usage of these models and structures, we developed fast and an accurate protein sequence and structure comparison algorithm which achieves high speed and produces accurate results in comparison with state-of-the-art algorithms. In this part we also present our protein sequence clustering approach which is based on a graph analysis. It is a simple graph based clustering algorithm which uses the process of finding connected components of the graph. For the creation of the graph we use our method for finding protein sequences similarities. This clustering algorithm is also very fast and achieves very good results in comparison with the human crafted biological database SCOP - Structural Classification of Proteins.

The last part of this work is focused on the analysis of micro RNA molecules. Micro RNA (miRNA) molecules are small parts of non-coding regions of RNA molecules. These small molecules play very important role in protein synthesis, since they regulate life cycle of mRNA molecules which are subsequently translated into protein molecules. The analysis is done on real unique data which comes from a clinical environment. It is focused on patients with sarcoidosis which is a chronic disease of unknown cause. Through this analysis we found miRNA molecules and 
target genes and biological molecular pathways which affect the process of the disease. 


\title{
Analýza biologických dat
}

\author{
Mgr. Tomáš Novosád \\ VŠB - Technická univerzita Ostrava, Ostrava, May 2015
}

Školitel: Prof. RNDr. Václav Snášel, CSc.

Tato disertační práce se zabývá analýzou biologických dat. Hlavně je zaměřena na proteinové struktury a sekvence a dále na malé molekuly mikro RNA, které hrají klíčovou roli v regulaci tvorby RNA molekul a potažmo proteinů. Analýza trojrozměrné struktury proteinů je velmi důležity úkol v oblasti molekulární biologie. V současné době je řešení tohoto problému prováděno pomocí state-of-the-art technik jako je např́iklad spektroskopie s využitím nukleární magnetická rezonance (NMR) nebo krystalografie založená na rentgenové analýze. Výsledek těchto technik je nejlépe vidět na stále rostoucím počtu záznámů v databázy PDB (Protein Data Bank). Protein Data Bank je databáze trojrozměrných strukturálních dat, které popisují velké biologické molekuly jako jsou proteiny nebo nukleové kyseliny DNA a RNA. Již v minulosti bylo dokázáno, že strukturálně podobné proteiny mají tendeci mít také stejnou funkci i když sekvence aminokyselin, ze kterých jsou složené, jsou odlišné. Proto je velmi důležité hledat proteiny s podobnou strukturou (i když jen částečně), ze stále se rozšiřující proteinové databáze, a zkoumat funkce těchto molekul. Ačkoliv jsou technologie jako například NMR velice přesné, nemohou nikdy pokrýt množství nových proteinů, které jsou sekvenovány, jelikož proces sekvenování je nesrovnatelně rychlejší a také podstatně levnější. Proto je velmi důležité mít postupy a metody, které mohou predikovat trojorozměrnou strukturu proteinu přímo ze sekvence aminokyselin, ze kterých se skládají. Jedna z velice důležitých modelovacích (prediktivních) metod je založena na znalosti proteinových sekvencí s již známou trojrozměrnou strukturou, která slouží jako tzv. šablona. Takovéto metody ovšem vyžadují přesné a rychlé nástroje pro analýzou proteinových sekvencí. Bylo dokázáno, že proteiny s určitou mírou podobnosti 
sekvence, vypočitáné párovým porovnáním, mají tendenci mít i podobnou strukturu a funkční vlastnosti, i když tyto sekvence nejsou zcela totožné. Bylo zjištěno, že pouhá $30 \%$ podobnost oblastí zkoumaných sekvencí, je dostačující pro nalezení stejných funkčních a strukturních vlastností proteinových molekul. Proto je snaha vyvíjet a zpřesňovat metody pro hledání podobností na úrovni proteinové sekvence neboli primární struktury proteinu.

Tato disertační práce se skládá ze tří hlavní částí. První část představuje teoretické pozadí, které je nutné pro pochopení dalších částí této práce. Zaměřujeme se zda jak na popis biologických struktur, tak na oblast informačních technologií. Z oblasti biologie jsou zde představeny základní pojmy týkající se proteinů, RNA, mikro RNA nebo proteinových databází. Z oblasti informatiky zde přinášíme základní popis struktur, modelů a metod používaných v oblasti nazývané dokumentografické informační systémy neboli anglicky information retrieval. Struktury a metody z této oblasti nadále využíváme pro analýzu proteinových struktur a sekvencí.

Druhá část této práce je zaměřena na náš nový př́stup pro analýzu proteinových molekul ve smyslu terciální (trojorozměrné) struktury a stejně tak i primární struktury. Pro tento účel jsme využili modelů z oblasti Information Retrieval, jako je např́ílad dobře známý vektorový model dokumentů, invertované seznamy nebo různé schémata pro vážení termů apod. Jelikož si proteinovou molekulu můžeme představit jako sekvenci po sobě jdoucích aminokyselin, můžeme vhodně využít strukturu, která se nazývá sufixový strom. S využitím těchto struktur a postupů jsme vyvinuly rychlý a přesný algoritmus pro porovnávání proteinových sekvencí a struktur. Tento algoritmus dosahuje velmi kvalitní přesnost a nízkou časovou náročnost, ve srovnání se state-of-the-art algoritmy, které jsou v současné době používáné. Dále v této části práce práce popisujeme náš přístup pro shlukování proteinových sekvencí. Tento přístup je založen na předchozí metodě pro porovnávání proteinů a dále využívá grafovou reprezentaci, která je konstruována právě na základě informací získaných ze vzájemného porovnávání proteinových sekvencí. Jedná se o jednoduchý algoritmus založený na hledání spojených komponent $\mathrm{v}$ grafu. Pro vytvoření takového grafu využíváme právě informace o podobnosti proteinů, spočítaných předchozí metodou. Tento shlukovací algoritmus dosahuje také vysoké rychlosti a hlavně velice dobré přesnosti ve 
srovnání s databází proteinových sekvencí SCOP - Structural Classification of Proteins - která je vytvářena experty z oblasti molekulární biologie a to především z velké části manuálně.

Poslední část této disertační práce je zaměřena na analýzu malých mikro RNA molekul. Mikro RNA (miRNA) jsou malé části nekódujících oblastí RNA molekul. Tyto malé molekuly hrají klíčovou roli v syntéze proteinů, jelikož regulují tvorbu RNA molekul a tím pádem i proteinových molekul, které jsou právě vytvářeny překladem z mRNA. Tato analýza je prováděna na reálných datech, které pocházejí od pacientů z klinického prostředí. Zkoumali jsme pacienty s nemocí, která se nazýva sarkoidóza, což je chronické onemocnění, u kterého není známa přesná příčina. Pomocí naší analýzy jsme našli mikro RNA molekuly a cílové geny a biologické signální dráhy, které mají vliv na průběh tohoto onemocnění. 


\section{Contents}

$\begin{array}{ll}\text { Preface } & \text { i }\end{array}$

$\begin{array}{lll}\text { Abstract } & \text { iii }\end{array}$

$\begin{array}{ll}\text { Abstrakt vi } & \text { vi }\end{array}$

1 Introduction 1

1.1 Problem Statement . . . . . . . . . . . . . . . . . . . 4

1.2 Overview of the Thesis . . . . . . . . . . . . . . 5

1.3 Key Thesis Benefits . . . . . . . . . . . . 6

$\begin{array}{lll}\text { I Theoretical Background } & 9\end{array}$

2 Biological Background $\quad 11$

2.1 Proteins . . . . . . . . . . . . . . . . . . . 11

2.1 .1 Primary Structure . . . . . . . . . . . . . . . 12

2.1.2 Secondary Structure . . . . . . . . . . . . . . . . . . 12

2.1.3 Tertiary Structure . . . . . . . . . . . . . . . . . . . . 13

2.1.4 Quaternary Structure . . . . . . . . . . . . . . . . . 13

2.1.5 Dihedral angles . . . . . . . . . . . . . . . . . . . 14

2.1.6 Blocks Substitution Matrix . . . . . . . . . . . 15

2.2 Protein Databases . . . . . . . . . . . . . . . . 16

2.2.1 Protein Databank - PDB . . . . . . . . . . . . 16

2.2.2 SCOP: Structural Classification of Proteins . . . . . . . . 17 
2.2.3 CATH Protein Structure Classification . . . . . . . . . 19

2.2.4 DALI - Distance matrix ALIgnment . . . . . . . . . . . 19

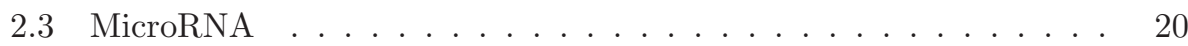

3 Data Analysis Background 23

3.1 Information Retrieval . . . . . . . . . . . . . . . . . 23

3.2 Vector Space Model . . . . . . . . . . . . . . . . . . 24

3.3 Suffix Trees . . . . . . . . . . . . . . . . . . 26

3.3.1 Suffix Tree Construction Algorithms . . . . . . . . . . . 28

3.4 Graph and Components . . . . . . . . . . . . . . . 29

\section{Proteins - Structure and Sequence Similarity 33}

4 Algorithmic and Implementation Details 35

4.1 Suffix Tree Construction . . . . . . . . . . . . . . . . . 35

4.1 .1 Naive method . . . . . . . . . . . . . . . 36

4.1 .2 Implementation Improvements . . . . . . . . . . . . . 47

4.2 Maximal Common Subsequence . . . . . . . . . . . . . . . . 47

4.3 Vector Space Model Construction . . . . . . . . . . . . . . . . 48

5 Analysis of Protein 3D Structures 51

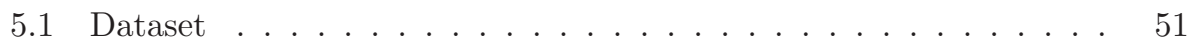

5.1.1 Creating Proteins Collection . . . . . . . . . . 52

5.1.2 Encoding the 3D Protein Main Chain Structure for Indexing 52

5.2 Protein Structure Similarity Algorithm . . . . . . . . . . . . . 53

5.3 Experiments and Evaluation . . . . . . . . . . . . . . 54

5.4 Discussion . . . . . . . . . . . . . . . 59

6 Analysis of Protein Sequences $\quad 65$

6.1 Dataset Description . . . . . . . . . . . . . 66

6.2 Amino Acid Substitution Suffix Tree . . . . . . . . . . . . . 67

6.3 Protein Sequence Similarity and Clustering Algorithm . . . . . . . 69

6.4 Experiments and Evaluation . . . . . . . . . . . . . . 70

6.4.1 Evaluation .................. 71 
6.4.2 Experiments with Sequence Similarity . . . . . . . . . . 74

6.4.3 Experiments with Sequence Clustering . . . . . . . . . . 74

6.5 Discusion ....................... 84

$\begin{array}{lll}\text { III Micro RNA Analysis } & 89\end{array}$

7 Analysis of Micro RNA in Sarcoidosis $\quad 91$

7.1 Sarcoidosis Disease and Micro RNA . . . . . . . . . . . . . . 91

7.2 Dataset description . . . . . . . . . . . . . . . . . . 93

7.3 Experiments and Evaluation . . . . . . . . . . . . 93

7.3.1 Identification of Significant miRNA . . . . . . . . . . . 94

7.3.2 Classification and Clustering of Subjects . . . . . . . . . 96

7.3.3 Identification of Signaling Pathways . . . . . . . . . . . . 104

7.4 Discussion . . . . . . . . . . . . . . . . . 107

IV Conclusions 113

8 Conclusions $\quad 115$

$\begin{array}{ll}\text { References } & 119\end{array}$

A List of Author's Publications $\quad$ I

Journal Articles . . . . . . . . . . . . . . . . . . . . I I

Books Chapters . . . . . . . . . . . . . . . . . II

Conference Papers . . . . . . . . . . . . . . . . . II II

Other Conference Papers . . . . . . . . . . . . . . . . III 


\section{List of Figures}

2.1 Chemical structure of two amino acids. . . . . . . . . . . . 12

2.2 Secondary structure elements and domain example. . . . . . . . . 13

2.3 Tertiary structure of an Apoptosome-Procaspase-9 CARD complex. 14

2.4 The dihedral angles $\phi$ and $\psi$ of the amino acids peptide bond. . . . 15

2.5 A sample part of the BLOSUM62 scoring matrix. . . . . . . . . . . 16

2.6 SCOP hierarchical structure . . . . . . . . . . . . . 18

2.7 Biogenesis and mechanism of creation and function of miRNA molecule. 21

3.1 Geometrical representation of cosine similarity. . . . . . . . . . . 26

3.2 Example of the generalized suffix tree. . . . . . . . . . . . . . 28

3.3 Example of simple a graph. . . . . . . . . . . . . . . 30

3.4 Example subgraphs $G^{\prime}{ }_{1}$ and $G^{\prime}{ }_{2}$ of graph $G$. . . . . . . . . . . . . 31

4.1 Suffix Tree Construction - Insertion of Suffix $p_{1}[1 . . l]$ and Suffix $p_{1}[2 . . l] \ldots \ldots \ldots \ldots \ldots \ldots$

4.2 Suffix Tree Construction - Insertion of Suffix $p_{1}[3 . . l]$ and Suffix $p_{1}[4 . . l] \ldots \ldots \ldots \ldots \ldots \ldots$

4.3 Suffix Tree Construction - Insertion of Suffix $p_{1}[5 . . l]=\mathrm{MV} \#$. . . . 39

4.4 Suffix Tree Construction - Insertion of Suffix $p_{1}[6 . . l]=\mathrm{V} \# \quad$. . . . . 39

4.5 Suffix Tree Construction - Insertion of Suffix $p_{2}[1 . . m]=$ VLAVMV\# 40

4.6 Suffix Tree Construction - Insertion of Suffix $p_{2}[2 . . m]=\mathrm{LAVMV} \#$. 40

4.7 Suffix Tree Construction - Insertion of Suffix $p_{2}[3 . . m]=A V M V \#$. . 41

4.8 Suffix Tree Construction - Insertion of Suffix $p_{2}[4 . . m]=V M V \# \quad$. . 41

4.9 Suffix Tree Construction - Insertion of Suffix $p_{2}[5 . . m]=\mathrm{MV} \#$. . . . 42 
4.10 Suffix Tree Construction - Insertion of Suffix $p_{2}[6 . . m]=\mathrm{V} \#$. . . . . 42

4.11 Suffix Tree Construction - Insertion of Suffix $p_{3}[1 . . n]=$ AVAMVLE\# 43

4.12 Suffix Tree Construction - Insertion of Suffix $p_{3}[2 . . n]=$ VAMVLE\# 43

4.13 Suffix Tree Construction - Insertion of Suffix $p_{3}[3 . . n]=$ AMVLE\# . 44

4.14 Suffix Tree Construction - Insertion of Suffix $p_{3}[4 . . n]=$ MVLE\# . . 44

4.15 Suffix Tree Construction - Insertion of Suffix $p_{3}[5 . . n]=$ VLE\# . . . 45

4.16 Suffix Tree Construction - Insertion of Suffix $p_{3}[6 . . n]=\mathrm{LE \#} \ldots . . . \quad 45$

4.17 Suffix Tree Construction - Insertion of Suffix $p_{3}[7 . . n]=\mathrm{E} \#$. . . . . 46

5.1 (PDB - 2eng) Endoglucanase V. . . . . . . . . . . . 57

5.2 1st Rank - PDB 3eng (Structure of Endoglucanase V Cellobiose Complex). . . . . . . . . . . . . . . 57

5.3 4th Rank - PDB 118f (Structure of 20K-Endoglucanase from Melanocarpus Albomyces at 1.8A). . . . . . . . . . . . . . . 58

5.4 8th Rank - PDB 1aun (Pathogenesis-Related Protein 5D from Nicotiana Tabacum). . . . . . . . . . . . . . . 58

5.5 Protein Class Membership Percentage Accuracy. . . . . . . . . . . 61

5.6 Protein Folding Pattern Membership Percentage Accuracy. . . . . 61

5.7 Protein Super-Family Membership Percentage Accuracy. . . . . . . 62

5.8 Protein Family Membership Percentage Accuracy. . . . . . . . . . 62

5.9 Protein Domain Membership Percentage Accuracy. . . . . . . . . 63

6.1 Example of the amino acid substitution generalized suffix tree. . . 68

6.2 Protein sequences data processing. . . . . . . . . . . . . . . 69

6.3 SCOP HAMP domain-like Fold, Super-Family and Family detected by our algorithm. . . . . . . . . . . . . . . . 70

6.4 A simple example of the calculation of the Matthews Correlation Coefficient and the way of determining true, false positive and negative values. . . . . . . . . . . . . . . . 73

$6.5 R O C_{5}$ comparison - SCOP Fold category. . . . . . . . . . . . . 77

$6.6 R_{5}$ comparison - SCOP Super-family category. . . . . . . . . 77

$6.7 R O C_{5}$ comparison - SCOP Family category. . . . . . . . . . . . 78

$6.8 R_{5}$ comparison - SCOP Domain category. . . . . . . . . . 78 
$6.9 R O C_{5}$ comparison - SCOP Species category. . . . . . . . . . . 79

6.10 Matthews correlation coefficient - SCOP Fold category. . . . . . . . 80

6.11 Matthews correlation coefficient - SCOP Super-family category. . . 81

6.12 Matthews correlation coefficient - SCOP Family category. . . . . . 81

6.13 Matthews correlation coefficient - SCOP Domain category. . . . . . 82

6.14 Matthews correlation coefficient - SCOP Species category. . . . . . 82

7.1 Relative expression of miR-214 - patients and controls. . . . . . . . 96

7.2 Relative expression of miR-150 - patients and controls. . . . . . . . 97

7.3 Relative expression of miR-25 - patients and controls. . . . . . . . 97

7.4 Relative expression of miR-146a - patients and controls. . . . . . . 98

7.5 Relative expression of miR-204 - patients and controls. . . . . . . . 98

7.6 Relative expression of miR-92 - remission and progression subjects. 99

7.7 Relative expression of miR-let-7c - remission and progression subjects. 99

7.8 Heatmap of patients and controls - 25 miRNAs. . . . . . . . . . . . 101

7.9 Heatmap of patients and controls - 5 the most significant miRNAs. 101

7.10 Heatmap of patients with remitting and progressing sarcoidosis - 25 miRNAs. ...................... 102

7.11 Heatmap of patients with remitting and progressing sarcoidosis - 5 the most significant miRNAs. . . . . . . . . . . . . . . 102

7.12 An idea of Random Forest algorithm. . . . . . . . . . . . . . . . 103

7.13 TFG- $\beta$ signaling pathway. . . . . . . . . . . . . . . . 108

7.14 WNT signaling pathway. . . . . . . . . . . . . . . . 109

7.15 JAK-STAT signaling pathway. . . . . . . . . . . . . . . 110

7.16 Cytokine-Cytokine Receptor Interaction signaling pathway. . . . . 111 


\section{List of Tables}

4.1 Maximal Common Subsequences . . . . . . . . . . . . . . 48

5.1 The ten most similar proteins to the protein labeled $2 E N G$ and the SCOP classifications . . . . . . . . . . . . 56

5.2 Class classification percentage accuracy $\ldots \ldots \ldots \ldots \ldots$

5.3 Proteins unclassified by using SCOP found by our algorithm and their membership percentage accuracy (mpa) to a given Class, Fold, Super-family, Family and Domain. . . . . . . . . . . . 63

6.1 The $R O C_{165,000}$ score of the protein sequence comparison methods 75

6.2 The number of queries with the $R O C_{5}$ score of the protein sequence comparison methods . . . . . . . . . . . . . . 76

$6.3 M C C$ for Protein Sequence Clusters _ . . . . . . . . . . 83

$6.4 M C C$ for Protein Sequence Clusters . . . . . . . . . . . . 86

6.5 Overall $M C C$ accuracy for protein sequence clusters . . . . . . 87

6.6 Time and Memory Requirements . . . . . . . . . . . . 88

$7.1 p$-values for Patient vs. Control Group and Remission vs. Progression Group . . . . . . . . . . . . . . . . . . 95

7.2 Random Forest for All 25 miRNAs . . . . . . . . . . . . . 105

7.3 Random Forest for significant miRNAs . . . . . . . . . . . 105 


\section{Chapter 1}

\section{Introduction}

$\mathrm{D}$ ETERMINING the functional and structural properties of a protein is a very important task in molecular biology. Nowadays, the information about the structure of a protein molecule is obtained by state-of-the-art technologies such as nuclear magnetic resonance (NMR) spectroscopy techniques or X-Ray crystallography, as seen in the increasing number of Protein Data Bank (PDB) [89] entries (108607 as of May 11, 2015). The Protein Data Bank is a database of 3D structural data of large biological molecules, such as proteins and nucleic acids. It was proved that structurally similar proteins tend to have similar functions even if their amino acid sequences are not similar to one another. Thus, it is very important to find proteins with similar structures (or parts) from the growing database to analyze protein functions. Yang et al. [112] exploited machine learning techniques including variants of Self-Organizing Global Ranking, a decision tree, and support vector machine (SVM) algorithms to predict the tertiary structure of trans-membrane proteins. Hecker et al. [43] developed a state of the art protein disorder predictor and tested it on a large protein disorder data-set created from the Protein Data Bank. The relationship of sensitivity and specificity is also evaluated. Habib et al. [39] presented a new SVM based approach to predict the sub-cellular locations based on amino acid and amino acid pair composition. More protein features can be taken into consideration to improve the accuracy significantly. Wang et al. [107] discussed an empirical approach to specify the 
localization of protein binding regions utilizing information including the distribution pattern of the detected RNA fragments and the sequence specificity of RNase digestion.

However, technologies like NMR cannot handle the ever increasing speed at which new proteins are sequenced, since protein sequencing is much more simple and cheaper then these methods. Thus it is important to have methods that can predict the protein structure directly from the sequence of amino acid residues. One of the very important, and often used, modeling methods is based on knowledge of a protein sequence with known structure as a template [116, 12, 115]. Such methods, however, require fast and accurate sequence analysis tools.

These days a large protein collections exists, and, to be able to predict protein structure from a sequence of amino acid residues, we need to know and understand protein evolutionary relationships and to classify particular protein sequences. Nowadays there are two main approaches to carrying out this classification - manually and automatically. Manual classification of proteins such as SCOP, UniProtKB/Swiss-Prot or CATH are done by human experts and requires deep knowledge of protein molecular properties. Although manual classification is very accurate, it faces a challenge from an ever increasing number of known protein sequences since it takes a considerable amount of time. On the other hand, there are automatic methods such as DALI, UniProtKB/TrEMBL or FSSP. These methods are fully automated and can classify proteins sequences much faster than manual methods but give different results in comparison to human maintained databases. One of the key challenges in bioinformatics is to find a method fast enough to be able to process large amounts of known protein sequences and to produce accurate results in comparison to manually annotated databases such as SCOP (Structural Classification of Proteins). A BLASTP, PSI-BLAST and the newest DELTABLAST algorithms represent a gold-standard in the field of sequence comparison methods. Although these methods are widely used by biologists and achieve good accuracy and sensitivity in the detection of homologue protein sequences, they still require high-performance computing hardware to achieve fast response times, otherwise they are very slow and, thus, not suitable for analyzing large protein databases.

It has been proven that proteins with a certain sequence similarity calculated 
by pairwise alignments tend to have similar structural and functional properties even if their sequences of amino acid residues are not similar [38, 14]. It has been found that $30 \%$ of sequence similarity over aligned regions is sufficient to find similar functional and structural properties of protein molecules $[17,88]$. In the SCOP database we can find lots of examples with low sequence similarity but a similar structure or function. These samples form larger groups which are, for example, super-families, families, domains and species in the context of the SCOP database. These groups of protein domain sequences correspond to clusters and thus it makes sense to develop automatic methods that can discover such groups.

Perhaps the first attempt at the automatic classification of proteins was introduced by Holm and Sander [51, 52] when applying a hierarchical clustering method based on pairwise structural similarity scores between the sequences of amino acids (DALI and FSSP databases). Another approach to finding groups of proteins with similar functions or structures and for the detection of remote protein homologues was presented in $[84,7]$. The authors of these works developed a graph-based clustering method and an extension to identify remote protein homologues with the usage of the mathematical properties of transitivity applied to protein sequences. Enright et al. [27] developed a method called TRIBE-MCL for large-scale clustering of protein sequences. This method relies on the Markov cluster algorithm [23] for the assignment of proteins into families. Edgar [26] presented the fast clustering method UCLUST for large protein databases. This method uses UBLAST and USEARCH algorithms that implement a fast heuristic designed to enable the rapid identification of one or a few good hits rather than processing all homologous sequences. Another popular clustering algorithm CD-HIT was developed by Fu et al. [31] and subsequently improved in response to the new next-generation sequencing technologies, which produces large amounts of DNA and RNA sequencing data. Both UCLUST and CD-HIT use dynamic programming to speed up the Smith-Waterman lookup. A more recent protein clustering approach is presented in [42]. The kClust algorithm developed by Hauser et al. is based on matching similar k-mers and ranking analyzed sequences by the sum of similarity scores through all similar k-mers. All three clustering algorithms are based on the incremental greedy clustering strategy [45]. A comparison of various protein sequence clustering approaches can be found in [105]. 
There is also another very important aspect in the analysis of protein molecules and that is a regulation of creation of these molecules. In the last decade, it has proven that the regulation of proteins is affected by small non-coding RNA molecules, which are called micro RNA (miRNA). MicroRNAs (miRNAs) are highly conserved small $\approx 22$ nucleotides $(n t)$ long RNAs involved in the negative post-transcriptional regulation of target messagner RNAs (mRNA) [22], which are then translated into a sequences of amino acid residues, which form protein molecules. MicroRNAs belong to the one of the most abundant classes of human genome regulators: more than $30 \%$ of human genes are regulated by miRNAs, whereas the main action is the degradation of the target mRNAs [36].

\subsection{Problem Statement}

This thesis is focused on the analysis of biological data and especially on protein molecules. We analyze proteins primary and tertiary structures and focus on the comparison of protein molecules. Our goal is to utilize information retrieval structures and models and show their usability in the field of biological data. We first introduce our method for the comparison of protein 3D structures which was the basis for out next research regarding the analysis of proteins primary structures - sequences. To measure the quality of our algorithms we use stateof-the-art databases such as the Protein Data Bank, in the case of protein 3D structure, and Structural Classification of Proteins, in the case of the protein primary structure. As was mentioned above, analyzing protein sequences and structures plays a key role in current bioinformatics. We have also targeted the speed of proposed algorithms, since these days database contains a large amount of data and, thus, it is important to have methods which can process this data in a reasonable time. We compare our method with "gold-standard" algorithms such as PSI-BLAST and DELTA-BLAST when we analyze protein primary structures. Since the protein databases, such as SCOP, contain information about group of proteins which have some functional, structural or evolutionary connection, we also present our graph-based clustering algorithm. All above mentioned databases contain tens of thousands entries and thus we analyze a large amount of biological data. 
Since the proteins are regulated by micro RNA molecules, we also targeted our research on the analysis of these molecules in connection with the disease known as Sarcoidosis. We collected data from a clinical environment from patients with this disease and used bioinformatics tools and databases to analyze the impact of certain miRNA molecules on the progress of the disease. Our aim was to find biological signaling pathways containing certain miRNAs which play an important role in the progress of this illness.

\subsection{Overview of the Thesis}

In Part I we start by describing the theoretical background needed in the subsequent parts of the thesis. We divided this part into two chapters. A brief description of the biological background is presented in Chapter 2. In this chapter we describe basic biological properties of protein molecules and micro RNA molecules and we also bring a brief description of protein databases. Chapter 3 is about the information retrieval model used for the analysis of biological data. In Section 3.2 there is the description of the vector space model, which we use for the representation of protein data. The next section, 3.3, deals with a sequence analysis structure called the suffix tree. The last Section 3.4 of Chapter 3 discusses basic properties and theory about graphs, which we use for the clustering of proteins.

Part II brings our method for the comparison of protein 3D structures, protein sequences and clustering of the protein sequences. This part of the thesis is divided into the tree chapters. In the beginning of Part II (Chapter 4) we describe in detail the construction of the generalized suffix data structure (Section 4.1). In Section 4.2 there is a description of one important structure which we call the maximal substructure cluster or maximal common subsequence respectively. The last Section 4.3, of Chapter 4 presents an example of the vector space model construction based on the previous generalized suffix tree and maximal common subsequence.

Chapter 5 deals with the analysis of protein 3D structures - the calculation of protein similarities based on their three dimensional structure. The chapter is divided into three sections. Section 5.1 presents the description of the dataset 
used for the experiments. Next, Section 5.2 describes our algorithm used for the analysis of protein molecules. Section 5.3 is about experiments and evaluations of our method for 3D protein structure similarity calculation. The Last section of this chapter discusses the results achieved by our algorithm for computing protein 3D similarities.

The analysis of protein domain sequences is discussed in Chapter 6. This chapter has a similar structure as the previous Chapter 5. The first section, 6.1, describes the dataset used in this part of our work. The following section, 6.2, deals with a new Amino Acid Substitution Suffix Tree data structure which we developed for the purpose of better remote homology detection ability. Our protein sequence similarity and clustering algorithm is described in Section 6.3 and is followed by Section 6.4, in which we present the experiments and the evaluation used in this part of thesis. The last section, 6.5 , is dedicated to a discussion about our protein sequence similarity and clustering approach.

The last, Part III of the thesis, is engaged in the analysis of micro RNA molecules which play an important role in the disease sarcoidosis. It is targeted on real patients with this illness and the data used in this part of the work comes from a clinical environment. The first section, 7.1, briefly describes the disease sarcoidosis and micro RNA molecules which impact the progress of the disease. The description of the data used in this research is presented in Section 7.2. In Section 7.3 we describe the process of the identification of significant miRNAs (Section 7.3.1), experiments with clustering and classification with the Random Forest algorithm (Section 7.3.2) and a process of finding biological signaling pathways involved in the progress of sarcoidosis (7.3.3). The last section, 7.4 of Chapter 7 , summarizes our experiments and results with the analysis of micro RNA and sarcoidosis.

\subsection{Key Thesis Benefits}

This work is about the analysis of biological data and applications of bioinformatics tools and methods. One of the key benefit of this thesis is the development of algorithms for the analysis of protein molecules. The first proposed algorithm is the method for comparing protein 3D structures based on the positions of the 
atoms in their amino acid residues. We proposed a method for encoding protein 3D structure into a sequence with the usage of dihedral angles which define the relation of two consecutive amino acid residues. Subsequently we used information retrieval methods and models in connection with the suffix tree data structure to find similar substructures of the protein molecules. We demonstrated the ability of the algorithm on the Protein Data Bank and SCOP database.

The second goal of this work is a protein sequence analysis algorithm. Based on our first work with protein 3D structures we developed a method for calculating the protein primary structure - sequence - similarities. The calculated similarities were then used for the clustering of protein domain sequences. We did a comparison with state-of-the-art algorithms for protein sequence analysis such as PSI-BLAST, BLASTP and the newest DELTA-BLAST and were shown that our algorithm performs almost the same in the case of distantly related protein sequences and is much better in the detection of closely related protein sequences. One of the key benefits of this algorithm is its speed, since it rapidly outperforms the "goldstandard" BLAST algorithms - 15x faster than the most accurate DELTA-BLAST algorithm. We also proposed a simple graph-based clustering and compare it to the man made biological SCOP database and were shown that the clustering method can produce clusters absolutely identical to the ones in the SCOP database.

Lastly we analyzed real clinical data from patients with a disease called sarcoidosis. This research was targeted on micro RNA profiles of patients with sarcoidosis and the key benefit was the identification of a cell signaling pathways that are involved in the course of the disease. We used statistical methods for the identification of significant micro RNA molecules and than we used machine learning approaches for the next analysis of this data. We proved the importance of the identification of significant micro RNA molecules with Random Forest classification algorithm as well as on hierarchical agglomerative clustering. Using the random forest algorithm we are able to classify patients with sarcoidosis with $100 \%$ accuracy and patients with remitting and progressing disease with $82 \%$ accuracy. All the results were validated with 10-Fold cross validation to prove the correctness of the results. Final goal of this research was identification of 4 cell signaling pathways involved in progress of sarcoidosis. 


\section{Part I}

\section{Theoretical Background}





\section{Chapter 2}

\section{Biological Background}

\subsection{Proteins}

Proteins are large molecules that provide structure and control reactions in all cells. In many cases only a small part of the structure - an active site - is directly functional, the rest exists only to create and fix the spatial relationship among the active site residues [61]. Chemically, protein molecules are long polymers typically containing several thousand atoms, composed of a uniform repetitive backbone (or main chain) with a particular side chain attached to each residue. The amino acid sequence of a protein records the succession of side chains. There are twenty different amino acids that make up essentially all protein molecules on earth. Every amino acid has its own original design composed of a central carbon (also called the alpha carbon - $C_{\alpha}$ ) which is bonded to hydrogen, carboxylic acid group, amino group and unique side chain or R-group. The chemical properties of the $\mathrm{R}$ group are what give an amino acid its character.

The Danish protein chemist K.U. Linderstrøm-Lang described the protein structure in three different levels: a primary structure, a secondary structure and a tertiary structure. For proteins composed of more than one subunit, J.D. Bernall called the assembly of the monomers the quaternary structure. 


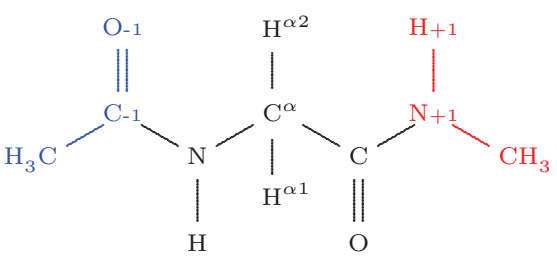

(a) Glycine

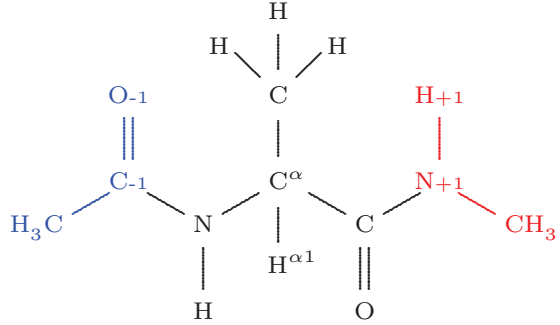

(b) Alanine

Figure 2.1: Chemical structure of two amino acids.

\subsubsection{Primary Structure}

The unique sequence of amino acids in a protein is termed the primary structure. When amino acids form a protein chain, a unique bond, termed the peptide bond, exists between two amino acids. The sequence of a protein begins with the amino of the first amino acid and continues to the carboxyl end of the last amino acid. Each of the amino acids has its own unique one letter abbreviation (e.g. Alanine - A, Methionine - M, Arginine - R, ...). Thus the primary structure of the protein can be expressed as a string of letters. The examples of protein's primary structure encoding is as follows:

$$
\begin{aligned}
& \text { MVLSEGEWQLVLHVWAKVEADVAGHGQDILIRLFKSHPETLEKFDRVKHL . . } \\
& \text { MNIFEMLRIDEGLRLKIYKDTEGYYTIGIGHLLTKSPSLNAAKSELDKAI . . } \\
& \text { AYIAKQRQISFVKSHFSRQLEERLGLIEVQAPILSRVGDGTQDNLSGAEK . . }
\end{aligned}
$$

\subsubsection{Secondary Structure}

The second level in the hierarchy of a protein structure consists of the various spatial arrangements resulting from the folding of localized parts of a polypeptide chain; these arrangements are referred to as secondary structures [63]. These foldings are either in a helical shape, called the alpha-helix ( $\alpha$-helix) (which was first proposed by Linus Pauling et. al in 1951 [83]), or a beta-pleated sheet ( $\beta$-sheet) shaped similar to the "zig-zag" foldings of an accordion. The turns of the alpha-helix are stabilized by hydrogen bonding between every fourth amino acid in the chain. The beta-pleated sheet is formed by the folding of successive planes [86]. Each plane is five to eight amino acids long. Alpha helices and beta sheets are linked by less structured loop regions to form domains (Figure 2.2). The 


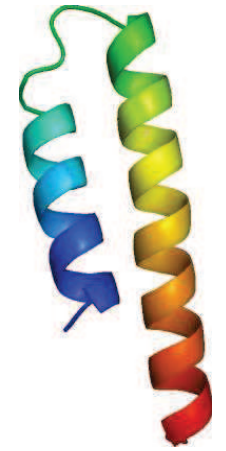

(a) $\alpha$-helix

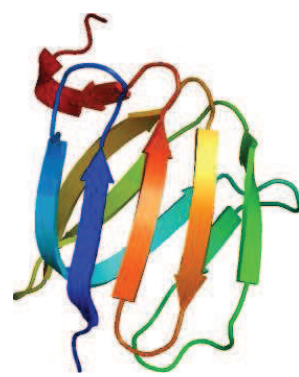

(b) $\beta$-sheet

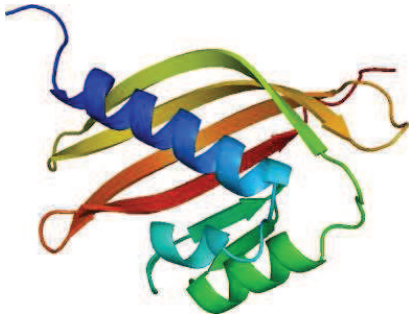

(c) Domain

Figure 2.2: Secondary structure elements and domain example.

domains can potentially form fully functional proteins.

\subsubsection{Tertiary Structure}

A tertiary structure refers to the overall conformation of a polypeptide chain that is the three-dimensional arrangement of all its amino acid residues. Each of the atoms of an amino acid residue has its own 3 -D $x, y, z$ coordinates. In contrast with secondary structures, which are stabilized by hydrogen bonds, a tertiary structure is primarily stabilized by hydrophobic interactions between non-polar side chains, hydrogen bonds between polar side chains, and peptide bonds. These stabilizing forces hold elements of secondary structure $\alpha$-helices, $\beta$-strands, turns, and random coils compactly together. The most the protein structures (about 90\%) available in the Protein Data Bank have been resolved by X-ray crystallography. This method allows one to measure the 3-D density distribution of electrons in the protein (in the crystallized state) and thereby infer the 3-D coordinates of all the atoms to be determined to a certain resolution. Just only about $9 \%$ of the known protein structures have been obtained by Nuclear Magnetic Resonance techniques (NMR spectroscopy) [10].

\subsubsection{Quaternary Structure}

Some proteins need to functionally associate with others as subunits in a multimeric structure. This is called the quaternary structure of the protein. This 


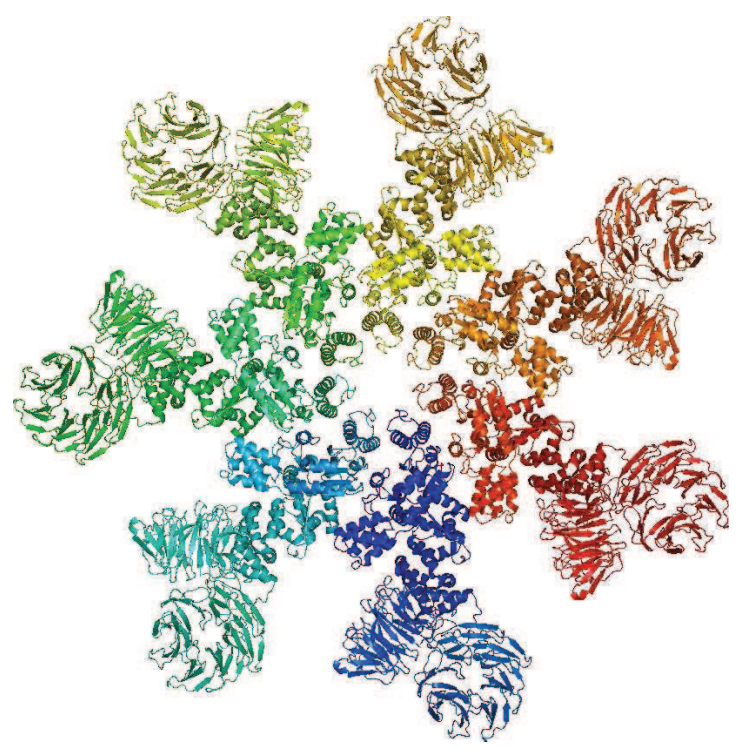

Figure 2.3: Tertiary structure of an Apoptosome-Procaspase-9 CARD complex.

can also be stabilized by disulphide bonds and by non-covalent interactions with reacting substrates or cofactors. An excellent example of quaternary structure is that of hemoglobin. Adult hemoglobin consists of two alpha subunits and two beta subunits, held together by non-covalent interactions [86].

\subsubsection{Dihedral angles}

In the peptide chain the amino acids are bound by a covalent bond between the carboxyl of the first and the amino acid group of the second amino acid. This kind of bond is termed the peptide bond. The peptide bond can not freely rotate and the distance between carbon $(C)$ and nitrogen $(N)$ is shorter than other $\mathrm{C}-\mathrm{N}$ bonds. Four atoms of the peptide bond $(C, N, H, O)$ and the two alpha carbons $C_{\alpha}$ of amino acid residues lie approximately in a plane. The oxygen of the carboxyl and the hydrogen of a $\mathrm{N}-\mathrm{H}$ group are mutually in a position called trans. The rest of the amino acid $\left(R^{1}, R^{2}\right)$ bound to alpha carbon can freely rotate around it. A shape of the peptide molecule is then given by angles that enclose the planes of the peptide bonds (separated by by groups $-\mathrm{CH}-\mathrm{R}$ ). These angles make the creation of the secondary structure. The angles are called dihedral angles and are 


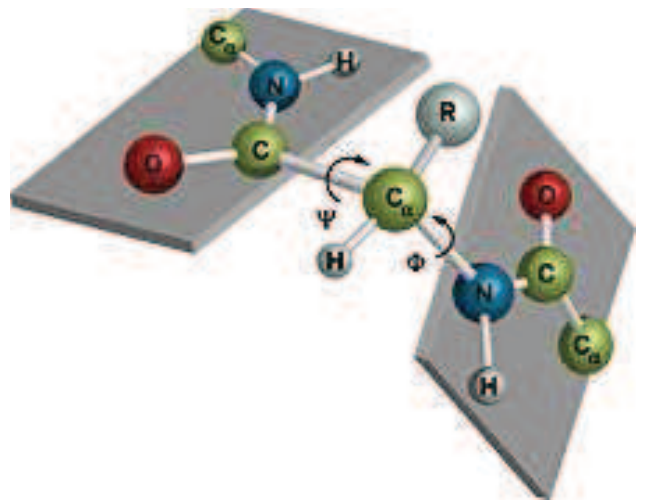

Figure 2.4: The dihedral angles $\phi$ and $\psi$ of the amino acids peptide bond. denoted as $\phi$ (rotation around $C_{\alpha}-N$ axis) and $\psi$ (rotation around $C_{\alpha}-C$ axis). An example of the peptide bond and its dihedral angles is presented in Figure 2.4.

\subsubsection{Blocks Substitution Matrix}

Proteins are molecules which comprise of a sequences of amino acid residues. These sequences are gradually changed across generations through the action of DNA mutations. Evolution can influence individual amino acid residue to mutate into various other amino acids. For example, the hydrophobic residue Valine is more likely to be substituted by another hydrophobic residue such as Alanine, then it can mutate into a hydrophilic residue such as Arginine. This leads to the observation that two different protein sequences can have a similar function because they have a common ancestor sequence. Such sequences are called remote homologue protein pairs. Commonly used algorithms for sequence alignment such as PSI-BLAST [1] or DELTA-BLAST [11] use amino acid substitution matrices.

Definition 1 Substitution matrix $S$ is $20 \times 20$ matrix where $S_{a b}$ is a score which represents the evolutionary relation of amino acids a and $b$.

There are different ways how to compute this score and thus we have different substitution matrices such as BLOSUM [44] or PAM [21]. In this work we utilize the block substitution matrix BLOSUM62 matrix since it is widely used in protein sequence comparison [101]. In this matrix a more positive score $S_{a b}$ is given to the more likely substitutions while a negative score is given to the less likely 


\section{Example of BLOSUM62 Matrix}

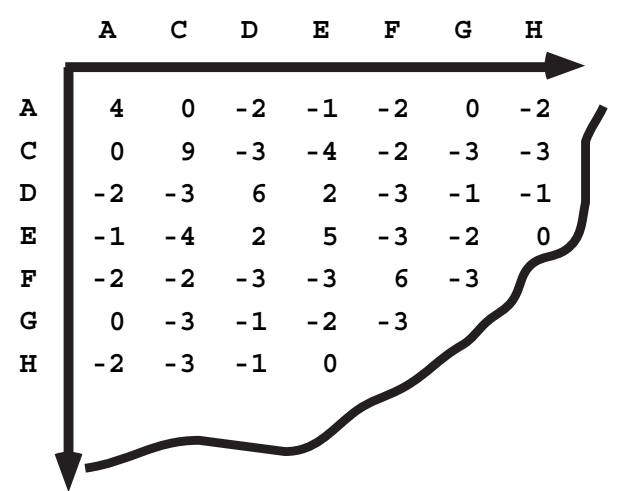

Lewitter, 1998

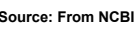

Figure 2.5: A sample part of the BLOSUM62 scoring matrix.

substitutions. A sample part of the BLOSUM62 substitution matrix is showed in Figure 2.5.

\subsection{Protein Databases}

These days there are several protein databases publicly available on-line. These databases assemble various information about proteins, protein structures, protein functions, protein relationships, etc. Probably the main, and most valuable, database is the Protein Databank which consists of three dimensional protein structures resolved by state-of-the-art techniques such as X-Ray crystallography or NMR spectroscopy. Other on-line databases are generated by automated computer methods or by biologists them selves.

\subsubsection{Protein Databank - PDB}

The PDB was established in 1971 at Brookhaven National Laboratory and originally contained 7 structures. Nowadays the PDB archive contains almost 110,000 resolved structures and is still growing practically every day. The PDB archive is the single worldwide repository which contains information about experimentally- 
determined structures of proteins, nucleic acids, and complex assemblies. The structures in the archive range from tiny proteins and bits of DNA to complex molecular machines like the ribosome. The structures in this archive are resolved by the state-of-the-art methods of X-Ray crystallography and NMR spectroscopy. As a member of the wwwPDB, the RCSB PDB curates and annotates PDB data according to agreed upon standards [89]. The PDB archive is freely available to everyone and is updated each week at the target time of Wednesday 00:00 UTC (Coordinated Universal Time). This database can be accessed online at http://www.pdb.org. The structures can be also downloaded from their FTP service at ftp://ftp. wwpdb.org/pub/pdb/.

\subsubsection{SCOP: Structural Classification of Proteins}

This database provides a detailed and comprehensive description of the structural and evolutionary relationships of proteins whose three-dimensional structures have been determined by X-Ray crystallography or NMR spectroscopy (PDB Databank entries). The recent version 2.05 (December 2014) of this database includes 71,015 PDB entries. The classification of protein structures in the database is based on evolutionary relationships and on the principles that govern their threedimensional structure. The method used to construct the protein classification in SCOP is essentially the visual inspection and comparison of structures through various automatic tools are used to make the task manageable and help provide generality $[81,74,62,2,3]$.

Each of the protein entries in the SCOP database is classified on six different levels - class, fold, super-family, family, domain and species. Figure 2.6 represents part of the SCOP database and and we can see that the class, fold and superfamily form bigger groups (clusters) and the family, domain, and species form smaller groups. The numbers in parentheses in Figure 2.6 represent the number of members of each SCOP category. There are 11 classes in the SCOP, 1,390 folds, 2,220 super-families, etc. The SCOP database is represented as a tree structure, thus the categories closer to the root form large clusters (e.g. SCOP class groups) whereas the categories closer to the leaves (SCOP species groups) represent the smallest clusters. The leaves in the SCOP tree structure represent the protein 


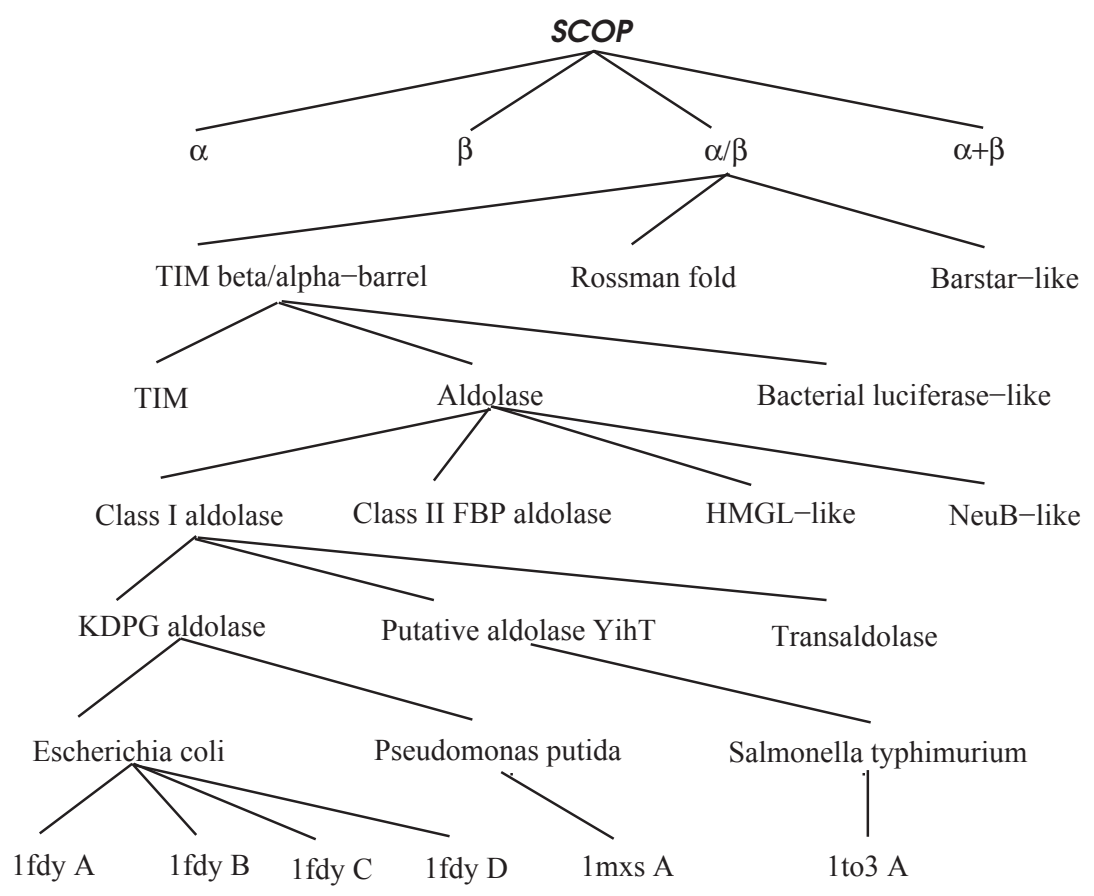

Class (11)

Fold (1390)

Super-Family (2220)

Family (4834)

Domain (12034)

Species (21458)

PDB/Ref Sequence ID

Figure 2.6: SCOP hierarchical structure 
domain sequences.

\subsubsection{CATH Protein Structure Classification}

The CATH is a database constructed using a semi-automatic method for the hierarchical classification of protein domains [82]. The CATH stands for - Class, Architecture, Topology and Homologous super-family. CATH shares many broad features with its main rival, SCOP, however there are also many areas in which the detailed classification differs greatly. CATH defines four classes: mostly-alpha, mostly-beta, alpha and beta, and a few secondary structures. Much of the work in the CATH database is done by automatic methods compared to the SCOP, though there are important manual tasks to the classification. The most important step in CATH classification is to separate proteins into domains. The domains are then automatically sorted into classes and clustered on the basis of sequence similarities. These clusters (groups) form the $\mathbf{H}$ levels of the classification (homologous super-family groups). The topology level is formed by structural comparisons of the homologous groups. Finally, the A level (architecture) is assigned manually [82]. For more detailed descriptions of the CATH database building process and comparison with SCOP and other databases please see [40, 20]. The CATH database can be accessed and searched at http://www. cathdb.info/.

\subsubsection{DALI - Distance matrix ALIgnment}

The DALI database is based on an exhaustive all-against-all 3D structure comparison of protein structures currently in the PDB. The structural neighborhoods and alignments are automatically maintained and regularly updated using the DALI search engine. The DALI algorithm works with the 3D coordinates of each protein that are used to calculate residue-to-residue $\left(C_{\alpha}\right.$-to- $\left.C_{\alpha}\right)$ distance matrices. The distance matrices are first decomposed into elementary contact patterns, e.g. hexapeptide-hexapeptide submatrices. Then, similar contact patterns in the two matrices are paired and combined into larger consistent sets of pairs. This method is fully automatic and identifies structural resemblances and common structural cores accurately and sensitively, even in the presence of geometrical distortions $[49,50]$. The DALI database can be accessed from the DALI server at 
http://ekhidna.biocenter.helsinki.fi/dali.

\subsection{MicroRNA}

MicroRNAs (miRNAs) are highly conserved small $\approx 22$ nucleotides (nt) long RNAs involved in the negative post-transcriptional regulation of target messagner RNAs (mRNA) [22]. MicroRNAs belong to the one of the most abundant classes of human genome regulators: more than $30 \%$ of human genes are regulated by miRNAs, whereas the main action is the degradation of the target mRNAs [36]. Because of a high similarity and binding on different sequences on mRNA, each miRNA may suppress multiple mRNA targets (average $\approx 200$ ) and one mRNA can be targeted by many miRNAs [6]. Their multistep genesis from miRNA genes localized in the genomic DNA is shown in Figure $2.7[8,59]$. Since their first discovery in humans in 2001 [55], more than 1,420 human miRNAs have been identified to date (miRBase v17).

MicroRNAs participate in the regulation of almost every aspect of cell physiology $[108,100]$. Besides their involvement in developmental timing, cell differentiation, apoptosis or anti-viral defence, recent studies showed that miRNAs also play a crucial role in the development of immune cells and function of the immune system, including the differentiation and survival of immune cells, antibody production and the inflammatory mediator release. Based on the crucial role of miRNAs in human physiology, their abnormal expression (upregulation or downregulation) may lead to the development of such diverse diseases such as cancer, cardiovascular disorders, schizophrenia, musculoskeletal disorders, lung diseases, and developmental abnormalities [57].

Figure 2.7 presents the biogenesis and mechanism of creation and action of miRNAs. MicroRNAs are transcribed by RNA polymerase II from the genomic DNA to 100 to 1,000 nucleotides long primary miRNA transcripts (pri-miRNAs). In the nucleus, a pri-miRNA is then cleaved by the ribonuclease Drosha/Pasha to a 70 nucleotides long precursor miRNA (pre-miRNA). After transport to the cytoplasm, the pre-miRNAs are cleaved by RNase III Dicer into $\approx 22$ nucleotides miRNA duplexes. The "passenger" $\left(\mathrm{miR}^{*}\right)$ strand undergoes degradation and the "guide" (miR) strand is incorporated into the RNA-induced silencing complex 
(RISC) and serves as a functional, mature miRNA. This miRNA-RISC complex acts by two different mechanisms:

- (A) deadenylation and subsequent degradation of the target mRNA occurs when miRNA is near-perfectly complementary with 3' untranslated region of target mRNA (major mechanism)

- (B) translational inhibition occurs when miRNA is only partially complementary to its target mRNA.

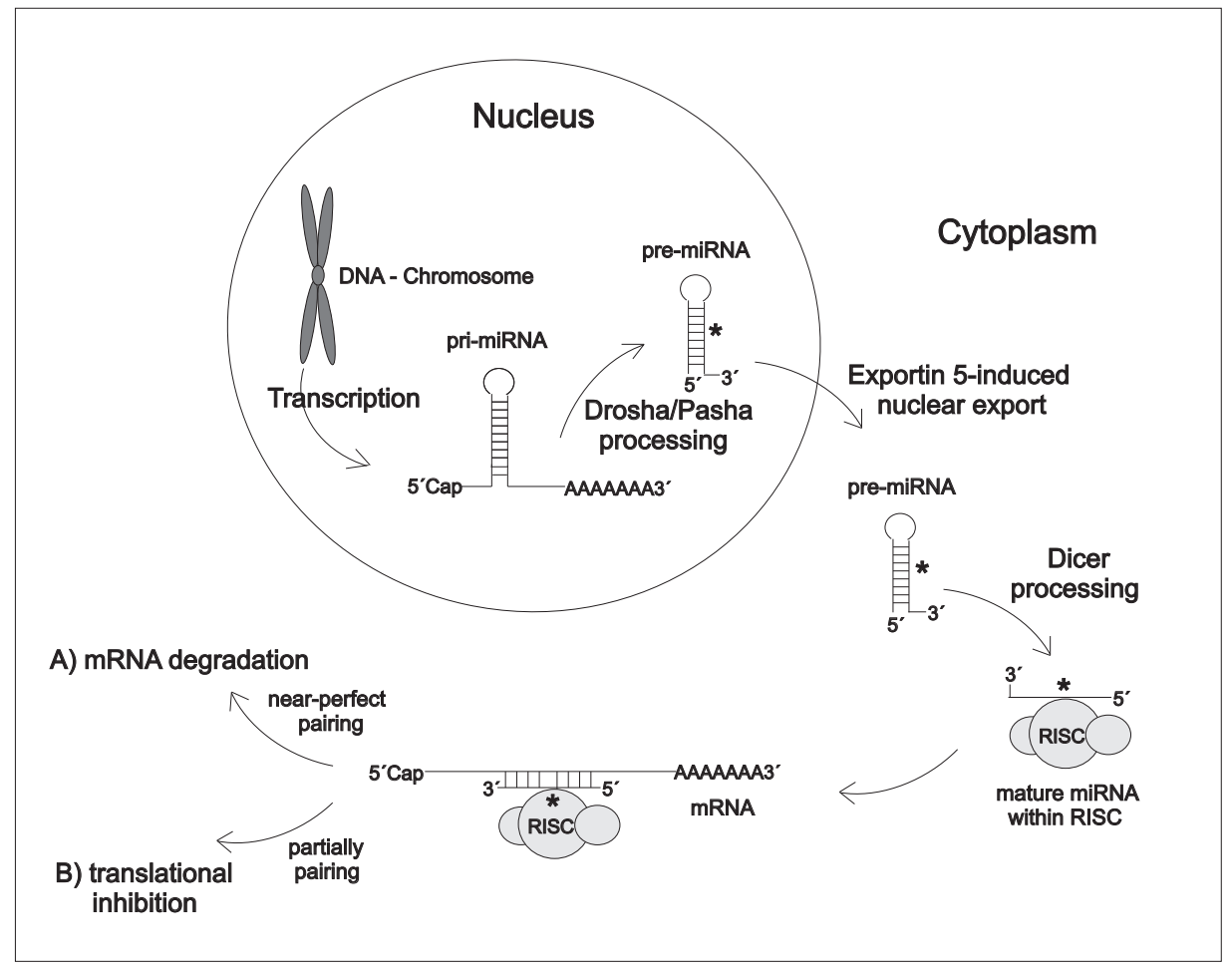

Figure 2.7: Biogenesis and mechanism of creation and function of miRNA molecule. 


\section{Chapter 3}

\section{Data Analysis Background}

\subsection{Information Retrieval}

Information retrieval (IR) deals with the representation, storage, organization of, and access to information items. In the past 20 years, the field of information retrieval has grown well beyond its primary goals of indexing text and searching for useful documents in a collection. Nowadays, research in IR includes modeling, document classification, similarity and categorization, system architecture, clustering, data visualization, filtering, etc. Although the information retrieval system was primarily designed for the analysis and manipulation of textual documents, we can also adopt the models and structures from this area for biological data. For example, the representation of the protein primary structure, which is a sequence of characters, can be seen as a document of words. Here amino acid residues can represent words and whole protein sequences can represent documents. There are many useful models and structures in the area of information retrieval. Mainly it is models for the representation of data or structures for data comparison. There are main three retrieval models - the Boolean model, Vector space model and Probabilistic model. The Boolean model is a simple model based on a set theory and Boolean algebra. The vector model recognizes that the use of binary weights is too limiting and proposes a framework in which terms are represented by non-binary weights. The probabilistic model attempts to capture the IR problem within a 
probabilistic framework. The main idea of this model is marking a set of retrieved documents as relevant and repeat the retrieval process with these documents. It requires user interaction and more iterations of this process.

For the purpose of this work we adopted the vector space model for the biological data representation and suffix tree structure for data comparison. Both the vector space model and the suffix trees have been widely studied and it was proved their usefulness in the field of document retrieval systems and sequence data analysis.

The information retrieval process is composed of many different tasks. In this work we are mainly focused on data preprocessing, indexing, searching and ranking. Since we deal with biological data and not textual documents we first need to encode protein structural or sequence information into index terms. The next steps of the information retrieval processes remains similar as with the documents. In the next chapters we show the information retrieval models and structures are suitable and effective for the analysis, searching, manipulation, and ranking of biological data as well. We also bring a comparison of the information retrieval approach with the traditional approaches for the analysis of protein structure and sequence data.

\section{$3.2 \quad$ Vector Space Model}

The vector model [5] of objects was established in the 1970s and was first used for encoding textual documents [90, 91]. Generally the vector space model can be used for any objects whose attributes can be encoded into a vector, e.g. textual documents, protein structures, protein sequences, mobile phone data [80] etc. For simplicity purposes we describe the vector model on textual documents for which it was primarily designed. A document in the vector model is represented as a vector. Each dimension (element) of this vector corresponds to a separate term appearing in the document collection. If a term occurs in the document, its value in the vector is non-zero. The vector model is a widely used information retrieval scheme for measuring similarity between documents it them selves or between user query and documents in the collection $[69,76,77,79,24,46,94,92,60]$. 
In the vector model there are $m$ different terms $t_{1}, \ldots, t_{m}$ for indexing $N$ documents. Then each document $d_{i}$ is represented by a vector:

$$
d_{i}=\left(w_{i 1}, w_{i 2}, \ldots, w_{i m}\right),
$$

where $w_{i j}$ is the weight of term $t_{j}$ in document $d_{i}$. These term weights are ultimately used to compute the degree of similarity between each document stored in the system and the user query. The weight of the term in the document vector can be determined in many ways. A common approach uses the so called $t f \times i d f$ (Term Frequency $\times$ Inverse Document Frequency) method [93], in which the weight of the term is determined by these factors: how often term $t_{j}$ occurs in document $d_{i}$ (term frequency $t f_{i j}$ ) and how often it occurs in the whole document collection (document frequency $d f_{j}$. Precisely, the weight of term $t_{j}$ in document $d_{i}$ is [60]:

$$
w_{i j}=t f_{i j} \times i d f_{j}=t f_{i j} \times \log \frac{n}{d f_{j}}
$$

where $i d f$ stands for the inverse document frequency. This method assigns high weights to terms that appear frequently in a small number of documents in the document set.

An index file of the vector model is represented by the matrix:

$$
D=\left(\begin{array}{cccc}
w_{11} & w_{12} & \ldots & w_{1 m} \\
w_{21} & w_{22} & \ldots & w_{2 m} \\
\vdots & \vdots & \ddots & \vdots \\
w_{n 1} & w_{n 2} & \ldots & w_{N m}
\end{array}\right)
$$

where $i$-th row matches $i$-th document, and $j$-th column matches $j$-th term.

The similarity of two documents in the vector model is usually given by the following formula - Cosine Similarity Measure:

$$
\operatorname{sim}\left(d_{i}, d_{j}\right)=\cos \theta=\frac{\sum_{k=1}^{m}\left(w_{i k} w_{j k}\right)}{\sqrt{\sum_{k=1}^{m}\left(w_{i k}\right)^{2} \sum_{k=1}^{m}\left(w_{j k}\right)^{2}}}
$$

Suppose we have two documents $d_{1}=\left(w_{11}, w_{12}\right)$ and $d_{2}=\left(w_{21}, w_{22}\right)$, where $w_{11}, w_{12}$ represent the weights of terms $t_{1}, t_{2}$ in document $d_{1}$ and $w_{21}, w_{22}$ represent the weights of terms $t_{1}, t_{2}$ in document $d_{2}$. Then the geometrical representation of cosine similarity is shown in Figure 3.1. 


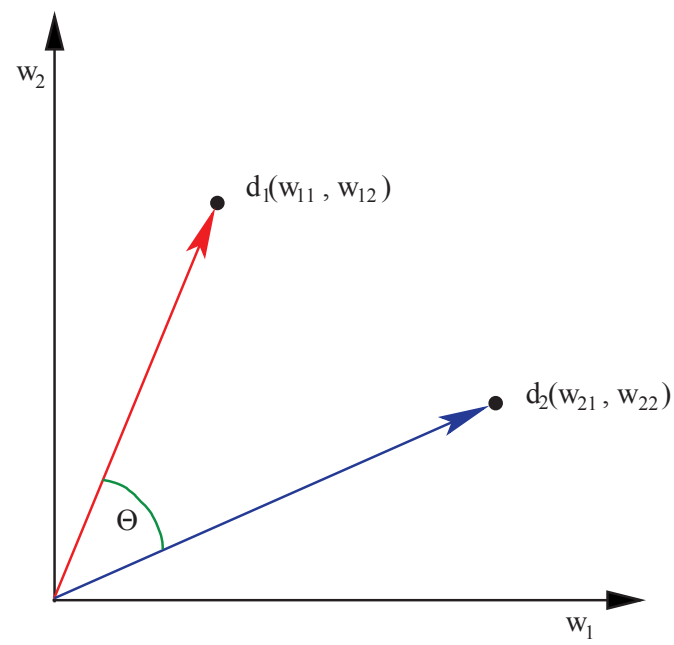

Figure 3.1: Geometrical representation of cosine similarity.

Similarities between objects (documents, protein sequences) in the vector model are usually represented as a matrix which is the called similarity matrix and is given by:

Objects similarity matrix:

$$
S=\left(\begin{array}{cccc}
1 & \operatorname{sim}\left(p_{1}, p_{2}\right) & \ldots & \operatorname{sim}\left(p_{1}, p_{n}\right) \\
\operatorname{sim}\left(p_{2}, p_{1}\right) & 1 & \ldots & \operatorname{sim}\left(p_{2}, p_{n}\right) \\
\vdots & \vdots & \ddots & \vdots \\
\operatorname{sim}\left(p_{n}, p_{1}\right) & \operatorname{sim}\left(p_{n}, p_{2}\right) & \ldots & 1
\end{array}\right)
$$

where the $i$-th row matches the $i$-th document, and the $j$-th column matches the $j$-th document. The similarity matrix is diagonally symmetrical of order $n$ and represents all pairwise document similarities appearing in the given database.

For more information about the vector space model, please consult $[65,85,5$, $90,91,92]$.

\subsection{Suffix Trees}

A suffix tree is a data structure that enables efficient string matching and querying. Suffix trees have been studied and used extensively and have been applied to 
fundamental string problems, such as finding the longest repeated substring [109], string comparisons [25], and text compression [87]. Suffix trees commonly deal with strings as a sequence of characters. The protein molecule can be also described as a sequence of characters which represent consecutive amino acids chains, so the suffix tree is also very suitable for analyzing protein sequences. Generally, suffix trees can be used for analysis of any data which can be encoded to a sequence of characters or numbers $[68,80,99,70]$. The suffix tree of a given string is simply a rooted directed tree, which contains all the suffixes of that string.

A suffix tree of string $S$ of length $L$ can be constructed by a naive straightforward method in $O\left(L^{2}\right)$ time, but also exist several linear time algorithms $[72,104,109]$. To be precise, these algorithms also exhibit a time dependency on the size of the vocabulary (or the alphabet when dealing with character-based trees). They actually have a time bound of $O(L \times \min (\log |V|, \log L))$, where $|V|$ is the size of the language. These methods are more difficult to implement than the naive method with several improvements which speed up the naive method. We have used the naive method with several improvements, which is sufficiently suitable for our purposes, since the construction time of the suffix tree over a dataset containing 165,843 protein sequences takes only 90 seconds. The method is described in more detail in $[69,78]$. More information on suffix trees, construction algorithms, and improvements can be found in [37].

Commonly, suffix trees solve the problem of a single string (longest repeated substring, string matching, etc.) In our case we need a suffix tree which can store multiple strings since we want to discover the common parts of all protein sequences in our dataset. Such a suffix tree is called a generalized suffix tree. The generalized suffix tree stores all suffixes of all strings being analyzed and can thus discover the common parts of more than one string.

Definition 2 A generalized suffix tree $T$ for a set $S$ of $n$ strings $S_{n}$, each of length $m_{n}$, is a rooted directed tree with exactly $\sum m_{n}$ leaves. Each internal node, other than the root, has at least two children and each edge is labeled with a non-empty substring of characters of a string in S. No two edges out of the internal node can have edge labels beginning with the same character. For any leaf $(i, j)$, the concatenation of the edge labels on the path from the root to the leaf $(i, j)$ 


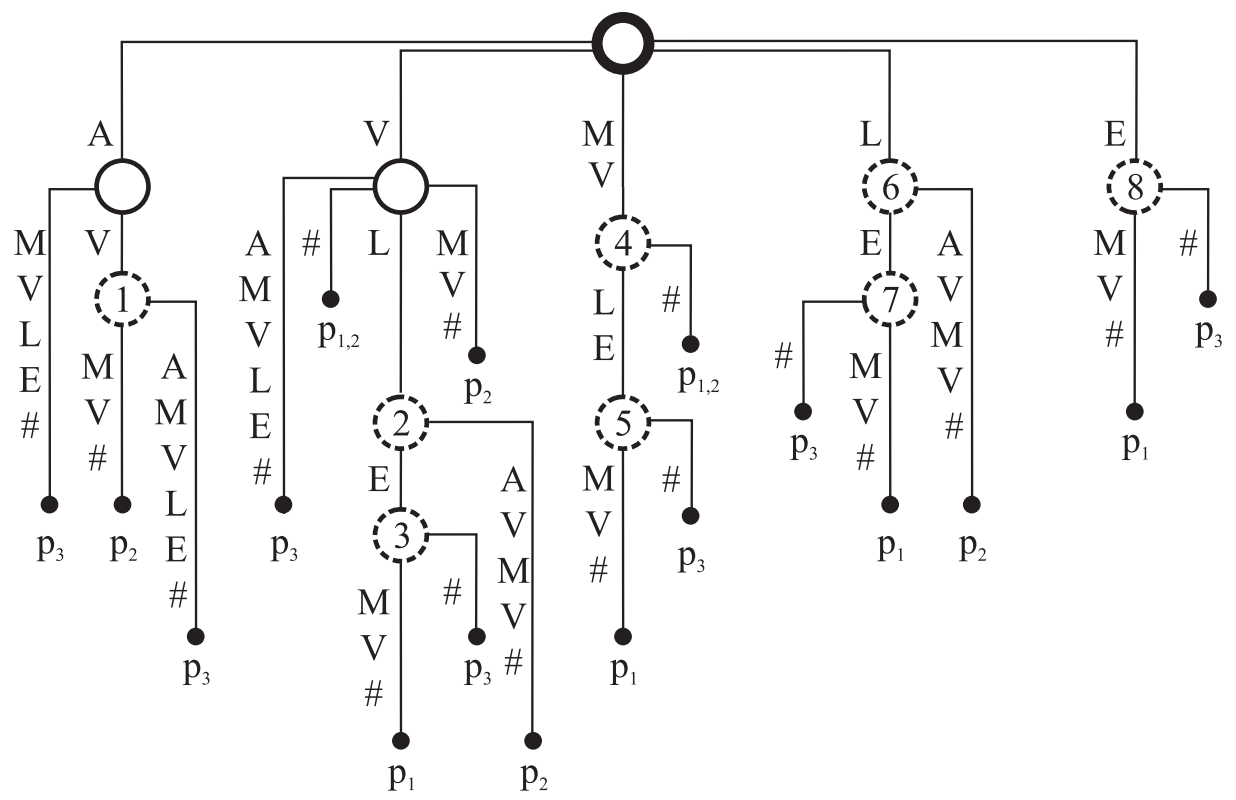

Figure 3.2: Example of the generalized suffix tree.

exactly spells out the suffix of $S_{i}$ that starts at position $j$. That is, it spells out the suffix $S_{i}\left[j \ldots m_{i}\right][3 r]$.

Figure 3.2 is an example of a generalized suffix tree of a set of three short protein sequences - $p_{1}=M V L E M V \#, p_{2}=V L A V M V \#, p_{3}=A V A M V L E \#$. For further reference, some of the internal nodes are drawn as dashed circles and are marked with numbers $1 \ldots 8$. Leaves are drawn as dots and labeled $p_{i}=$ $\left(p_{1}, \ldots, p_{3}\right)$, which indicates the sequence from which that suffix originates. Each sequence is considered to have a unique terminating symbol (see [37]).

\subsubsection{Suffix Tree Construction Algorithms}

The naive, straightforward method to build a suffix tree for a string $S$ of length $L$ takes $O\left(L^{2}\right)$ time. The naive method first enters a single edge for suffix $S[1 \ldots L]$ into the tree. Then it successively enters suffix $S[i \ldots L]$ into the growing tree for $i$ increasing from 2 to $L$. The details of this construction method are described in Chapter 4 Section 4.1 . 
Several linear time algorithms for constructing suffix trees exist $[109,72,104]$. To be precise, these algorithms also exhibit a time dependency on the size of the vocabulary (or the alphabet when dealing with character based trees): they actually have a time bound of $O(L \times \min (\log |V|, \log L))$, where $L$ is the length of the string and $|V|$ is the size of the language. These methods are more difficult to implement then the naive method, which is sufficiently suitable for our purposes.

Some implementation improvements of the naive method to achieve better than the $\mathrm{O}\left(L^{2}\right)$ worst-case time bound can also be made. With these improvements, constant access time for finding an appropriate child of the root (this is important because the root node has the same count of child nodes as is the size of the alphabet - count of terms in the document collection) and logarithmic time to find an existing child or to insert a new child node to any other internal nodes of the tree can be achieved $[69,78,37]$.

\subsection{Graph and Components}

A graph is a relatively general concept and we can deal with it in many different senses. In computer science graphs are used to represent networks of communication or similarity, data organization, computational devices, etc. In our case graphs represent a network of objects and relations between these objects. As we are studying relations between protein sequences, the objects of graphs correspond to protein sequences. Each object in a graph is represented by a node which is commonly named a vertex. Relations in a graph are represented by edges. The fact that two objects in a graph have some kind of relation is given by a link between vertices representing these objects. In the graphical representation of a graph, vertices are displayed as circles and edges are depicted as lines between those circles (Figure 3.3). Edges in a graph can be either directed or undirected. Undirected edges represent symmetric relations between objects, which is our case. This symmetric binary on vertices set $V$ is called the adjacency relation of graph $G$. Namely, for each edge $e \in E$, the vertices that are connected by edge $e$ are said to be adjacent to one another. Definitions of graph and related terms are as follows: 


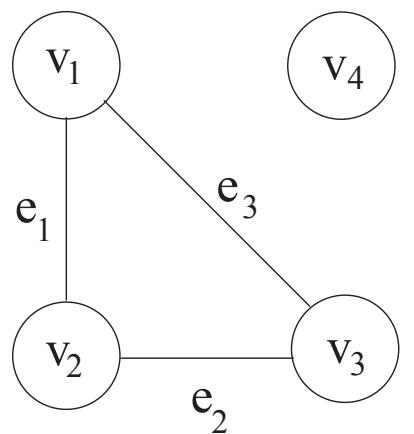

Figure 3.3: Example of simple a graph.

Definition 3 Graph is triplet $G=(V, E, \gamma)$, where

- $V$ is set of vertices $V=v_{1}, v_{2}, \ldots, v_{m}$

- $E$ is set of edges $E=e_{1}, e_{2}, \ldots, v_{m}$

- $\gamma$ is incidence mapping (incidence function) which is given by prescription:

- for undirected graph:

$E \rightarrow V \otimes V$, where $V \otimes V$ indicates a set of all unordered pairs of items from set $U$.

- for directed graph:

$E \rightarrow V \times V$, where $V \otimes V$ indicates Cartesian product (i.e. a set of all ordered pairs of items from set $U$ ).

Number of edges in set $E$ we denote by $|E|$ (is true that $|E|=m$ and the number of vertices in set $V$ is denoted by $|V|$ (holds that $|V|=n$ ).

As we are interested in discovering protein clusters, we need to define the terms subgraph and component.

Definition 4 Let it be given graph $G=(V, E, \gamma)$. Then graph $G^{\prime}=\left(V^{\prime}, E^{\prime}, \gamma^{\prime}\right)$ such that

- $V^{\prime} \subseteq V$ (a set of vertices of graph $G^{\prime}$ is a subset of a set of vertices of graph $G)$, 


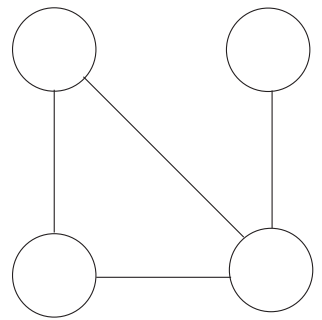

G

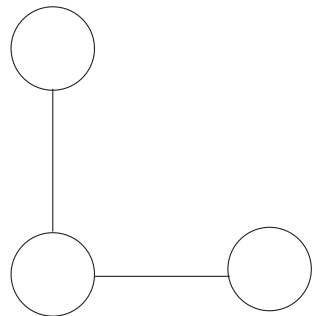

$\mathrm{G}_{1}$

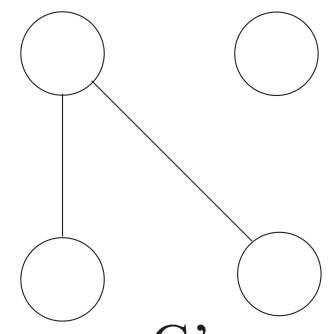

$\mathrm{G}_{2}^{\prime}$

Figure 3.4: Example subgraphs $G^{\prime}{ }_{1}$ and $G^{\prime}{ }_{2}$ of graph $G$.

- $E^{\prime} \subseteq E$ (a set of edges of graph $G^{\prime}$ is a subset of a set of edges of graph $G$ ),

- for each edge $e \in E^{\prime}$ holds that $\gamma^{\prime}(e)=\gamma(e)$ (incidence function of graph $G^{\prime}$ is a tapering of incidence function of graph $G$ )

we call the subgraph of graph $G$.

In the case when $U^{\prime}=U$ (a set of all vertices is retained) we call subgraph $G^{\prime}$ a factor of graph $G$. In Figure 3.4 there is graph $G$ and two its subgraphs $G^{\prime}{ }_{1}$ and $G^{\prime}{ }_{2}$. Moreover subgraph $G^{\prime}{ }_{2}$ is the factor of graph $G$ (it preserves a set of vertices of $G)$.

Definition 5 Let it be given graph $G=(V, E, \gamma)$ and its two vertices $u$ and $v$. A walk between vertices $u$ and $v$ is a finite sequence of vertices and edges

$$
u, e_{i 1}, v_{i 1}, e_{i 2}, v_{i 2}, \ldots, v_{i k-1}, e_{i k}, v
$$

such that

$$
\gamma\left(h_{i r}\right)=u_{i r-1}, u_{i r} \text { for } r=1, \ldots, k
$$

A walk in the graph is the consecutive sequence of edges, where every two following edges in the sequence have a common terminal vertex, which is placed sequentially between them. A trail between vertices $u$ and $v$ is a walk between these two vertices where every edge is traversed, at most, once. A path between vertices $u$ and $v$ is a trial between these two vertices where there is any inner vertex which does not appear more than once (i.e. $u_{i r} \neq u_{i s}$ for $r \neq s$, and $r=0, \ldots, k$, 
$s=0, \ldots, k-1$. A closed path (when $u=v$ ) is referred to as a circuit. The graph, where, for each two vertices, a path exists, is called a connected graph.

Definition 6 A component of the graph we call every maximal connected subgraph (not null graph). A connected subgraph of the given graph is maximal when it is not possible to extend it by adding more edges or vertices of the initial graph, such that, the subgraph remains still connected (so it is not own subgraph of any other connected subgraph).

The discovering of the connected components is generally done by the DepthFirst Search (DFS) or Breadth-First Search (BFS) graph traversal algorithms and can be completed in time $\Theta(|V|+|E|)$. Depth-first search is a classic recursive method for systematically examining each of the vertices and edges in a graph. To visit a vertex:

- Mark it as having been visited.

- Visit (recursively) all the vertices that are adjacent to it and that have not yet been marked. 


\section{Part II}

\section{Proteins - Structure and Sequence Similarity}





\section{Chapter 4}

\section{Algorithmic and \\ Implementation Details}

In this part of thesis we describe in more detail the construction of the generalized suffix tree and the building of the vector space model for the purpose of our protein structure and sequence similarity algorithms. Our protein structure and sequence similarity algorithm is based on the information retrieval vector space model and a structure for fast sequence analysis called the suffix tree. Since the protein structure as well as the protein sequence is always a sequence of amino acid residues, but in a different forms, the suffix tree is very suitable for the analysis and comparison of this kind of data. Generally suffix trees were successfully used for string data processing, compressions or indexing. As the vector model and the suffix tree structure is not wholly trivial, we first introduce (in more detail) the construction of a generalized suffix tree followed by a simple example of a computation of similarities between protein sequences using the vector model, term weighting, and a cosine similarity measure.

\subsection{Suffix Tree Construction}

The suffix tree is very useful and a very fast data structure for analyzing sequential data such as strings or sequences. Although it has a disadvantage concerning the 
memory requirements (approximately ten times of input data), in these days this issue is not so critical, even for large datasets. Suffix trees can be constructed in various ways. Linear time construction algorithms exist [104, 72, 109], but they are difficult to implement and also are not suitable for indexing a set of strings, only a single string. Moreover we need to keep the information about protein sequences in the suffix tree and thus we must anyway traverse the tree to the leaves which is inappropriate for linear time algorithms that take advantage of various tree traversal skipping, suffix links, etc. To be able to index a set of strings or sequences, we need to construct a generalized suffix tree (recall Section $3.3)$.

\subsubsection{Naive method}

In this work we utilize a straightforward suffix tree construction algorithm which is then improved to achieve better than $O\left(m^{2}\right)$ time complexity. This method first enters a single edge for suffix $S[1 . . m] \#$, where $m$ is the length of $\mathrm{S}$, into the tree. After that is successively enters suffix $S[i . . m] \#$ into the growing tree, for $i=2 \ldots m$. We let $S T_{i}$ denote the temporary tree that stores all suffixes from 1 to $i$.

At the beginning, tree $S T_{1}$ contains only one edge out of the root to the leaf node. The label of this edge is whole string $S \#$ (Figure 4.1a). The construction of tree $S T_{i+1}$ from tree $S T_{i}$ starts at the root of $S T_{i}$ and finds the longest path from the root whose label matches a prefix of $S[i+1 . . m] \#$. This path is given by successively calling a function match $(a, b)=$ true (4.1). The input parameters to this function are characters (amino acids or encoded dihedral angles) from suffix $S[i+11 . . m] \#$ and characters along a unique path from the root. Thus the found path must be unique because no two edges out of a node can have labels that begin with the same character. When $\operatorname{match}(a, b)=$ false, no suffix of $S \#$ is a prefix of any other suffix of $S \#$. In this case the algorithm is either in node $r$ or it is at some position on an edge. If it is at some position on and edge, $(p, q)$ say, it then breaks the edge $(p, q)$ and insert a new internal node, called $r$, just after the last character on the edge for which $\operatorname{match}(a, b)=$ true and just before the first character on the edge for which match $(a, b)=$ false (see e.g Figures 4.3, 4.4, 
4.5). The new edge $(p, r)$ is labeled with the first part of $(p, q)$ which corresponds to $S[i+1 . . m]$ and a new edge $(r, q)$ is labeled with the second part of $(p, q)$ label. At this point (whether node $r$ existed or was newly created) the algorithm creates a new edge $(r, s)$ and a new leaf node. A label of new edge $(r, s)$ represents the unmatched part of suffix $S[i+1 . . m] \#$. Now the algorithm continues again at the root node and builds the next intermediate tree, until all the suffixes are inserted and the final suffix tree $S T$ is created.

In the case of the generalized suffix tree of a set of string the algorithm proceeds in the same way, the only difference is that the concrete suffix of newly inserted string can completely matches one path out of the root to one leaf, that is already stored in the tree. In this case we can, for example, only store a new string identifier in the matched leaf node (see Figure 4.9 or 4.10 ).

$$
\operatorname{match}(a, b)=\left\{\begin{array}{l}
\text { true for } a \equiv b \\
\text { false for } a \neq b
\end{array}\right.
$$

The following figures describe the construction process of the generalized suffix tree of a set of three short protein sequences - $p_{1}=M V L E M V \#, p_{2}=$ $V L A V M V \#, p_{3}=A V A M V L E \#$ with lengths $l=7, m=7, n=8$. For further reference, some of the internal nodes are drawn as dashed circles and are marked with numbers $1 \ldots 8$. Leaves are drawn as dots and labeled $p_{i}=\left(p_{1}, \ldots, p_{3}\right)$, which indicates the sequence from which that suffix originates. Each sequence is considered to have a unique terminating symbol (see [37]). 


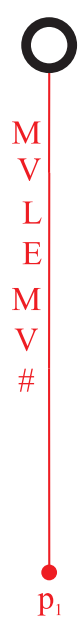

(a) Suffix $p_{1}[1 . . l]=$ MVLEMV\#

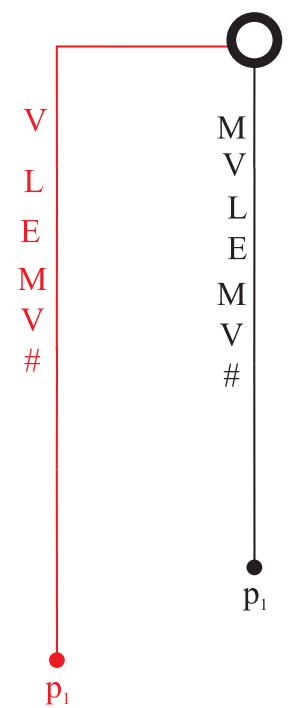

(b) Suffix $p_{1}[2 . . l]=$ VLEMV\#

Figure 4.1: Suffix Tree Construction - Insertion of Suffix $p_{1}[1 . . l]$ and Suffix $p_{1}[2 . . l]$

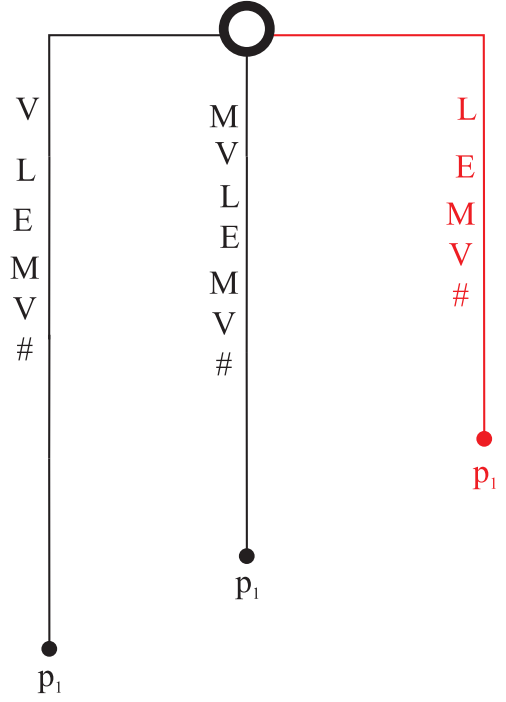

(a) Suffix $p_{1}[3 . . l]=$ LEMV\#

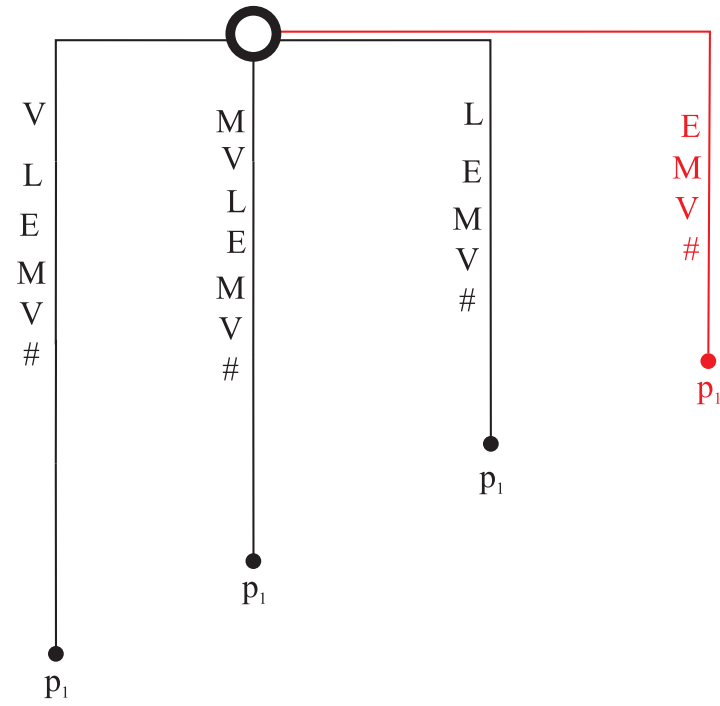

(b) Suffix $p_{1}[4 . . l]=\mathrm{EMV} \#$

Figure 4.2: Suffix Tree Construction - Insertion of Suffix $p_{1}[3 . . l]$ and Suffix $p_{1}[4 . . l]$ 


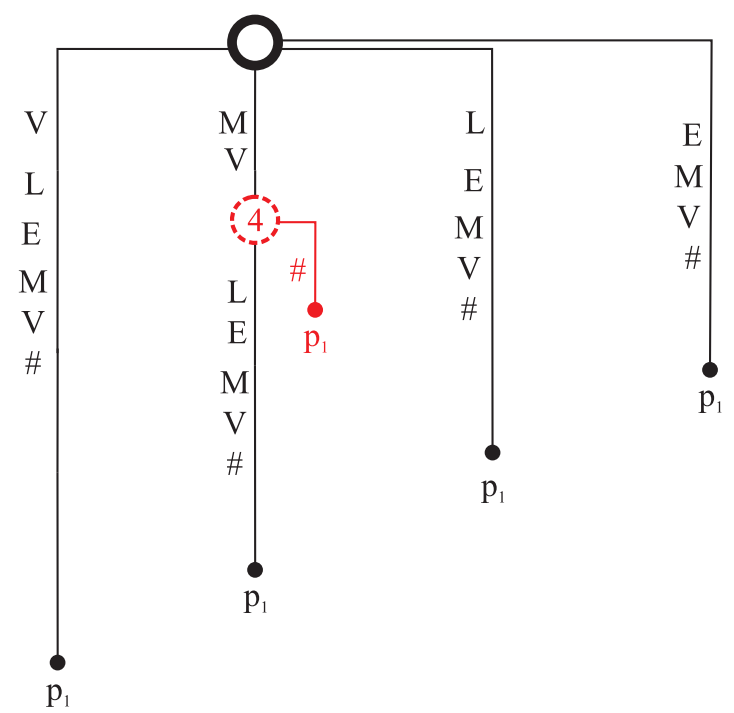

Figure 4.3: Suffix Tree Construction - Insertion of Suffix $p_{1}[5 . . l]=\mathrm{MV \#}$

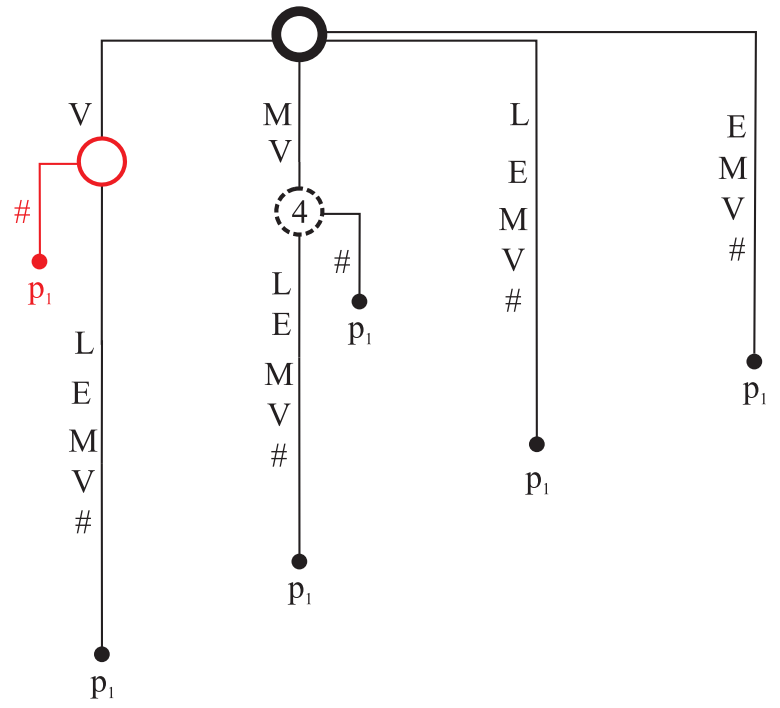

Figure 4.4: Suffix Tree Construction - Insertion of Suffix $p_{1}[6 . . l]=V \#$ 


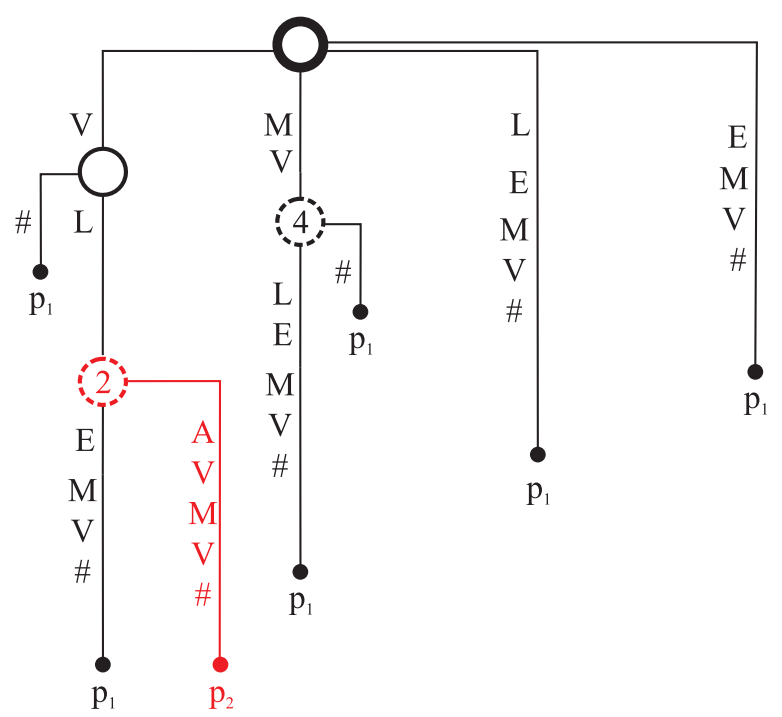

Figure 4.5: Suffix Tree Construction - Insertion of Suffix $p_{2}[1 . . m]=$ VLAVMV\#

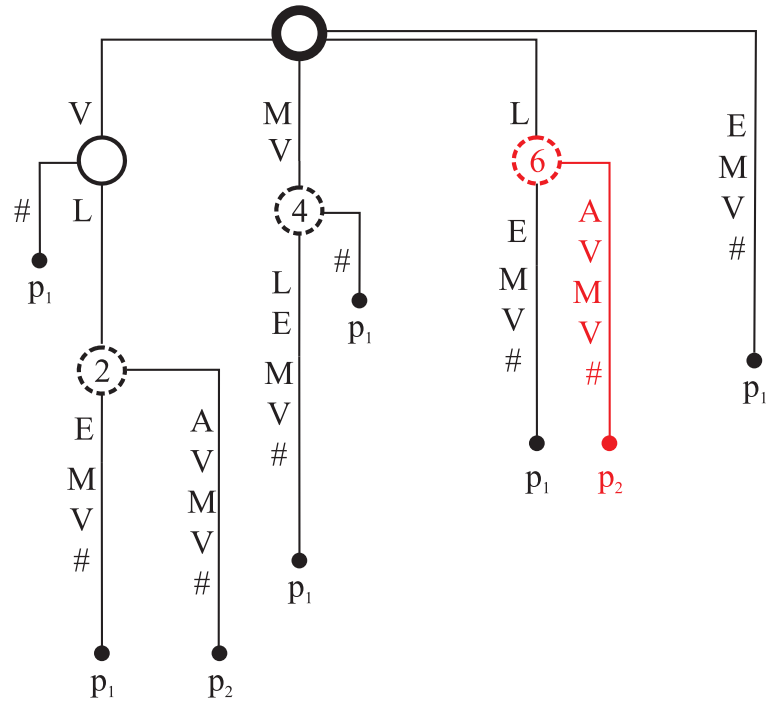

Figure 4.6: Suffix Tree Construction - Insertion of Suffix $p_{2}[2 . . m]=\mathrm{LAVMV \#}$ 


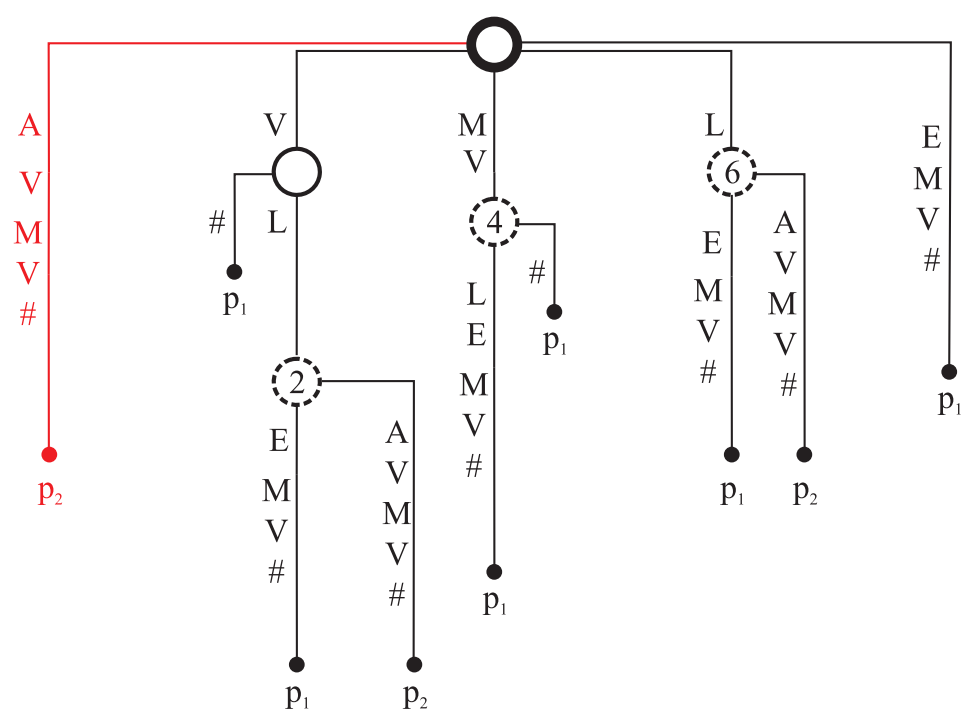

Figure 4.7: Suffix Tree Construction - Insertion of Suffix $p_{2}[3 . . m]=A V M V \#$

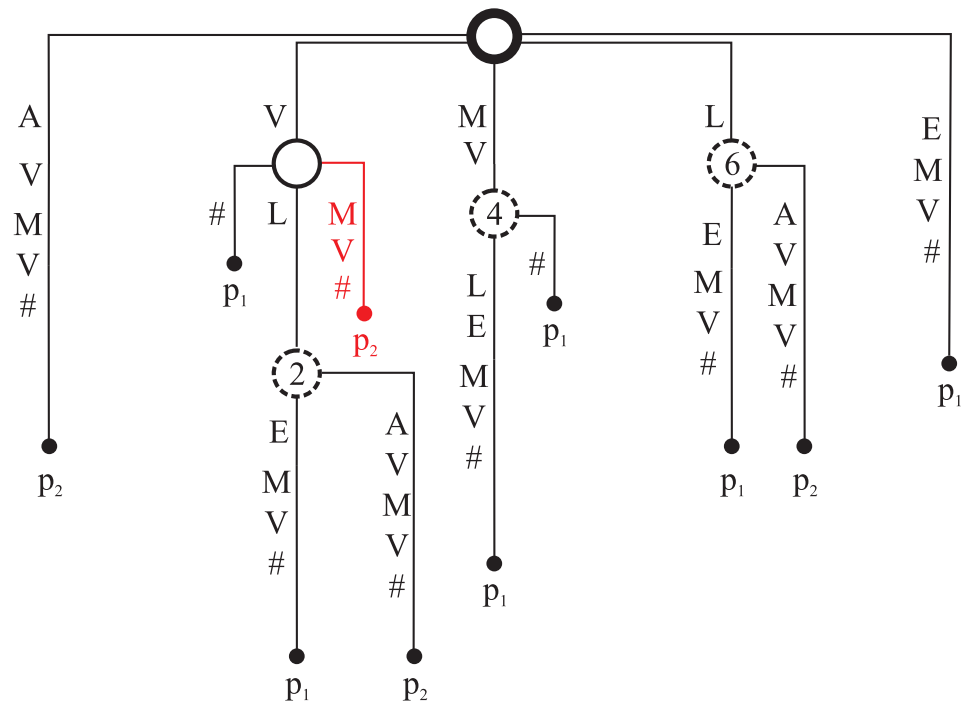

Figure 4.8: Suffix Tree Construction - Insertion of Suffix $p_{2}[4 . . m]=$ VMV\# 


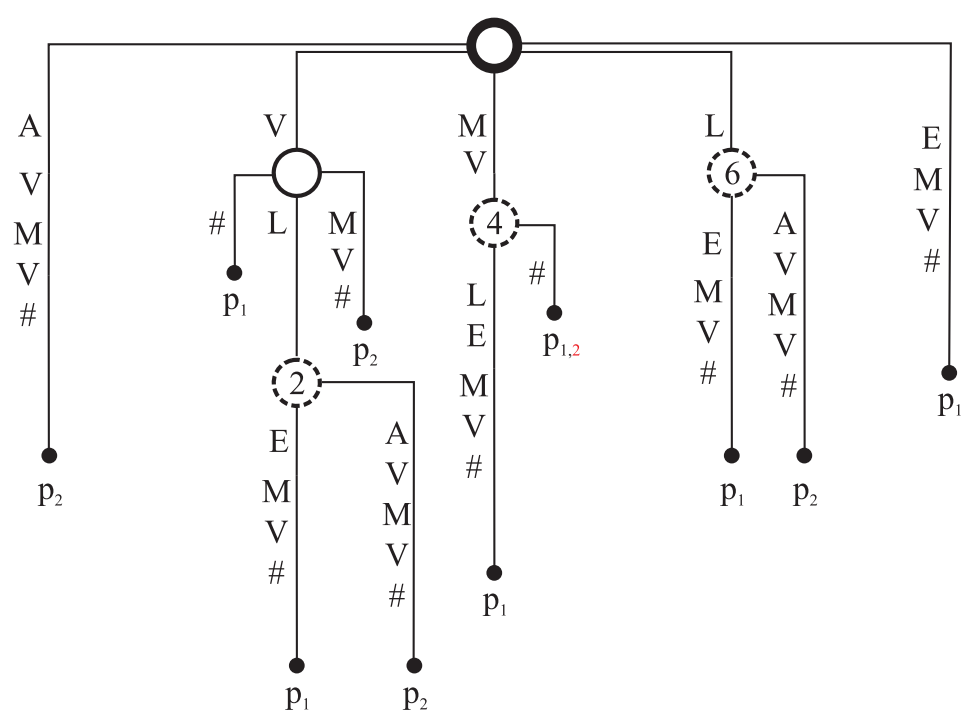

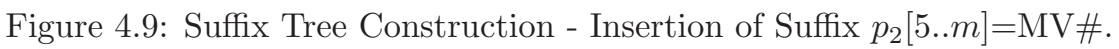

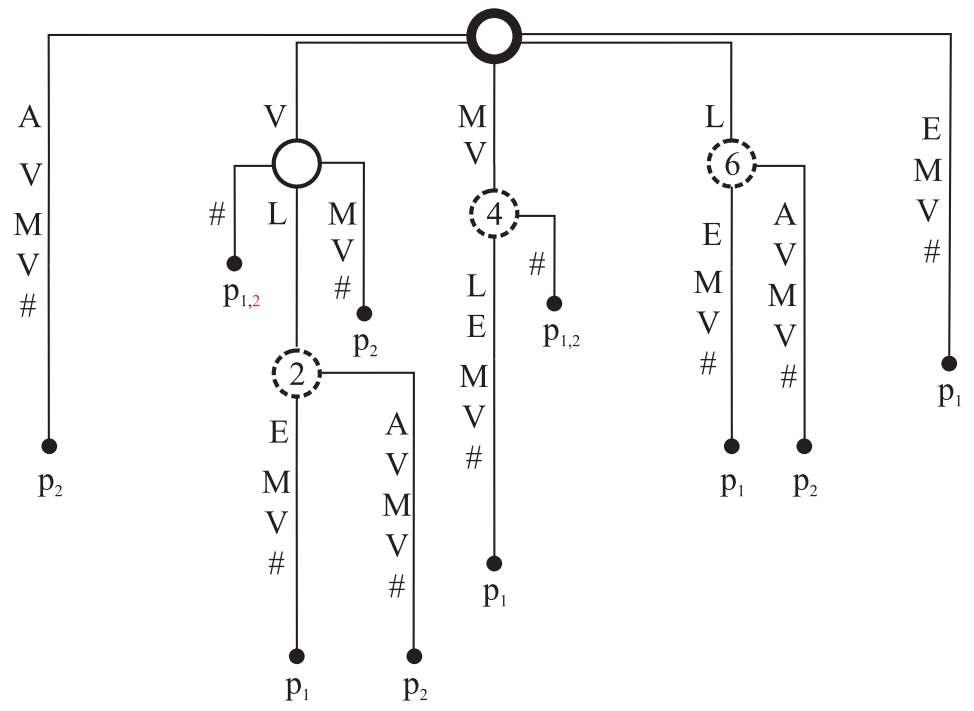

Figure 4.10: Suffix Tree Construction - Insertion of Suffix $p_{2}[6 . . m]=\mathrm{V} \#$ 


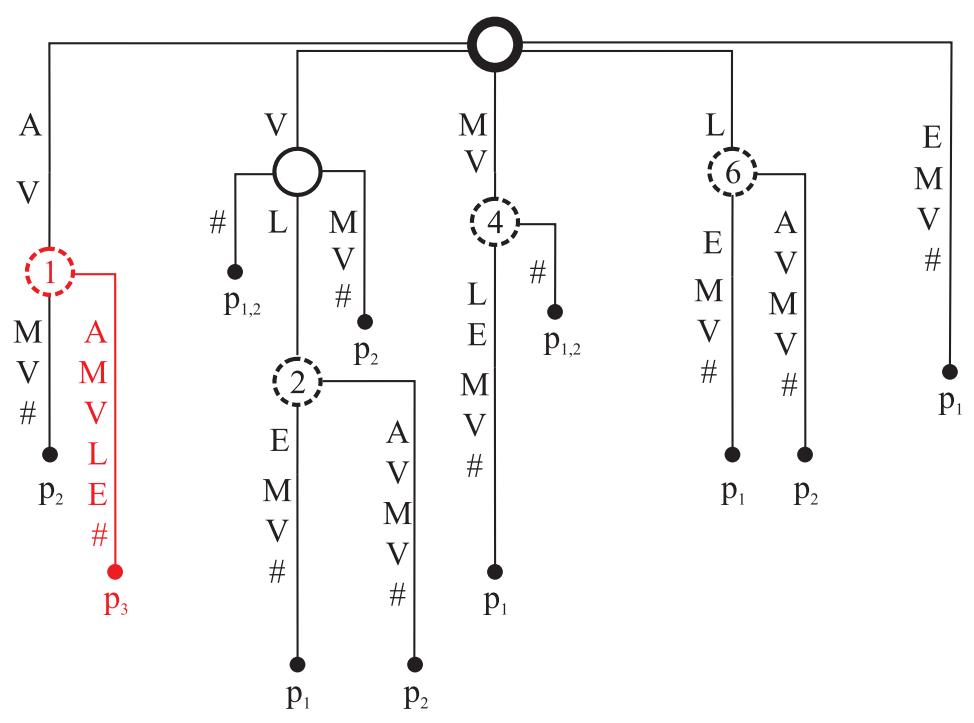

Figure 4.11: Suffix Tree Construction - Insertion of Suffix $p_{3}[1 . . n]=$ AVAMVLE\#

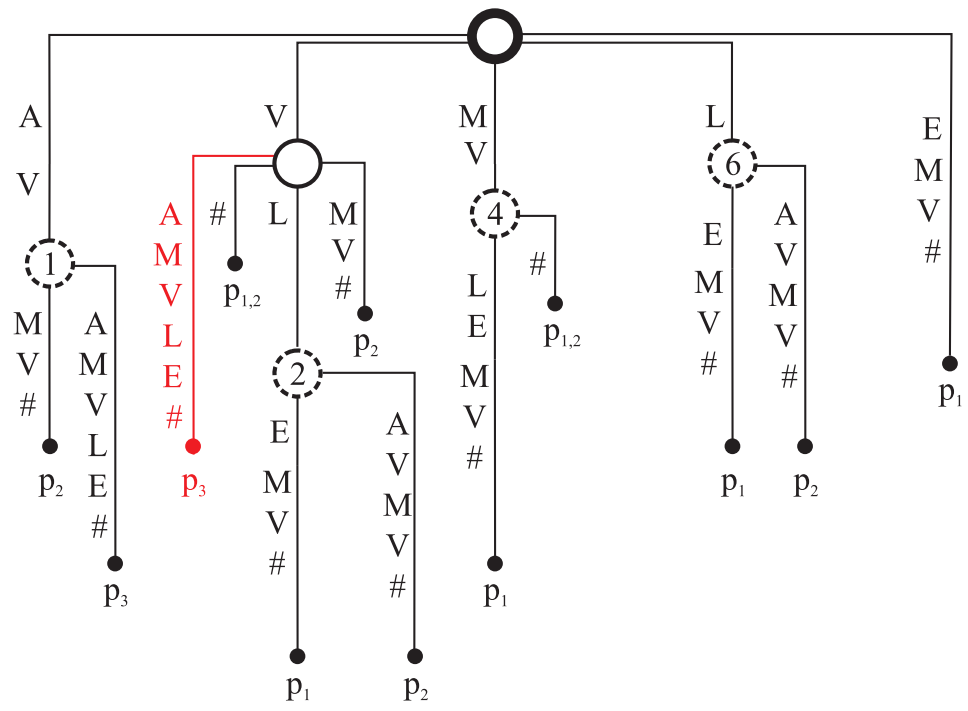

Figure 4.12: Suffix Tree Construction - Insertion of Suffix $p_{3}[2 . . n]=$ VAMVLE\# 


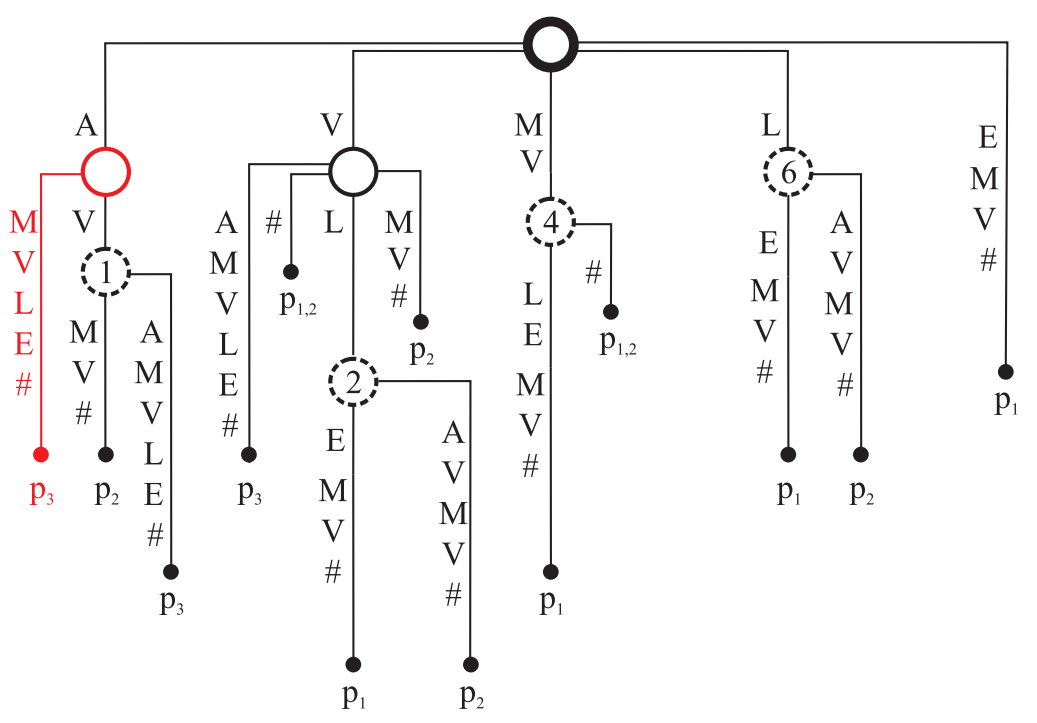

Figure 4.13: Suffix Tree Construction - Insertion of Suffix $p_{3}[3 . . n]=$ AMVLE\#

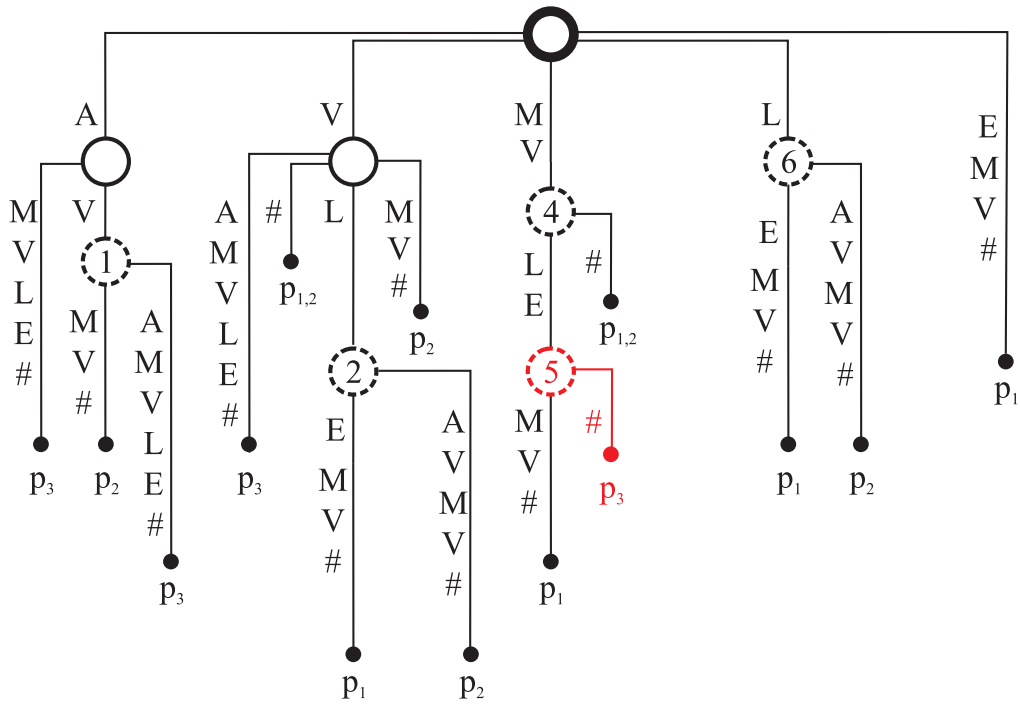

Figure 4.14: Suffix Tree Construction - Insertion of Suffix $p_{3}[4 . . n]=$ MVLE\# 


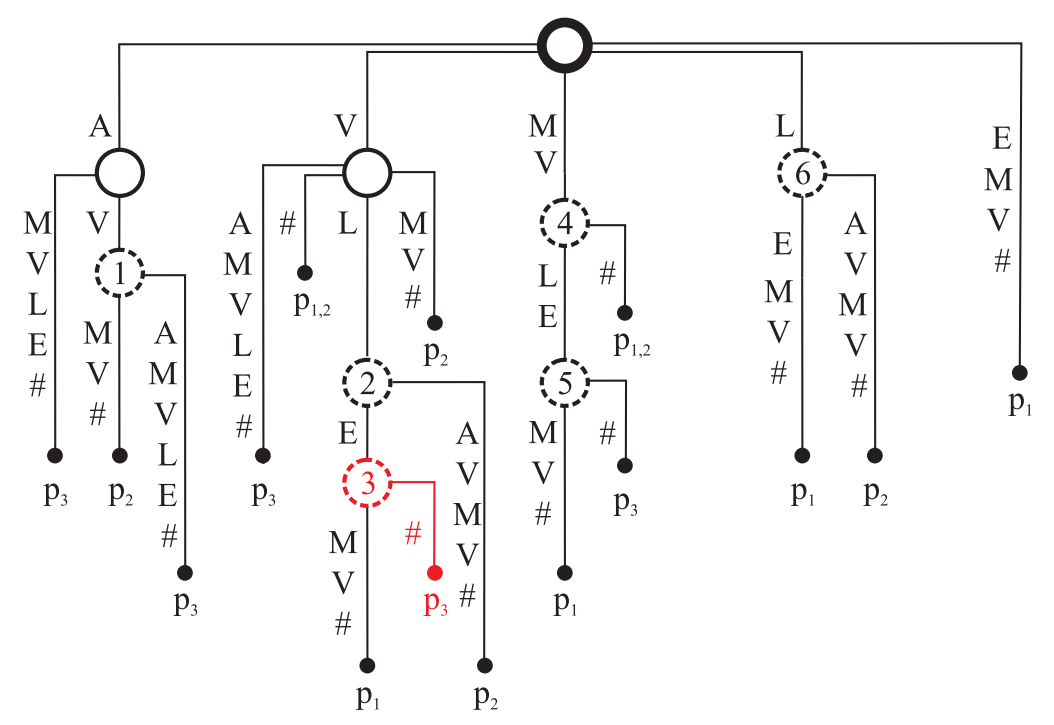

Figure 4.15: Suffix Tree Construction - Insertion of Suffix $p_{3}[5 . . n]=$ VLE\#

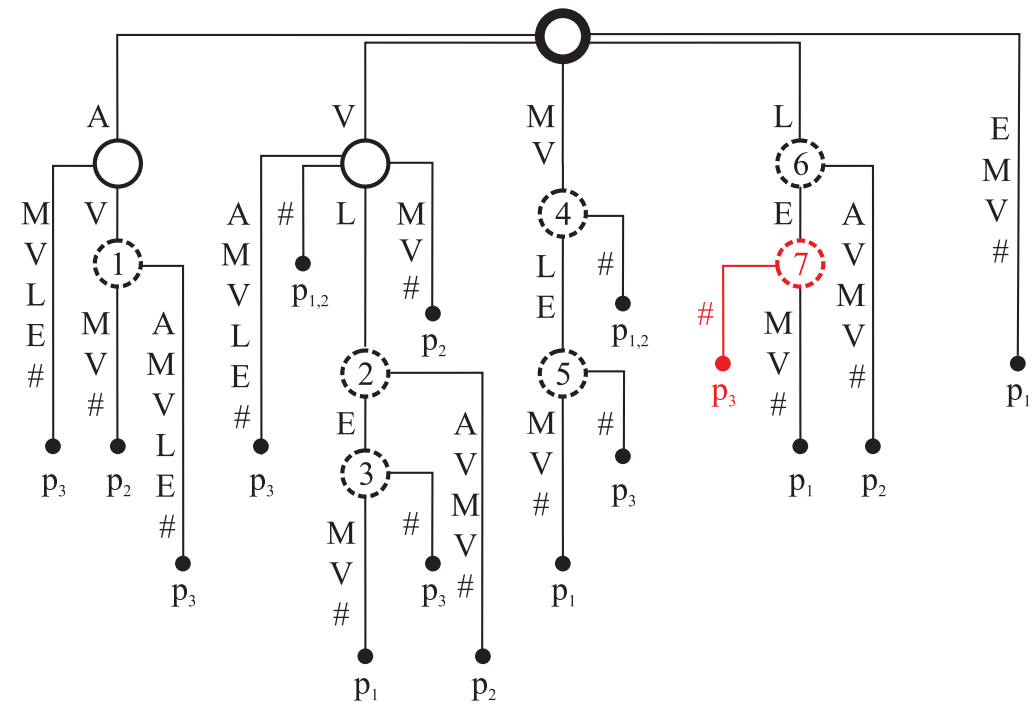

Figure 4.16: Suffix Tree Construction - Insertion of Suffix $p_{3}[6 . . n]=$ LE\# 


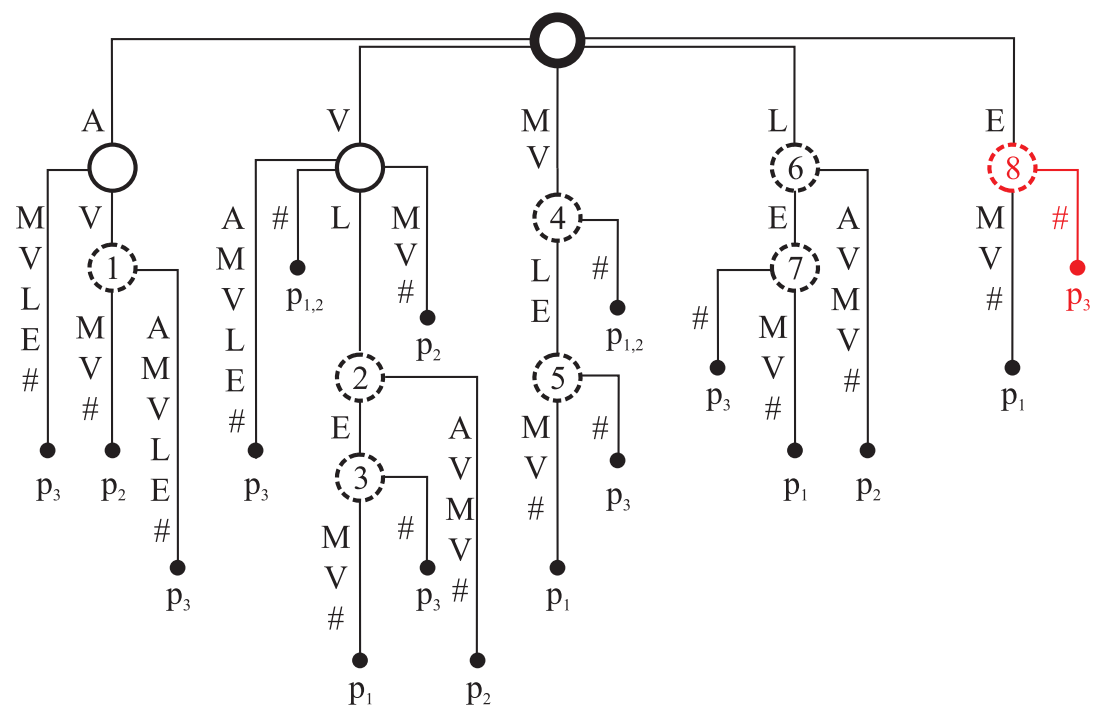

Figure 4.17: Suffix Tree Construction - Insertion of Suffix $p_{3}[7 . . n]=\mathrm{E} \#$ 


\subsubsection{Implementation Improvements}

To speed up the above described naive method for the construction of the suffix tree we did several implementation improvements [37, 78]:

- Branches (edges) are stored in a sorted linked list which reduces the average time to search for a given character and, in practice, speeds up the construction of the tree.

- Parent nodes have direct links to their first child nodes and child nodes have a direct link to their parent node.

- Edge labels are compressed and only starting end ending indexes are stored in appropriate nodes, which reduce the size of the tree.

- First floor of the tree is represented as an array (since our alphabet is always constant and small) and thus the search time at this point is constant.

- The algorithm of bisection is implemented in the procedure of finding the appropriate path out of the internal node.

By these implementation improvements we reached constant $O(1)$ time in the case of finding the path out of the root node, $O(\log n)$ time for finding the child node out of the internal node other then the root node, $O(\operatorname{logn})$ time for the insertion of a new child node and $O(1)$ time for the acquirement of all child nodes of the given internal node.

\subsection{Maximal Common Subsequence}

We use the vector space model for computing protein pairwise similarity, thus, we need to encode the protein structure or sequences into a vector. For the purpose of this example we consider a protein sequence. In our case, the element of such a vector is the longest common subsequence shared between at least two protein sequences in the dataset, which we call the Maximal common subsequence (MCS). The definition of the maximal common subsequence follows and is similar to the definition of the Maximal Phrase Cluster in [111] or Maximal Substructure Cluster in $[76,77,78,79]$ : 
Table 4.1: Maximal Common Subsequences

\begin{tabular}{lll}
\hline MCS No. & Common Subsequence & Protein sequences \\
\hline$s_{1}$ & $\mathrm{AV}$ & $p_{2}, p_{3}$ \\
$s_{2}$ & $\mathrm{VL}$ & $p_{1}, p_{2}, p_{3}$ \\
$s_{3}$ & $\mathrm{VLE}$ & $p_{1}, p_{3}$ \\
$s_{4}$ & $\mathrm{MV}$ & $p_{1}, p_{2}, p_{3}$ \\
$s_{5}$ & $\mathrm{MVLE}$ & $p_{1}, p_{3}$ \\
$s_{6}$ & $\mathrm{~L}$ & $p_{1}, p_{2}, p_{3}$ \\
$s_{7}$ & $\mathrm{LE}$ & $p_{1}, p_{3}$ \\
$s_{8}$ & $\mathrm{E}$ & $p_{1}, p_{3}$ \\
\hline
\end{tabular}

Maximal common subsequences identified in the generalized suffix tree presented in Figure 3.2 and 4.17.

Definition 7 A common subsequence is a subsequence that is shared by at least two protein sequences and the group of protein sequences that contain the subsequence. A maximal common subsequence (MCS) is a common subsequence whose subsequence cannot be extended by any amino acid without changing (reducing) the group of protein sequences that contains it.

Maximal common subsequences are the ones we are interested in. In Figure 3.2 , the maximal common subsequences $s_{i}=\left(s_{1}, \ldots, s_{8}\right)$ of three protein sequences $p_{1}, p_{2}, p_{3}$, defined in Section 4.1, are nodes drawn as dashed circles marked with numbers $1 \ldots 8$ (see Table 4.1 and Figure 4.17). Maximal common subsequences are identified by simply traversing the generalized suffix tree by the depth first search algorithm.

\subsection{Vector Space Model Construction}

A protein sequence in the vector model is represented as a vector. Each dimension of this vector corresponds to the maximal common subsequence discussed in the 
previous section, Section 4.2. To be more precise, each dimension of the vector represents the weight of the maximal common subsequence calculated by formula 3.1 presented in Section 3.2. If a maximal common subsequence occurs in more protein sequences and it does not appear in all protein sequences, its value in the vector is non-zero. In practice, maximal common subsequences which are contained in all protein sequences in the dataset are omitted because they have no impact on the resulting similarity (it is a certain analogy with stop words when textual documents are being analyzed). As we can see in Table 4.1 the maximal common subsequences that can be omitted from calculation of similarity are $s_{2}$, $s_{4}$ and $s_{6}$.

An index file for our three example protein sequences $p_{1}, p_{2}, p_{3}$ and their maximal common subsequences $s_{i}=\left(s_{1}, \ldots, s_{8}\right)$ correspond to Figure 4.17, which represent the weight vectors is as follows:

$$
P=\left(\begin{array}{cccccccc}
0.0 & 0.0 & 0.17 & 0.0 & 0.17 & 0.0 & 0.17 & 0.17 \\
0.17 & 0.0 & 0.0 & 0.0 & 0.0 & 0.0 & 0.0 & 0.0 \\
0.17 & 0.0 & 0.17 & 0.0 & 0.17 & 0.0 & 0.17 & 0.17
\end{array}\right)
$$

The resulting similarity matrix for the above mentioned protein sequences and their maximal common subsequences (Matrix 4.2) calculated by formula 3.2 is as follows:

$$
S=\left(\begin{array}{ccc}
1.0 & 0.0 & 0.894 \\
0.0 & 1.0 & 0.447 \\
0.894 & 0.447 & 1.0
\end{array}\right)
$$




\section{Chapter 5}

\section{Analysis of Protein 3D Structures}

In this chapter, we present our method for analyzing three dimensional protein structure using suffix trees and classical information retrieval methods and schemes [79]. Several studies were developed for indexing protein tertiary structures [32, 96]. These studies are targeted mainly at some kind of selection of the PDB database. The goal of this work is to introduce a new protein similarity metric and show the usage of the algorithm on the whole PDB database and to calculate the similarity of each protein in comparison with other proteins. We use the suffix tree, a very useful data structure, which can discover common substructures of proteins within a reasonable time (linear or logarithmic time), depending on the implementation of the construction algorithm. In this research, the similarity between any two proteins is based on common parts (substructures) of protein main chains.

\subsection{Dataset}

We describe the process of retrieving the data for protein indexing. We used the whole PDB database, which consisted of 65,527 known proteins, nucleic acids and complex assemblies, as of Tuesday May 25, 2010. 


\subsubsection{Creating Proteins Collection}

In the above mentioned PDB database, we can find proteins, nucleic acids and complex assemblies. Our study is focused only on the relations between proteins. We have filtered out all nucleic acids and complex assemblies from the entire PDB database. Next we have filtered out proteins which have incomplete $\mathrm{N}-\mathrm{C} \alpha-\mathrm{C}-\mathrm{O}$ backbones (e.g. some of the files have $\mathrm{C}$ atoms in the protein backbone missing, etc.).

After this cleaning step, we obtained a collection of 60,244 files. Each file contains a description of a specific protein and its three dimensional structure and contains only amino acid residues with a complete $\mathrm{N}-\mathrm{C} \alpha-\mathrm{C}-\mathrm{O}$ atom sequence.

Each retrieved file had at least one main chain (some proteins have more than one main chain) of at least one model (some PDB files contained more models of the three dimensional protein structure). In cases when the PDB file contained multiple chains or models, we took into account all of those (all main-chains of all models) $[76,77,79]$.

\subsubsection{Encoding the 3D Protein Main Chain Structure for Indexing}

To be able to index proteins by information retrieval (IR) techniques, we need to encode the 3D structure of the protein backbone into a sequence of characters, words or integers (as in our case). The area of protein 3D structure encoding has been widely studied by authors in previous works e.g. [113, 32, 16]. Since the protein backbone is the sequence of an amino acid residues (in 3D space) we are able to encode this backbone into the sequence of integers in the following manner $[76,77,79]$

For example, let us say the a protein backbone (main chain) consists of four amino acid residues $M V L S$ (abbreviations for Methionine, Valine, Leucine and Serine). The relationship between the two following residues can be described by its torsion angles $\phi, \psi$ and $\omega$. Since $\phi$ and $\psi$ are taking values from the interval $\left\langle-180^{\circ}, 180^{\circ}\right\rangle$ we have to do some normalization. From this interval we have obtained 37 values (the interval was divided into 36 equal sized subintervals, by $10^{\circ}$ degrees) e.g. $-180^{\circ},-170^{\circ}, \ldots, 0^{\circ}, 10^{\circ}, \ldots, 180^{\circ}$. Each of these values was 
labeled with non-negative integers as follows: 00, 01, ., 36 where 00 stands for $-180^{\circ}$. Now, let's say that $\phi$ is $-21^{\circ}$, the closest discrete value is $-20^{\circ}$ which has the label 16, so we have encoded this torsion with the string '16'. The same holds for $\psi$. The torsion angle $\omega$ was encoded as the two characters $A$ or $B$ since the $\omega$ tends to be almost in every case $0^{\circ}$ or $180^{\circ}$. After the concatenation of these three parts we get a string, which looks something like this 'A0102', which means that $\omega \approx 180^{\circ}, \phi \approx-170^{\circ}, \psi \approx-160^{\circ}$. Concatenation was done in the following manner: $\omega \phi \psi$.

The objective of this stage is to prepare the data for indexing by suffix trees. The suffix tree can index sequences. The resulting sequence in our case is a sequence of non-negative integers. For example, let's say we have a protein with a backbone consisting of 6 residues e.g. M V L S E G with three dimensional properties. The resulting encoded sequence can be, for example:

\{A3202, A2401, A2603, A2401, A2422\}

After obtaining this sequence of 5 words, we create a dictionary of these words (each unique word receives its own unique non negative integer identifier). The translated sequence appears as follows:

$\{0,1,2,1,3\}$

In this way, we encode each main chain of each model contained into one PDB file. This task is done for every protein included in our filtered PDB collection. Now the data is ready for indexing protein 3D structures using suffix trees and the vector space model.

\subsection{Protein Structure Similarity Algorithm}

We describe the algorithm for measuring protein similarity based on their tertiary structure. A brief description of the algorithm is as follows:

1. Prepare the data as was discussed in section 5.1.

2. Insert all encoded main chains of all proteins in the collection into the generalized suffix tree data structure.

3. Find all maximal substructure clusters in the suffix tree. 
4. Construct a vector model of all proteins in our collection.

5. Build proteins similarity matrix.

6. For each protein find top $\mathrm{N}$ similar proteins.

The first part of the algorithm represents the data preparation and this is described in detail in section 5.1. Algorithm then follows with the creation of the generalized suffix tree from our PDB dataset. As mentioned in Section 5.1, we obtain the encoded forms of the three dimensional protein structure main chains - sequences of positive numbers. All of these sequences are inserted into the generalized suffix tree data structure (section 4.1). After this stage algorithm continues with the identification of all the substructure clusters which corresponds to the maximal common subsequences as was explained in Section 4.2. This is done by simply traversal the generalized suffix tree and finding internal nodes which correspond to the definition of the maximal common subsequence (Definition 7). At this point the algorithm is ready to build the vector space model for protein structures in the dataset. In a classical vector space model, the document is represented by the terms (which are words) respectively and by the weights of the terms. In our model the document is represented not by the terms but by the common phrases (maximal phrase clusters)! - the term in our context is a common phrase i.e. maximal phrase cluster i.e. maximal common subsequence as was defined in Section 4.2. The protein similarity matrix is assembled as it is described in section 4.3. The last step is quite simple. When we have computed the similarity matrix $S$, we simply sort the documents (proteins) on each row, according to their similarity scores. The higher the score, the more similar the 2 proteins are. This is done for each protein in our protein collection.

\subsection{Experiments and Evaluation}

In order to evaluate the accuracy and effectiveness of our algorithm, we applied it to the well known SCOP [81] database (recall Section 2.2.2), which is maintained by humans in contrast with, for example, the CATH database, which uses automated methods. We used the SCOP database version v. 1.75 released in June 2009, which 
contains 38,221 classified proteins. We have chosen SCOP, because we wanted to evaluate our algorithm on manually classified proteins, rather than on automated ones.

For each protein $P$ in our collection $C$ we did the following:

1. For protein $P$ we determined the class, folding pattern group, super-family, family and domain [81].

2. Based on the similarity matrix, we found $N$ most similar proteins $P_{S}$ according to their score of similarity to protein $P$.

3. For each protein $P_{S}$ we determined the class, folding pattern group, superfamily, family and domain.

4. For all proteins in our collection we calculated the percentage of correctly classified proteins $P_{S}$ to protein $P$.

We did this for each protein in our collection and computed the overall percentage accuracy over our filtered collection. We did not classify approximately 25,000 proteins from the PDB, since they did not appear in the SCOP database. The highest possible score for two proteins is 1.0 which means the two proteins are completely similar. A score of 0.0 means the two proteins have no structural similarity discovered by our algorithm. The score can also be seen as the percentage of similarity if it is multiplied by 100 .

In more precise terms: If we have protein $P$, based on the calculated similarity matrix, we sort all other proteins $P_{S}$ in our protein collection in descending order according to their scores. The greater the score the more similar the protein is to protein $P$. We take only the top $N$ highest scoring proteins (the top $N$ most similar proteins to the given protein). We set $N$ to the value of 10 . After that we obtain a list such that the similar proteins for every protein in our collection, we have determined the SCOP classification of those proteins. Table 5.1 depicts the algorithm result for the a protein marked with the label 2ENG (Endoglucanase V). The SCOP Class with id=48724 means All beta proteins, the Fold with id $=50684$ means Double psi beta-barrel, the Super-family with id=50685 means Barwin-like endoglucanases, the Family with id=46463 means Eng V-like, the Domain with 
Table 5.1: The ten most similar proteins to the protein labeled $2 E N G$ and the SCOP classifications

\begin{tabular}{cccccccc}
\hline Rank & PDB & Score & Class & Fold & SuperF & Family & Domain \\
& 2eng & $\mathbf{1 . 0 0 0 0}$ & $\mathbf{4 8 7 2 4}$ & $\mathbf{5 0 6 8 4}$ & $\mathbf{5 0 6 8 5}$ & $\mathbf{5 0 6 8 6}$ & $\mathbf{5 0 6 8 7}$ \\
\hline 1 & 3eng & 0.7277 & 48724 & 50684 & 50685 & 50686 & 50687 \\
2 & 4eng & 0.7152 & 48724 & 50684 & 50685 & 50686 & 50687 \\
3 & 1hd5 & 0.6783 & 48724 & 50684 & 50685 & 50686 & 50687 \\
4 & 1l8f & 0.3355 & 48724 & 50684 & 50685 & 50686 & 50687 \\
5 & 1oa7 & 0.3289 & 48724 & 50684 & 50685 & 50686 & 50687 \\
6 & 1oa9 & 0.3283 & 48724 & 50684 & 50685 & 50686 & 50687 \\
7 & 1du5 & 0.1107 & 48724 & 49869 & 49870 & 49871 & 49874 \\
8 & 1aun & 0.1058 & 48724 & 49869 & 49870 & 49871 & 49872 \\
9 & 2r01 & 0.1057 & 0 & 0 & 0 & 0 & 0 \\
10 & 3hbc & 0.1051 & 0 & 0 & 0 & 0 & 0 \\
\hline
\end{tabular}

id=50687 means Endoglucanase $V($ Eng $V)$ and finally the Species with id=50688 means Humicola insolens.

Note that e.g. class $\mathrm{id}=0$ means that the protein is not classified by the SCOP database.

Table 5.1 displays the 10 most similar proteins to protein labeled $2 E N G$ and it is generated for every protein in our filtered protein collection. Figure 5.1 shows the picture of the secondary structure of protein marked $2 E N G$ in the PDB database. The next three figures 5.2, 5.3 and 5.4 represent the three structurally similar proteins to the protein labeled $2 E N G$, corresponding to Table 5.1. Images were generated using PyMOL software. 


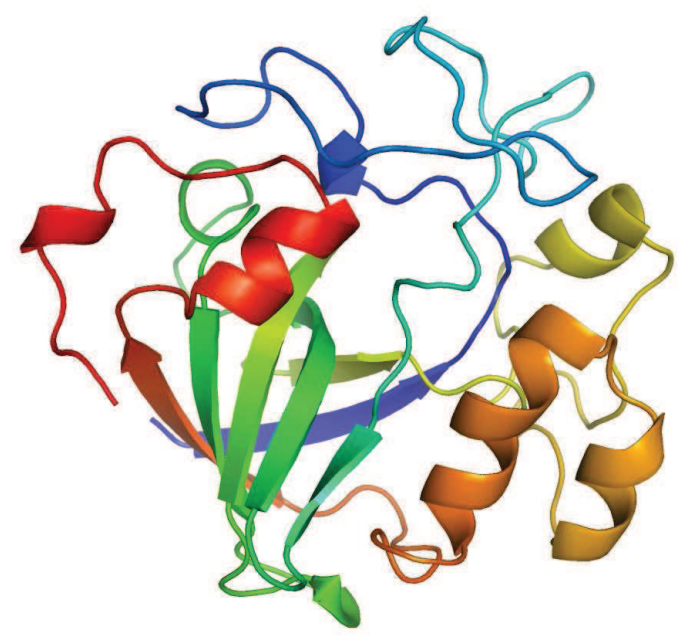

Figure 5.1: (PDB - 2eng) Endoglucanase V.

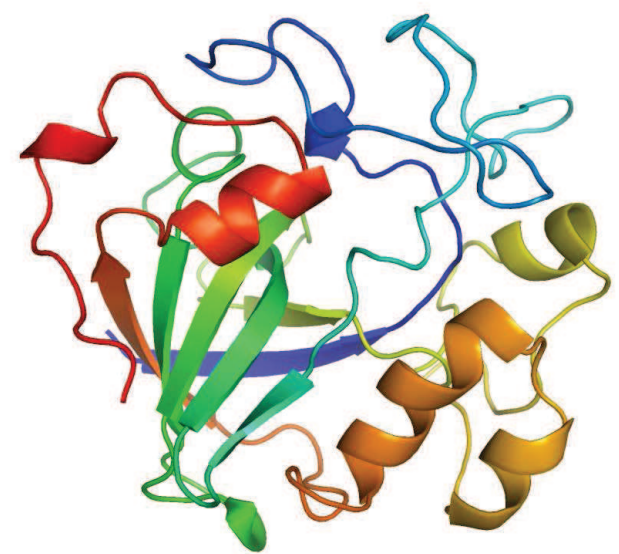

Figure 5.2: 1st Rank - PDB 3eng (Structure of Endoglucanase V Cellobiose Complex). 


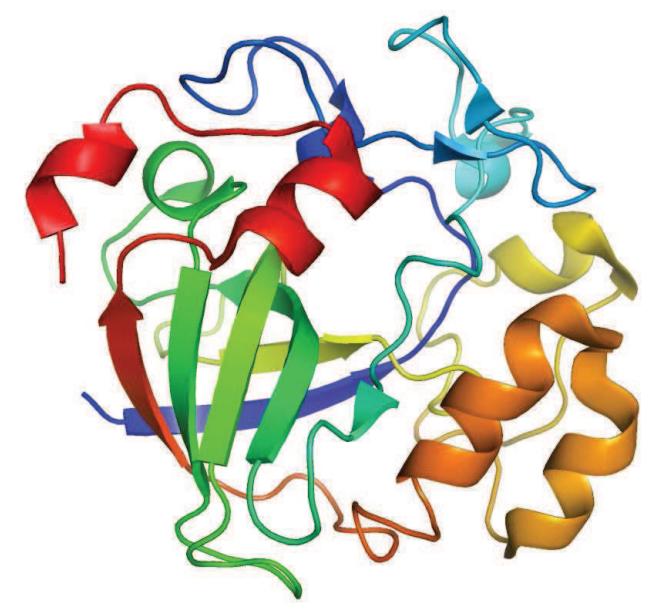

Figure 5.3: 4th Rank - PDB 118f (Structure of 20K-Endoglucanase from Melanocarpus Albomyces at 1.8A).

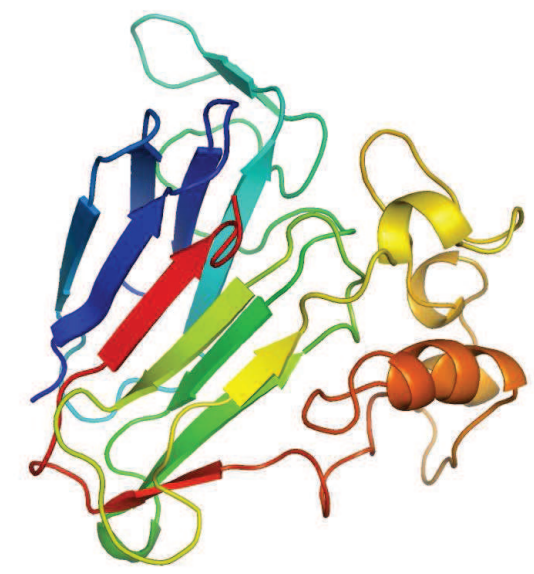

Figure 5.4: 8th Rank - PDB 1aun (Pathogenesis-Related Protein 5D from Nicotiana Tabacum). 
Table 5.2: Class classification percentage accuracy

\begin{tabular}{ccccccc}
\hline \multicolumn{7}{c}{ Similarity Score Cutoff } \\
\hline Rank & $\mathbf{0 . 0 0}$ & $\mathbf{0 . 1 4}$ & $\mathbf{0 . 2 8}$ & $\mathbf{0 . 4 2}$ & $\mathbf{0 . 5 6}$ & $\mathbf{0 . 7 0}$ \\
\hline 1 & 93.02 & 96.44 & 98.36 & 98.64 & 99.04 & 99.19 \\
2 & 88.61 & 91.89 & 94.65 & 95.63 & 97.02 & 98.25 \\
3 & 85.14 & 88.30 & 91.32 & 92.37 & 94.64 & 97.39 \\
4 & 82.15 & 85.07 & 88.16 & 89.44 & 92.16 & 96.10 \\
5 & 79.74 & 82.64 & 85.74 & 87.15 & 89.96 & 94.93 \\
6 & 77.43 & 80.17 & 83.39 & 84.83 & 87.83 & 93.75 \\
7 & 76.30 & 78.94 & 81.74 & 83.17 & 86.44 & 92.63 \\
8 & 74.37 & 76.98 & 79.86 & 81.36 & 84.25 & 91.08 \\
9 & 73.32 & 75.82 & 78.68 & 80.09 & 83.21 & 90.46 \\
10 & 71.76 & 74.27 & 77.37 & 78.86 & 81.97 & 89.67 \\
\hline Count & 35,908 & 33,011 & 29,018 & 26,756 & 22,049 & 12,291 \\
\hline
\end{tabular}

\subsection{Discussion}

Here we presented the results with the proposed method of measuring protein similarity based on their tertiary structures and in comparison with the SCOP database. All experiments were run on the computer with 32 GBytes of RAM and 4 AMD 64 bit Opteron dual core $1.8 \mathrm{GHz}$ CPUs. The whole PDB database indexed by our version of the suffix tree construction algorithm takes about 3.5 GBytes of RAM and about 40 minutes to complete. The calculation of the similarity matrix takes about 10 hours and 10 Gbytes of RAM since the similarity matrix is computed in memory. The total time needed to compute all pairwise similarities is about 12 hours for the whole current PDB database. All calculations were done on one $1.8 \mathrm{GHz} \mathrm{CPU}$ using only one thread. All parts of the application are written in $\mathrm{C}++$ programming language.

First we computed a percentage accuracy of all proteins in the entire SCOP 
database (35,908 proteins classified), next we have computed the accuracy only for proteins for which our algorithm found proteins with at least a given score of similarity (e.g. we have protein A and for this protein exists at least one protein which has a score of similarity with protein A of at least 0.14 - we cut off all proteins which do not satisfy this assumption) - this is some kind of threshold or cutoff.

The description of Table 5.2 is as follows. Figures 5.5, 5.6, 5.7, 5.8, 5.9 show these results in a graph representation. Column Rank means the ordering of similar proteins (e.g. Rank 1 means the most similar protein to a given protein, No. 10 means the 10th most similar protein to a given protein). Columns Similarity score cutoff stands for minimal similarity (e.g. 0.0 means that there exists at least one protein to the given protein which has a score of similarity of at least 0.0 , i.e. all proteins). Line Count means how many proteins with this cutoff (minimal similarity) were found in our collection.

In more precise terms: e.g. line 1 of Table 5.2 (not considering the header of the table) means that all proteins placed in the 1st place (i.e. the most similar protein to the given protein, see Table 5.1) have a $93.02 \%$ accuracy in the classification of class with no cutoff, and $96.44 \%$ accuracy with the cutoff of proteins scoring less than 0.14 , etc.

We have also identified class, fold, super-family, family and domain of proteins which are not classified by SCOP with almost $100 \%$ membership accuracy. Table 5.3 shows these results. Let's examine line 5 of this table. Column sim $=0.56$ means that we have chosen only proteins which have at least one structurally similar protein with a score of similarity of at least 0.56. Column $m p a_{C}$ means membership percentage accuracy to the scop protein class (same for Fold - mpa $a_{F o}$, Superfamily - $m p a_{S F}$, Family - $m p a_{F a}$ and Domain - $\left.m p a_{D}\right)$. Column UPC Unclassified proteins count is the count of proteins which are not classified by SCOP and which appear in the first place in the list of similar proteins to a given protein. Column TPC - Total proteins count is the total count of proteins which have at least one structurally similar protein with a score of similarity of at least 0.56. In summary this means that we have found 1356 unclassified proteins by using SCOP out of 22,374 , such that proteins have a $99.04 \%$ class membership accuracy, a $98.81 \%$ fold membership accuracy, a $98.80 \%$ super-family membership 


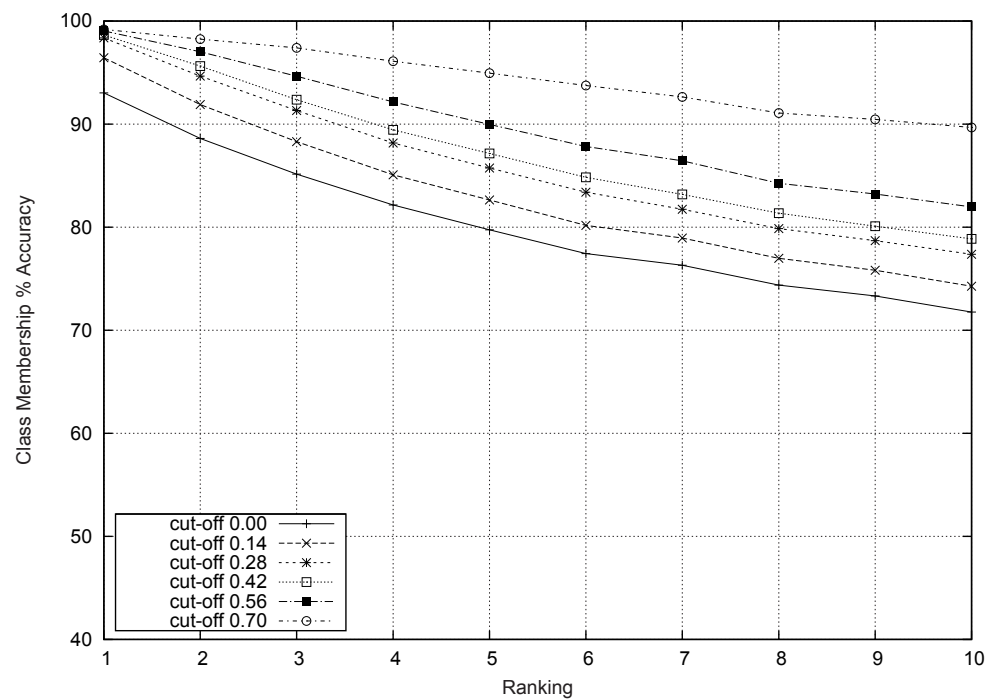

Figure 5.5: Protein Class Membership Percentage Accuracy.

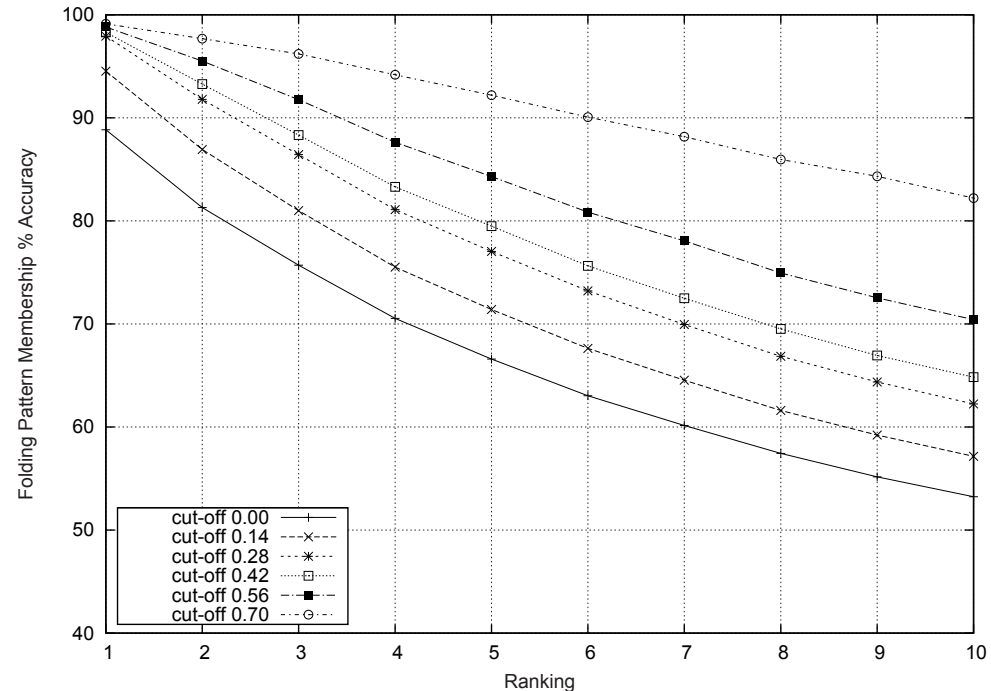

Figure 5.6: Protein Folding Pattern Membership Percentage Accuracy. 


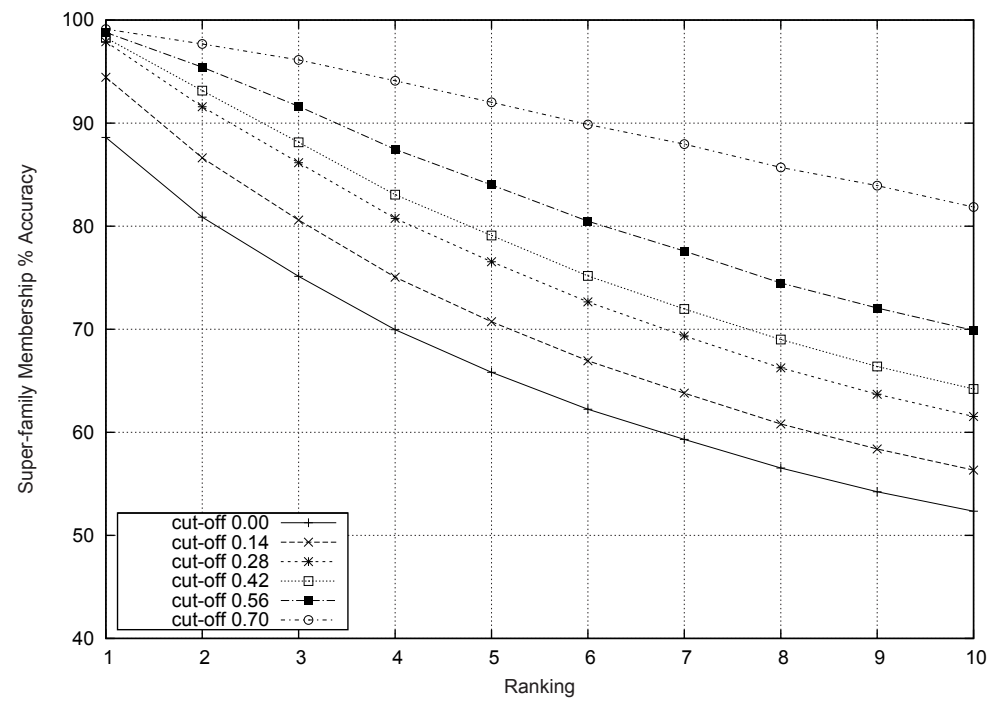

Figure 5.7: Protein Super-Family Membership Percentage Accuracy.

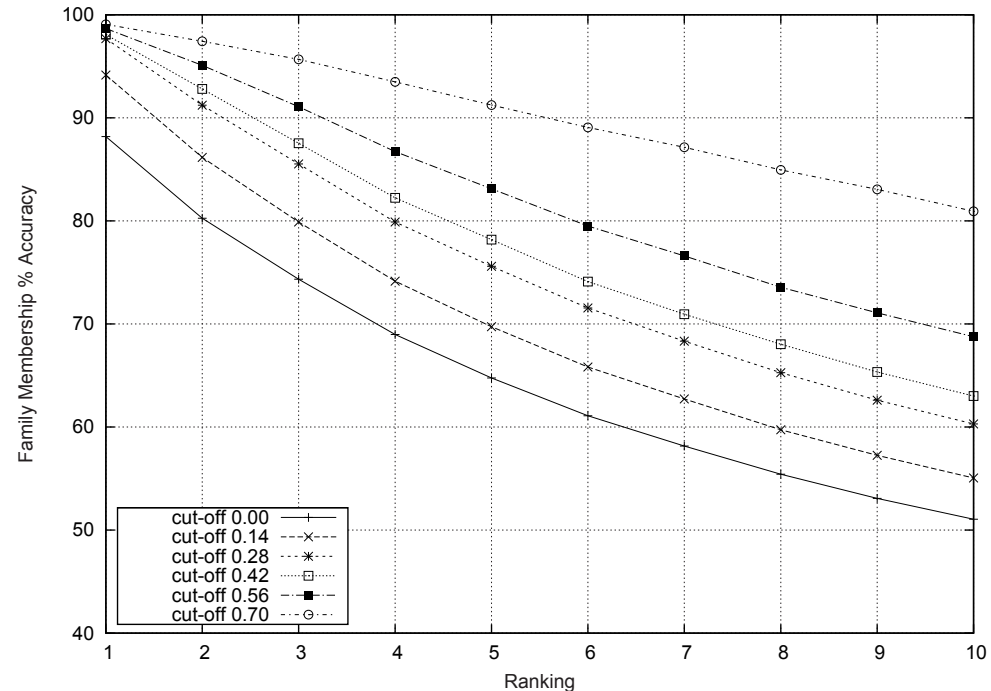

Figure 5.8: Protein Family Membership Percentage Accuracy. 


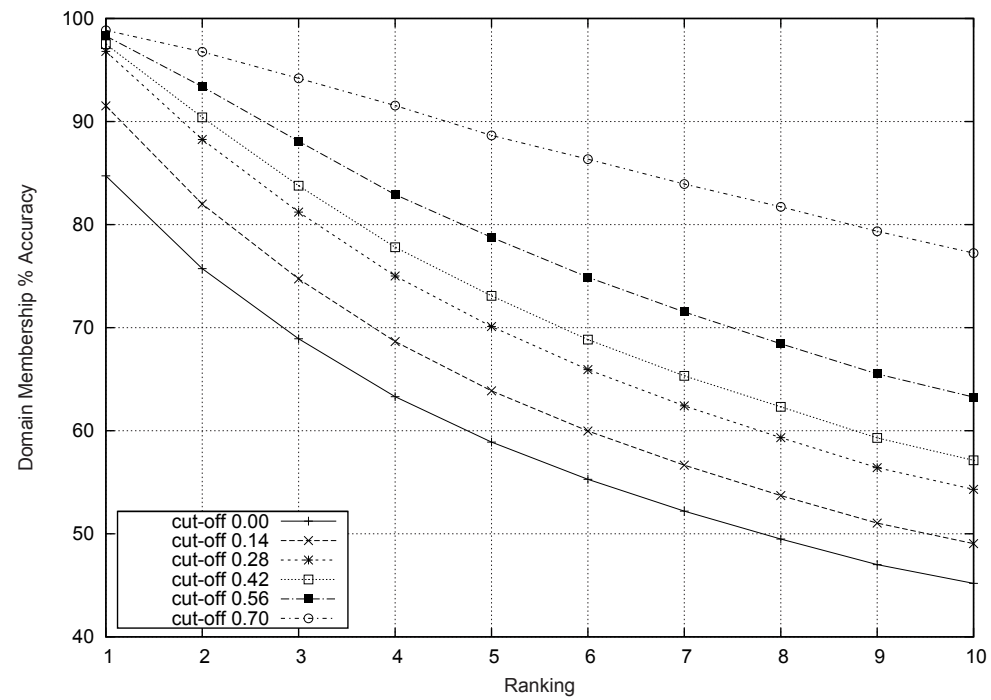

Figure 5.9: Protein Domain Membership Percentage Accuracy. accuracy, etc.

Table 5.3: Proteins unclassified by using SCOP found by our algorithm and their membership percentage accuracy (mpa) to a given Class, Fold, Super-family, Family and Domain.

\begin{tabular}{lccccccc}
\hline $\operatorname{sim}$ & $m p a_{C}$ & $m p a_{F o}$ & $m p a_{S F}$ & $m p a_{F a}$ & $m p a_{D}$ & UPC & TPC \\
\hline 0.00 & 93.02 & 88.83 & 88.61 & 88.17 & 84.72 & 4403 & 35908 \\
0.14 & 96.44 & 94.52 & 94.44 & 94.14 & 91.51 & 3491 & 33747 \\
0.28 & 98.36 & 97.91 & 97.89 & 97.67 & 96.80 & 2143 & 29526 \\
0.42 & 98.64 & 98.28 & 98.28 & 98.07 & 97.51 & 1813 & 27163 \\
0.56 & 99.04 & 98.81 & 98.80 & 98.66 & 98.30 & 1356 & 22374 \\
0.70 & 99.19 & 99.12 & 99.12 & 99.06 & 98.85 & 639 & 12462 \\
\hline
\end{tabular}

sim - similarity score cutoff, mpa - membership percentage accuracy, UPC count of proteins unclassified by SCOP, TPC - total proteins count with given cutoff. 


\section{Chapter 6}

\section{Analysis of Protein Sequences}

The aim of this chapter is to present a novel approach to clustering protein domain sequences and the detection of significant protein domain sequence groups. From the biological point of view, it is the analysis of the protein primary structure which corresponds to sequences of amino acid residues which are encoded as strings of letters (recall Section 2.1.1).

The algorithm is a simple graph-based clustering which relies on our new method for the comparison of protein sequences with the usage of information retrieval models. We called it STIRPC which stands for Suffix Tree and Information Retrieval Protein Clustering. In this chapter we first present our new method for the comparison of protein domain sequences and next we describe our protein domain sequence clustering algorithm. For the fast calculation of pairwise similarities, we employ a vector space model and, to discover the attributes for the model, we use a data structure called the generalized suffix tree, which can carry out fast and efficient sequence matching. Since we analyze protein sequences, we made an improvement of the classic generalized suffix tree data structure to be able to use amino acid substitution matrices such as BLOSUM62, which was discussed in Section 2.1.6. This allows us to make fast inexact string matching which leads to better results in the detection of more distantly related protein sequences. 
The algorithm also implements a parallel version of the protein sequence similarity calculation, which efficiently reduces the running time.

This new method is based on our previous algorithm for analyzing protein 3D structures $[76,77,79]$ discussed previously in Chapter 5 . The goal of this study is a new protein sequence comparison method and the classification of protein domain sequences on the level of the SCOP folds, super-families, families, domains and species with respect to SCOP hierarchical structure and a comparison of the results with the experts curated SCOP database. Another outcome of this work is the demonstration of an efficient employment of information retrieval methods and structures which are capable of quickly analyzing large amounts of data, which, in our case, represents the SCOP biological database. To show the efficiency of the method, we compare our results with state-of-the-art algorithms such as PSIBLAST [1], BLASTP and the newest DELTA-BLAST [11] algorithm, which were used for the calculation of protein domain sequence pairwise similarities. These algorithms represent a "gold standard" in the area of protein sequence comparison methods and are widely used by molecular biologists. We also provide a comparison of our clustering approach with the recent kCLUST algorithm developed by Hauser and Mayer [42]. The kClust algorithm developed by Hauser et al. is the incremental greedy clustering strategy [45] based on matching similar k-mers and ranking analyzed sequences by the sum of similarity scores through all similar kmers. This algorithm is intended for large scale protein sequence clustering since it performs at a very high speed and does not require large amounts of memory.

\subsection{Dataset Description}

In this research we have concentrated on the analysis of the protein primary structure which corresponds to protein sequences, not 3D structures, as was the case of the previous chapter. We focused on one of the latest versions SCOPe and ASTRAL, version 2.03, which was released in October 2013, and new PDB entries were last added in August 2014. Domain sequences were obtained from files appearing in a bundle of files available on ASTRAL [15] websites ${ }^{1}$. The SCOPe

\footnotetext{
${ }^{1}$ http://scop. berkeley.edu/downloads/scopeseq-2.03.tgz
} 
database of version 2.03 contains 63,103 PDB entries, which represent 177,326 protein sequence domains. Sequences are taken from the files astral-scopedom-seqresall-2.03-stable.fa and astral-ntcscopedom-seqres-gd-all-2.03.fa which correspond to SCOPe sequence categories appearing in SCOPe version 2.03. The dataset used for the evaluation consists of 165,843 protein domain sequences since some of the SCOPe 2.03 entries do not appear in the ASTRAL files and some entries are marked as rejected. Again, we analyze and evaluate the whole SCOPe database at all its levels or categories respectively.

As was mentioned above, this part of thesis is about the analysis of protein domain sequences - the protein primary structure. Thus there is no need to encode sequences of amino acid residues in some special way, since it is already encoded into a sequence of one letter codes of individual amino acids.

\subsection{Amino Acid Substitution Suffix Tree}

In this work we deal with protein domain sequences and thus we developed a new suffix tree data structure and we called the Amino Acid Substitution Suffix Tree. We took advantage of amino acid substitution matrices and incorporated them in the classic suffix tree. Thanks to this we are able to do inexact string matching based on the BLOSUM62 scoring matrix and take advantage of the evolutionary protein sequence features as was described in Section 2.1.6. As it turned out by experiments with the whole SCOPe database, the modified suffix tree achieves better results in the detection of more distantly related protein sequences which are called remote homologues.

The construction algorithm for the modified suffix tree is almost the same as the classical one. The key difference is only in the function that compares two amino acids. This function is necessary for the suffix tree construction algorithm when we traverse edges and find the first mismatch to create a new internal node as well as for finding the next path out of the existing internal node [37]. Function (4.1) match $=(a, b)$ for two amino acids $a$ and $b$ for the classical suffix tree was 


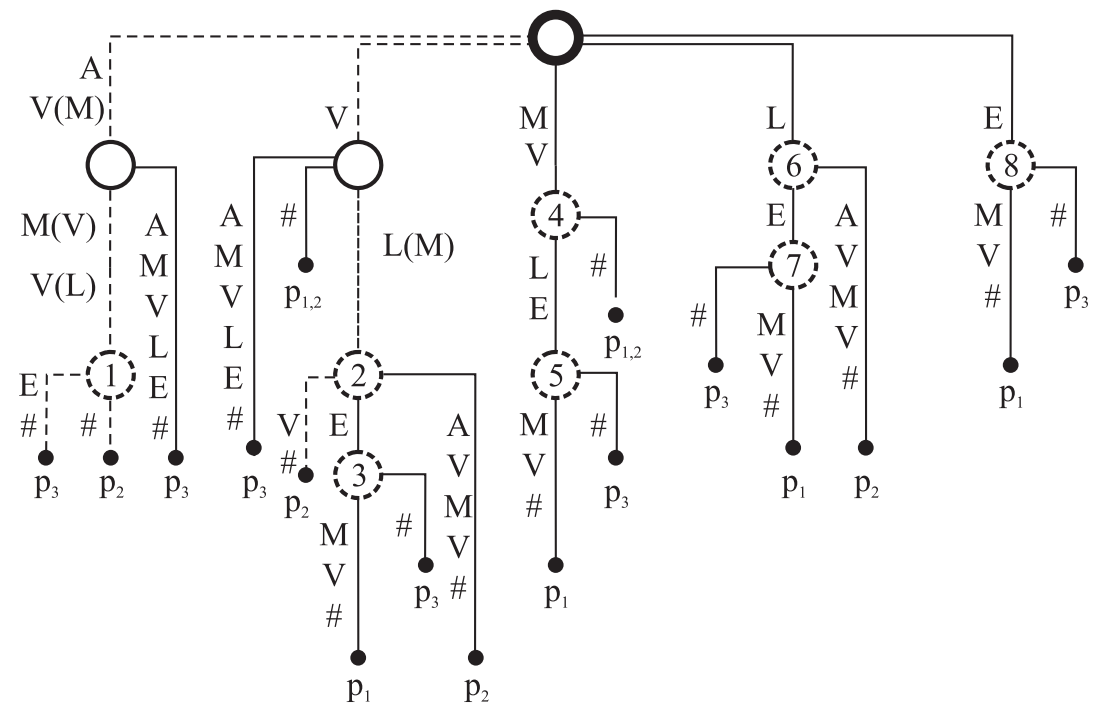

Figure 6.1: Example of the amino acid substitution generalized suffix tree.

defined in Section 4.1. The modified version of this function is defined as follows:

$$
\operatorname{match}(a, b)=\left\{\begin{array}{l}
\text { true for } S_{a b}>s t \\
\text { false for } S_{a b} \leq t
\end{array}\right.
$$

where $S_{a b}$ is the score of a possibility of the substitution of the amino acid $a$ for amino acid $b$ based on the the BLOSUM62 scoring matrix and st is a score threshold variable which is set at the beginning phase of the construction algorithm. When the algorithm is in the phase of finding a path out of the internal node, it can happen that we might find multiple matches according to equation 6.1. In this case we take the path where $S_{a b}$ is maximal.

Figure 6.1 is an example of an amino acid substitution generalized suffix tree for same three protein sequences as in Figure 3.2. The affected parts of the tree are represented with dashed lines. In this example we use the amino acid substitution matrix BLOSUM62 and set the score threshold variable st for Equation 6.1 to 0. In Figure 6.1 the related and substituted amino acids, according to score st and matrix BLOSUM62, are e.g. valine and methionine - V(M) or leucine and methionine - L(M). 


\subsection{Protein Sequence Similarity and Clustering Algorithm}

The STIRPC algorithm for the protein cluster detection is based on discovering components of a graph as was described in Section 3.4 and can be seen as a kind of partitioning clustering (Figure 6.2). The first step in the algorithm is the construction of a generalized suffix tree (see 3.3 and 6.2) and the subsequent formation of a vector space model, as was mentioned in Section 4.3. The result of this stage in the algorithm is a protein similarity matrix which represents all protein pairwise similarities in our protein sequence collection. This is similar to the protein structure similarity algorithm as it was described in Section 5.2.

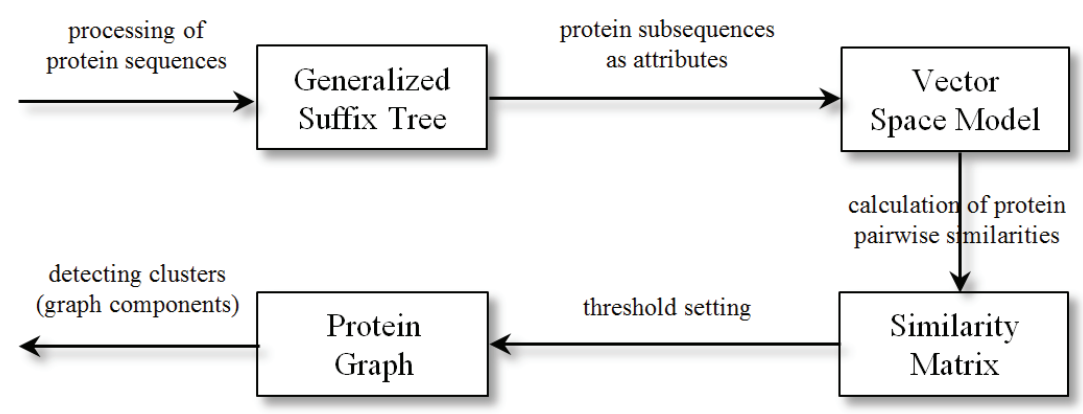

Figure 6.2: Protein sequences data processing.

In the next stage of the algorithm, we construct a protein graph, as defined in Section 3.4, which can be represented by an adjacency matrix. To be able to construct such a matrix from protein similarity matrix $S$, we need to define similarity threshold $t$. Then there exists an edge between any two protein sequences $p_{i}$ and $p_{j}$ (graph vertices), when the similarity between these proteins is greater than or equal to $t$. In other words, the protein similarity matrix corresponds to the protein graph adjacency matrix in that there exists an edge between any two proteins when $S\left(p_{i}, p_{j}\right) \geq t$.

The last task in detecting protein clusters corresponds to the process of discovering connected components, which can be seen as partitioning clustering. Discovering a graph connected components is commonly done by the Depth-First Search (DFS) or Breadth-First Search (BFS) graph traversal algorithms [53]. 


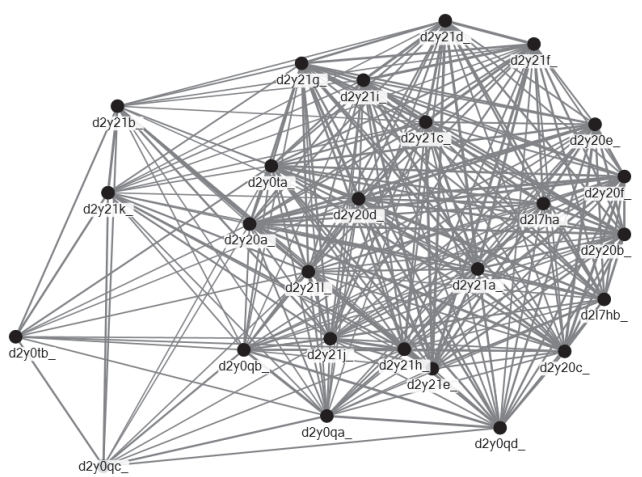

Figure 6.3: SCOP HAMP domain-like Fold, Super-Family and Family detected by our algorithm.

An example of the protein cluster (graph connected component) discovered by our algorithm is shown in Figure 6.3. This cluster precisely corresponds to SCOP HAMP domain-like Fold, Super-Family and Family, which contains exactly 26 protein sequences.

\subsection{Experiments and Evaluation}

The STIRPC software library is implemented in C++ using the Microsoft Visual Studio $9 \mathrm{C}++$ compiler. The cluster detection software library is written in the C++ programming language as well. Both libraries were developed and tested on common hardware which, in our case, is represented by a laptop computer with an Intel CORE I7 processor and 16 gigabytes of RAM running Microsoft Windows 7. We emphasized the efficient implementation of the proposed algorithm, so we do not need high-performance computing hardware or distributed computing between a large number of computers. The computational time for calculating all pairwise sequence similarities of the data set, which consists of 165,843 protein domain sequences, does not exceed 12 hours on the previously mentioned hardware. Memory consumption of the pairwise similarity algorithm, which consists of building the generalized suffix tree and computing the similarity matrix, is about 8 gigabytes of RAM. 


\subsubsection{Evaluation}

Since we present the protein sequence comparison method and the graph-based clustering algorithm, we separated the evaluation into two different steps. For both algorithms we evaluate the results at all levels of the SCOP hierarchy which means that we analyze the results at the level of the SCOP fold, super-family, family, domain and species (see Figure 2.6). It is also well known that many proteins are made up of evolutionarily independent domains and thus the classification of the protein as a whole, into e.g. a family, is a very difficult task. Therefore we analyze only protein domain sequences (not as a whole protein) which have a clearly defined SCOP class, fold, super-family, family, domain and species classification.

For the evaluation of the protein sequence comparison method, we use the Receiver Operating Characteristics (ROC) [34, 28, 29] and compare it with stateof-the-art methods, i.e. the PSI-BLAST [1], BLASTP and DELTA-BLAST [11] algorithms which are considered a "gold standard" in protein sequence analysis. Specifically, we used the truncated $R O C_{n}$ score, calculated by pooling the search results of all queries. The pooled search result is ordered by the e-value (in the case of BLAST algorithms) and by the cosine similarity measure (in the case of our algorithm) and then measuring the results only up to the $n$-th false positive [97]. For the pooled result we calculated $R O C_{165,000}$ which corresponds to approximately one false positive match per query sequence. We also calculated a separate $R O C_{5}$ score for each query in the dataset. In the context of the $R O C_{n}$ analysis we assume the true positive match (related) when the query and result sequence is from the same SCOP group (e.g. family) and the false positive match (unrelated) is considered the query and result sequence that belongs to a different SCOP group (e.g. the query and result sequence that belongs to different families). The equation for the the $R O C_{5}$ is following:

$$
R O C_{n}=\frac{1}{n T} \times \sum_{i=1}^{n} t_{i}
$$

where $T$ is the total number of true positives in the dataset and $n$ is the number of the first $n$ false positive matches appearing in the ranked result list and $t_{i}$ is the number of true positive matches ranked before $i$-th false positive match.

For the assessment of the quality of the clusters generated by the clustering 
algorithms, we use the combined statistical measure called Matthews Correlation Coefficient $(M C C)$. This measure depends on the definition of true and false positives (TP, FP) as well as on true and false negative (TN, FN) values. For every discovered cluster of the protein domain sequences, we count these values but not for pairs of the protein domain sequences but for the cluster as a whole. We compute these values for every level of the SCOP hierarchy within each cluster identified by our algorithm. Let us assume we are analyzing protein cluster $P C$ (the automatically detected connected component) on the level of the SCOP Family $S C O P_{\text {Fam }}$. The true positive value is represented by the number of protein sequences within the cluster $P C$ which are from the $S C O P_{F a m}$ (correctly included), the false positive value is the number of proteins within $P C$ which are not in $S C O P_{\text {Fam }}$ (incorrectly included), false negatives are represented by the protein sequences from $S C O P_{F} a m$ which do not appear within $P C$ (incorrectly excluded) and the true negative value is the number of protein sequences which are neither in $P C$ nor in the analyzed $S C O P_{F a m}$ (correctly excluded). Figure 6.4 presents a simple example of determining the true, false positive and negative values used in the calculation of the $M C C$. From the mathematical viewpoint, it must be given that:

$$
\begin{gathered}
N=T P+F P+F N+T N \\
M=T P+F N \\
T N=N-M-F P
\end{gathered}
$$

where $N$ is the number of sequences in the dataset and $M$ is the number of proteins in the considered SCOP category (e.g. Family).

In analyzing the effectiveness of the clustering algorithm, we employed derived quantitative measures, which summarize the values discussed above. The Matthews Correlation Coefficient $(M C C)$ [71] is a metric used for the assessment of the quality of a classification or prediction task. It is a combined measure which uses true and false positive and true and false negative values. This method is generally considered to be a measure which can be used even if the size of the classes 
MCC Example 1

SCOP Family - Cytokinin dehydrogenase 1 Number of sequences: 14

Total number of sequences: 165843

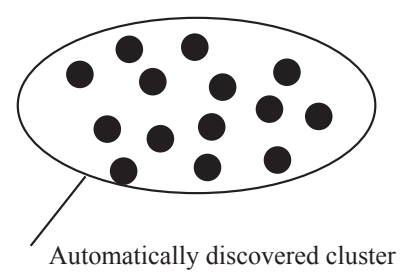

Number of true positves: 14

Number of false positves: 0

Number of true negatives: 165829

Number of false negatives: 0

Matthews Correlation Coefficient: 1.0
MCC Example 2

SCOP Family: Glucose permease-like

Number of sequences: 18

Total number of sequences: 165843

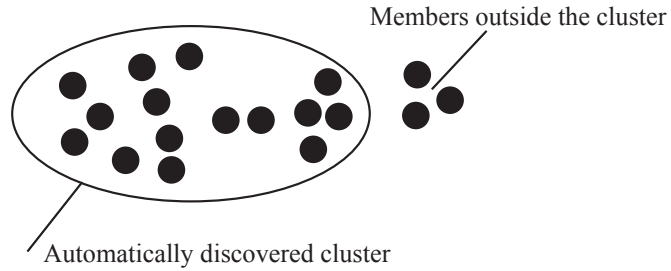

Number of true positves: 15

Number of false positves: 0

Number of true negatives: 165825

Number of false negatives: 3

Matthews Correlation Coefficient: 0.9129

Figure 6.4: A simple example of the calculation of the Matthews Correlation Coefficient and the way of determining true, false positive and negative values.

to which we classify are very divergent, and thus the large classes make the same contribution to the result as smaller ones.

$$
\begin{gathered}
S=\frac{T P+F N}{N} \\
P=\frac{T P+F P}{N} \\
M C C=\frac{\frac{T P}{N}-S \times P}{\sqrt{P \times S \times(1-S) \times(1-P)}}
\end{gathered}
$$

If any of the sums in the denominator are zero, then the $M C C$ is defined as zero. The $M C C$ takes values from interval $<-1 ; 1>$ where 1 represents a perfect classification, 0 is no better than a random prediction and -1 represents a total disagreement between the prediction and observation. In our case when the $M C C$ for the given cluster $P C$ is equal to 1 then we can state that the cluster $P C$ is absolutely the same as it is defined in the SCOP database. To demonstrate the effectiveness of the graph clustering approach we compare the result achieved by clustering based on the suffix trees (STIRPC) and clustering based on the BLAST algorithms. We also provide a comparison of the graph-based clustering approach 
with the more recent kCLUST algorithm [42] which is designed for the clustering of large protein databases with very low time complexity.

\subsubsection{Experiments with Sequence Similarity}

In this section we present the result of the experiments with our sequence analysis method based on suffix trees and the vector space model. The results are compared to "gold-standard" sequence comparison algorithms such as the basic BLASTP algorithm and the advanced PSI-BLAST and the newest DELTA-BLAST algorithm. We bring the comparison of proposed methods with the usage of $R O C_{n}$ analysis. We did this comparison for results pooled from all queries in the dataset as well as for each query separately.

Table 6.1 presents the $R O C_{165,000}$ scores with standard errors for the pooled results of all the queries in the dataset which correspond to approximately one false positive per query sequence. Table 6.2 presents a comparison of our protein sequence similarity method implemented in the STIRPC and AAS-STIRPC (Amino Acid Substitution STIRPC) with the BLASTP, PSI-BLAST and DELTA-BLAST algorithms. In the table the number of queries that yield the separate $R O C_{5}$ score above 0.5 and 0.9 are counted. For the AAS-STIRPC algorithm we show three different settings of the algorithm with respect to the substitution matrix score threshold variable st (recall the Section 6.2), where e.g. the AAS-STIRPC(1) denotes $s t=1$.

Table 6.1 summarizes the evaluation of the protein comparison methods with the pooled $R O C_{n}$ score which means that all retrieved results of all queries are measured (pooled and ordered by e-value in the case of the BLAST algorithms and ordered by cosine similarity measure in the case of the STIRPC algorithm). The results with the separate $R O C_{5}$ score analysis of each algorithm is summarized in Table 6.2.

\subsubsection{Experiments with Sequence Clustering}

The aim of our clustering algorithm is to find the highest amount of protein domain sequence groups as is defined in the experts crafted SCOPe database. Our experiments targeted the whole SCOPe database. Whereas we compared our pro- 
Table 6.1: The $R O C_{165,000}$ score of the protein sequence comparison methods

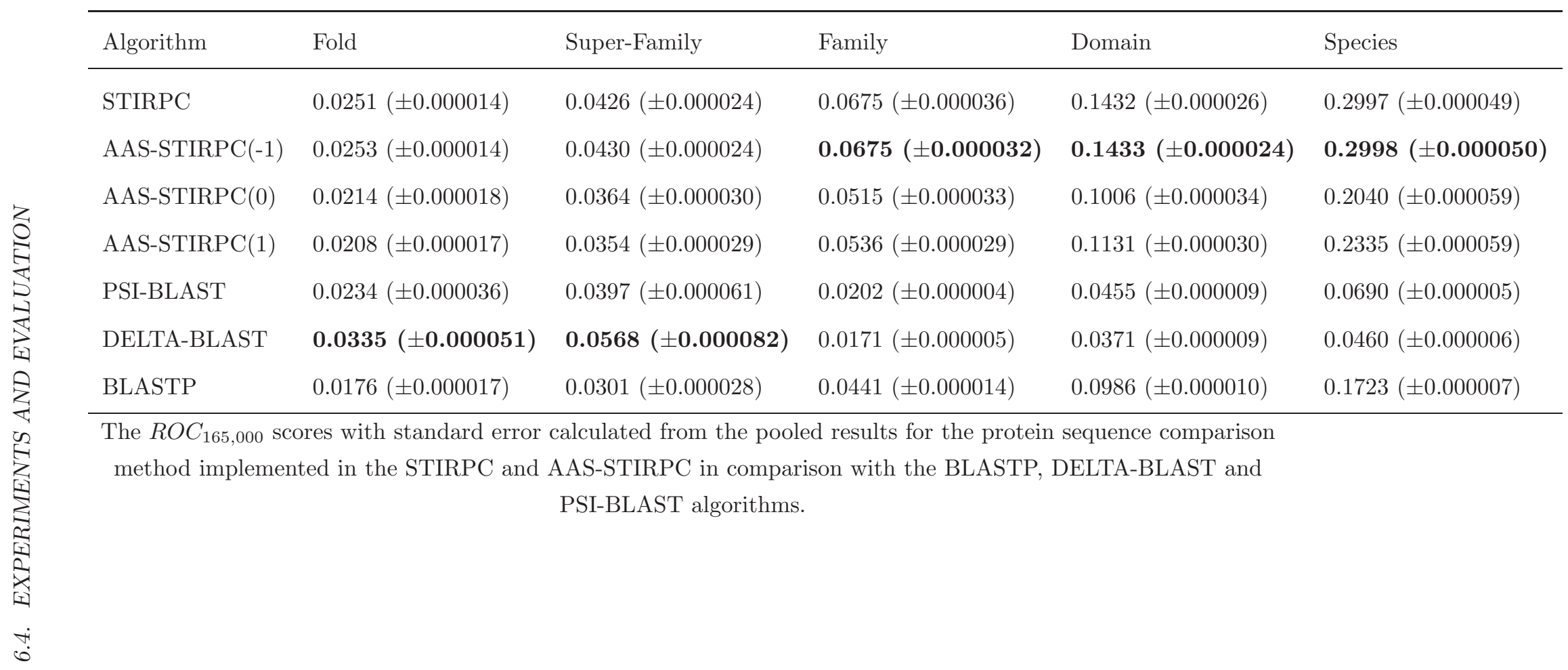


Table 6.2: The number of queries with the $R O C_{5}$ score of the protein sequence comparison methods

\begin{tabular}{lccccccccccc}
\hline \multirow{2}{*}{ Algorithm } & \multicolumn{2}{c}{ Fold } & \multicolumn{2}{c}{ Super-Family } & \multicolumn{2}{c}{ Family } & \multicolumn{2}{c}{ Domain } & \multicolumn{2}{c}{ Species } \\
& $>0.5$ & $>0.9$ & $>0.5$ & $>0.9$ & $>0.5$ & $>0.9$ & $>0.5$ & $>0.9$ & $>0.5$ & $>0.9$ \\
\hline STIRPC & 17652 & 5436 & 29541 & 10377 & 55402 & 26070 & 89662 & 55647 & 126014 & 105057 \\
AAS-STIRPC(-1) & 19546 & 6150 & 32426 & 11940 & 57877 & 28018 & 90662 & 56974 & 126157 & 105182 \\
AAS-STIRPC(0) & 20622 & 6829 & 33967 & 12846 & 58993 & 29293 & 87828 & 55458 & 121689 & 99624 \\
AAS-STIRPC(1) & 18423 & 5890 & 30366 & 10992 & 56495 & 27836 & 87383 & 54185 & 122765 & 100486 \\
PSI-BLAST & 51414 & 25181 & 73898 & 41441 & 77431 & 46101 & 84966 & 57104 & 97758 & 76183 \\
DELTA-BLAST & $\mathbf{6 5 8 6 5}$ & $\mathbf{3 1 6 2 2}$ & $\mathbf{9 1 8 5 7}$ & $\mathbf{5 1 0 6 0}$ & $\mathbf{7 9 6 4 1}$ & $\mathbf{4 7 9 9 9}$ & 81482 & 53008 & 90749 & 68990 \\
BLASTP & 43295 & 20546 & 64105 & 33943 & 76147 & 44416 & $\mathbf{9 9 6 9 5}$ & $\mathbf{6 8 7 5 4}$ & $\mathbf{1 2 8 7 4 6}$ & $\mathbf{1 1 0 6 6 2}$ \\
\hline
\end{tabular}

The separate $R O C_{5}$ scores calculated for each query in the dataset consisting of 165,843 protein domain sequences. For each query and SCOP category we calculated the separate $R O C_{5}$ score and counted the number of queries having the $R O C_{5}$ score above 0.5 and 0.9 . 


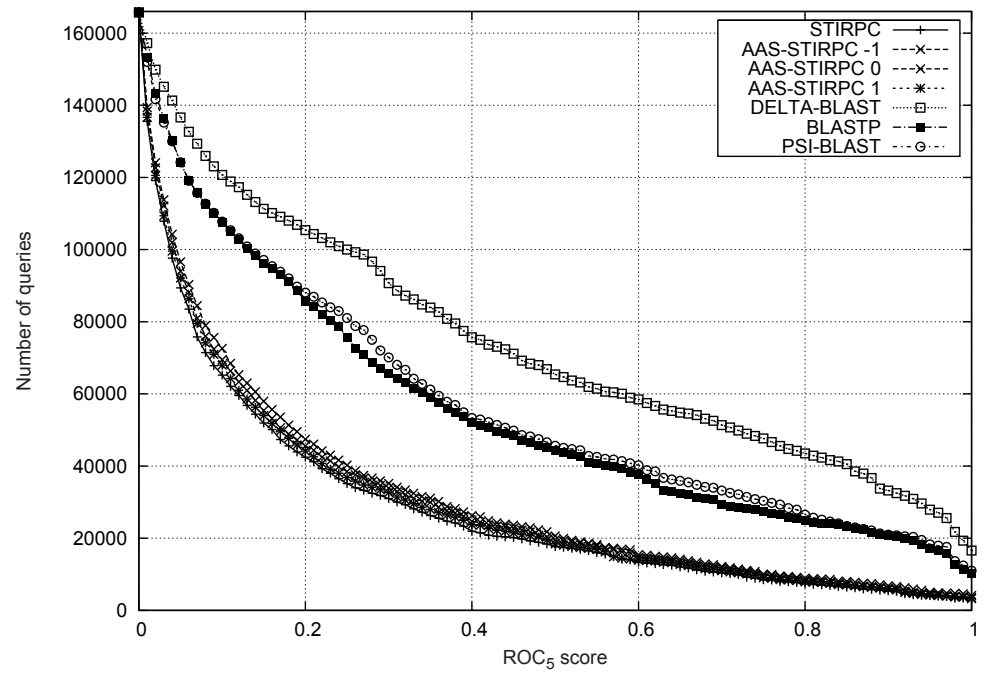

Figure 6.5: $R O C_{5}$ comparison - SCOP Fold category.

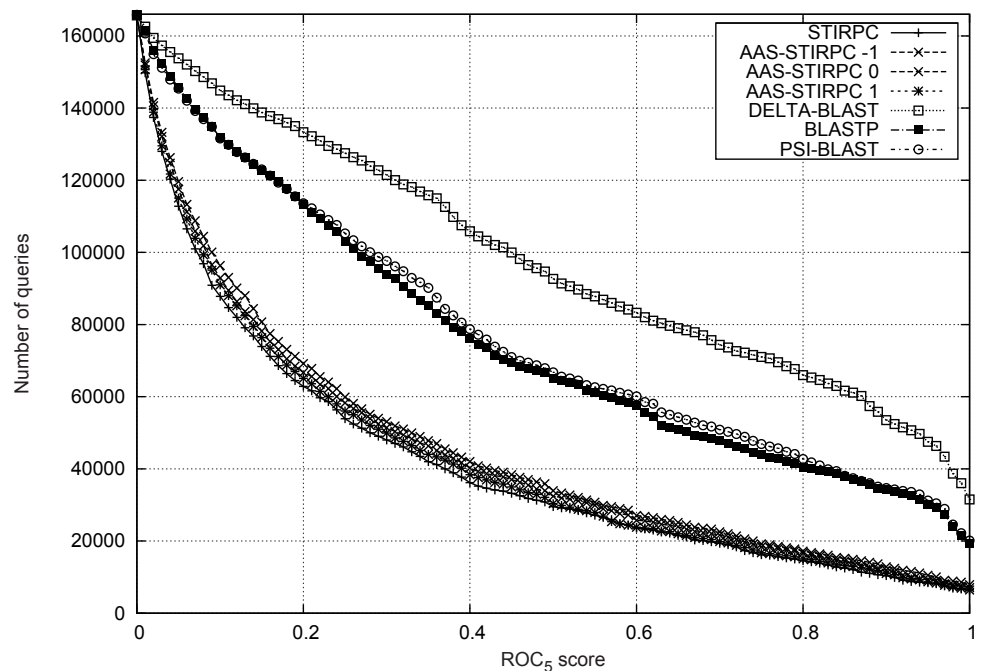

Figure 6.6: $R O C_{5}$ comparison - SCOP Super-family category.

tein sequence comparison method with BLAST algorithms, we used similarities calculated by BLAST algorithms for our graph based clustering and compared the algorithms with our clustering based on our sequence similarity method. We also did experiments on the same dataset with the kCLUST algorithm which is designed for larger scale clustering and is based on techniques other than ours. All 


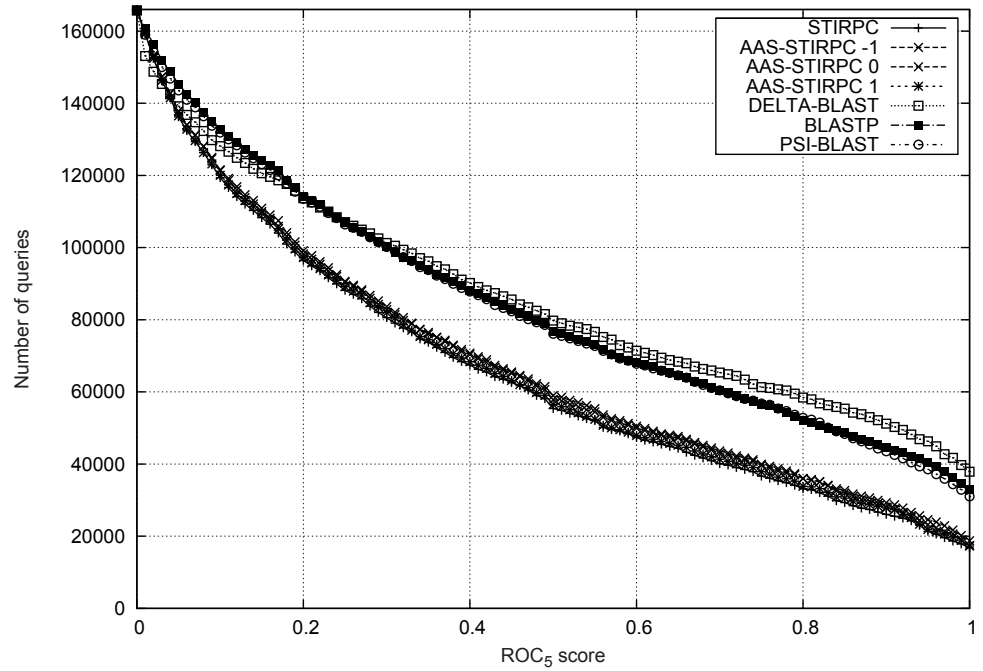

Figure 6.7: $R O C_{5}$ comparison - SCOP Family category.

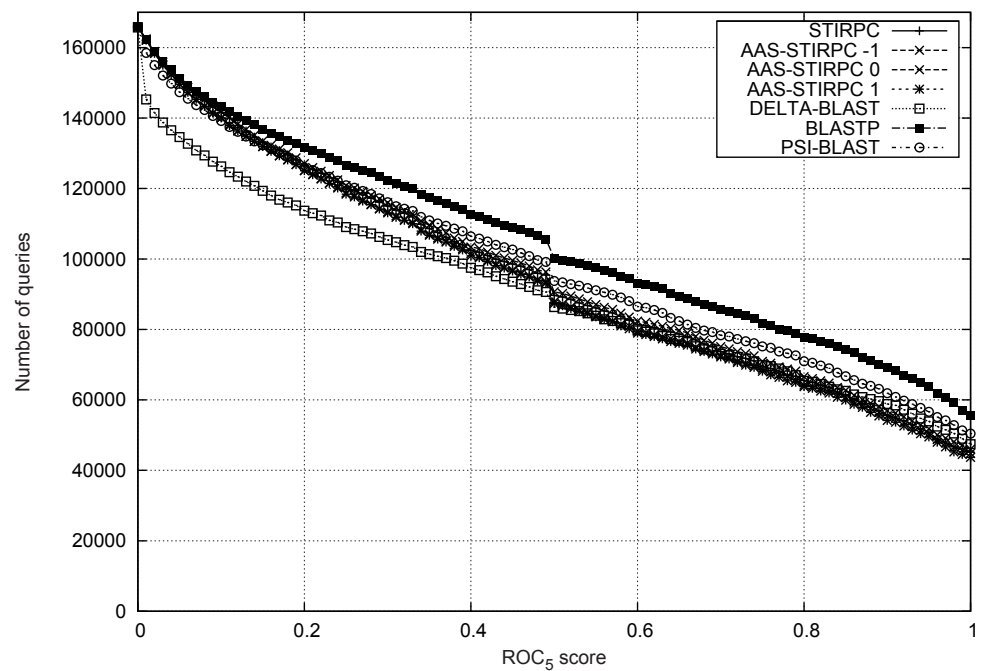

Figure 6.8: $R O C_{5}$ comparison - SCOP Domain category.

the clustering methods were compared using the Matthews Correlation Coefficient.

Figures $6.10,6.11,6.12,6.13$ and 6.14 present a comparison of our protein clustering algorithms STIRPC and AAS-STIRPC toward the BLASTP, PSI-BLAST, DELTA-BLAST based cluster detection approach and the kCLUST. In each figure the number of clusters that yield a $M C C$ score above $0.1,0.2, \ldots, 0.9$ and equal 


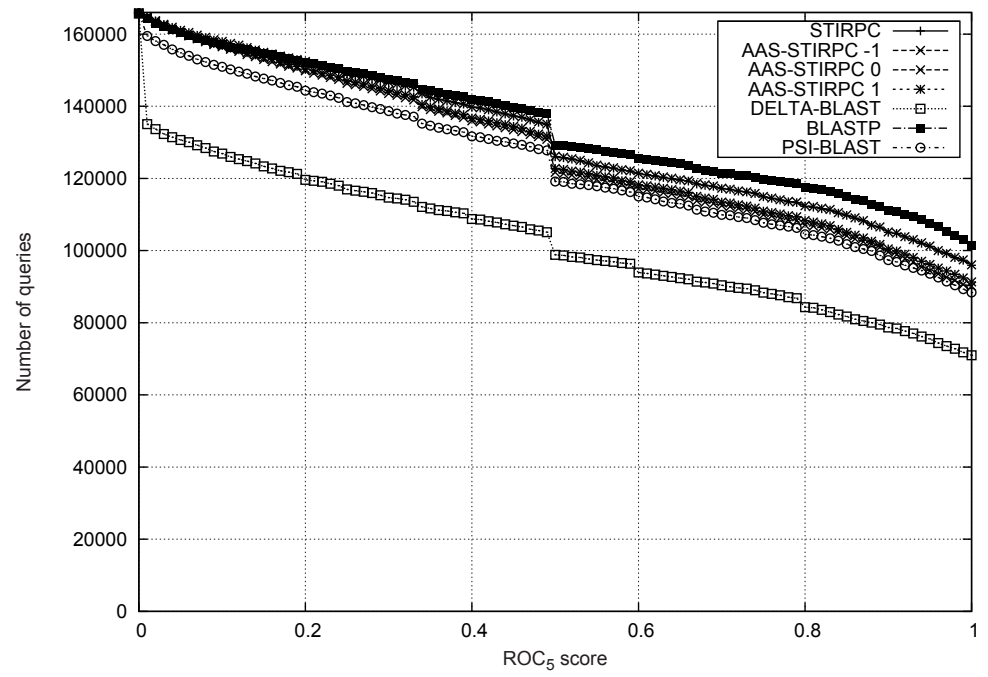

Figure 6.9: $R O C_{5}$ comparison - SCOP Species category.

to 1 are counted. All the methods except kCLUST are based on the detection of graph components and differ in the protein sequence similarity calculations. From the given figures, it is evident that the number of clusters discovered by our algorithm and the BLAST algorithms satisfy the given value of the Matthews correlation coefficient. For example (see Figure 6.12 and Table 6.4), we can say that our algorithm with the amino acid substation suffix tree (AAS-STIRPC $(0)$ ) detected 2,034 clusters having the $M C C$ equal to 1.0 at the level of the SCOP Family category, meaning a perfect partition (discovered 2,034 whole SCOP families with a $100 \%$ match), and we can see that 5,365 clusters have a $M C C$ of at least 0.75 at the level of the SCOP Family category, which still yields a good result. Tables 6.3 and 6.4 summarize these results for all clustering algorithms measured by the Matthews correlation coefficient. Each row of Tables 6.3, 6.4 represents the number of clusters for which the $M C C$ is greater or equal to the values of 0.5 , 0.75 and 1.0 when the given SCOP category was analyzed within the clusters. The last column, column $t$, in Table 6.3 and 6.4 represent the best similarity threshold for the given algorithm, which means the algorithm detected the largest number of clusters having the $M C C \equiv 1$ indicating a perfect match with SCOP. In the case of our algorithm, the similarity threshold $t$ represents the cosine similarity measure and in the case of the kCLUST and the BLAST family algorithms, the 


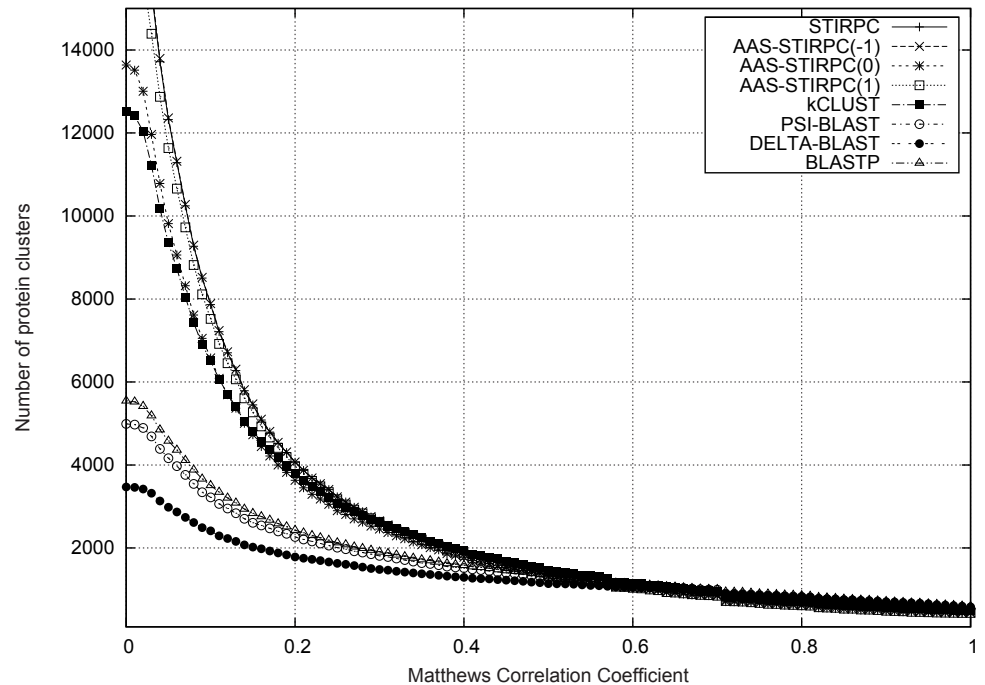

Figure 6.10: Matthews correlation coefficient - SCOP Fold category.

similarity threshold is represented with the $e-v a l u e$.

From figures $6.12,6.13,6.14$ and Tables $6.3,6.4$, it is obvious that our clustering algorithm performs best at the level of the SCOP family, domain and species groups. Although the kCLUST and the clustering based on the BLAST algorithms performs better at the level of the SCOP fold and super-family categories, our algorithm achieves comparable results in absolute values of the Matthews correlation coefficient. Perfect partitioning was achieved within the clusters discovered by the algorithm with respect to the statistical values of true positives and negatives in proportion to errors and in comparison with the cluster sizes. Our proposed method can, for example, automatically discover 2,034 out of 4,834 (42.1\%) SCOP family groups with perfect partitioning which means that the algorithm discovered these groups totally the same as they are defined in the expertly crafted SCOP database (have same members and same number of members). The same holds for 6,481 out of 12,034 (53.6\%) SCOP domain groups, 12,960 out of 21,458 (60.4\%) SCOP species groups, 762 out of 2,220 (20.8\%) super-family groups and 447 out of $1,390(32.2 \%)$ folds.

The overall clustering accuracy for all algorithms is presented in Table 6.5. As was mentioned above, when the $M C C$ is equal to 1.0 , then the given cluster is identical to the given SCOP group (e.g. fold, super-family, family, etc.). From 


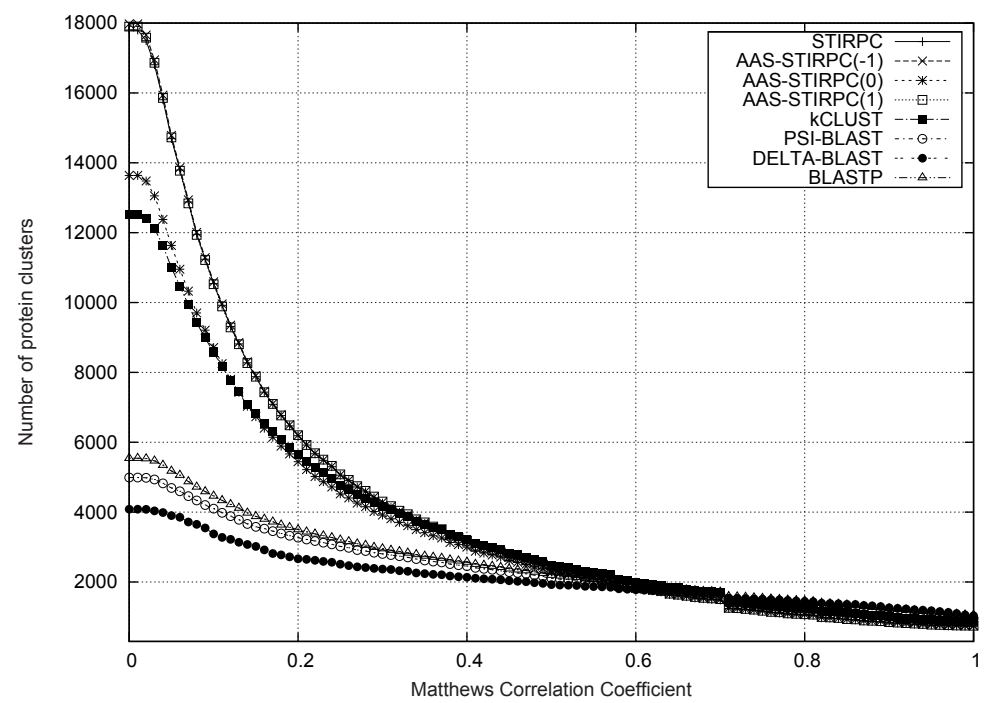

Figure 6.11: Matthews correlation coefficient - SCOP Super-family category.

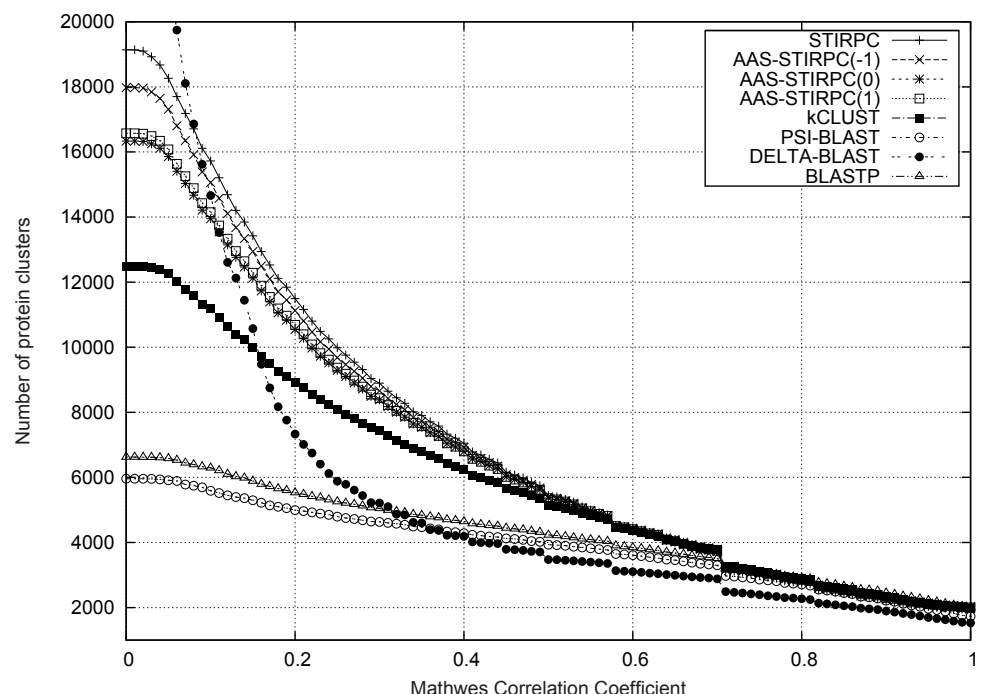

Figure 6.12: Matthews correlation coefficient - SCOP Family category. 


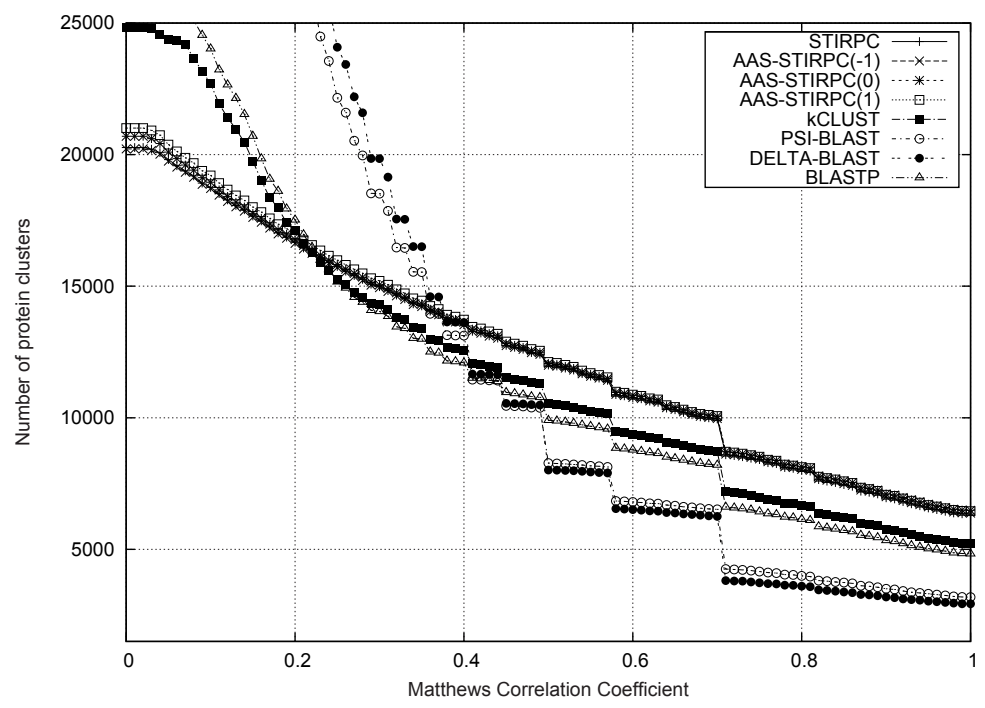

Figure 6.13: Matthews correlation coefficient - SCOP Domain category.

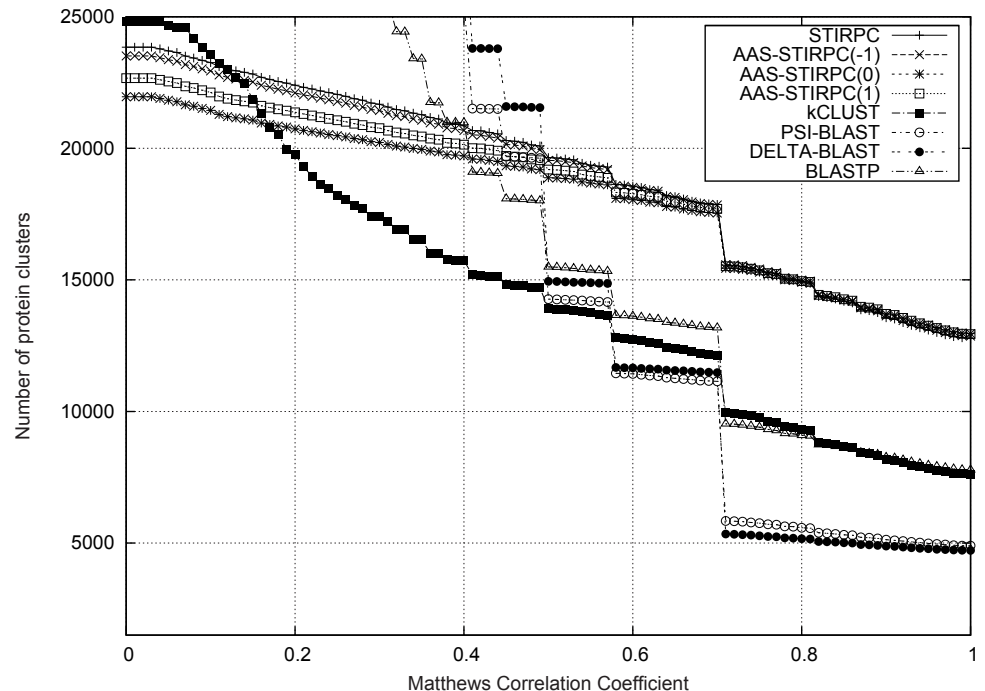

Figure 6.14: Matthews correlation coefficient - SCOP Species category. 
Table 6.3: $M C C$ for Protein Sequence Clusters

\begin{tabular}{lcccr}
\hline SCOP & $\geq 0.5$ & $\geq 0.75$ & $=1.0$ & $t$ \\
\hline Fo - STIRPC & 1334 & 662 & $426(30.6 \%)$ & 0.3 \\
Fo - AAS-STIRPC(-1) & 1341 & 669 & $434(31.2 \%)$ & 0.3 \\
Fo - AAS-STIRPC(0) & 1317 & 698 & $447(32.2 \%)$ & 0.1 \\
Fo - AAS-STIRPC(1) & 1333 & 656 & $435(31.3 \%)$ & 0.2 \\
Fo - kCLUST & 1454 & 778 & $497(35.8 \%)$ & $1 e-02$ \\
Fo - PSI-BLAST & 1313 & 876 & $538(38.7 \%)$ & $1 e-05$ \\
Fo - DELTA-BLAST & 1188 & 890 & $\mathbf{5 9 9}(\mathbf{4 3 . 1 \% )}$ & $1 e-02$ \\
Fo - BLASTP & 1324 & 900 & $593(42.7 \%)$ & $1 e-02$ \\
Sf - STIRPC & 2323 & 1161 & $733(33.0 \%)$ & 0.3 \\
Sf - AAS-STIRPC(-1) & 2339 & 1174 & $745(33.6 \%)$ & 0.3 \\
Sf - AAS-STIRPC(0) & 2286 & 1224 & $762(34.3 \%)$ & 0.1 \\
Sf - AAS-STIRPC(1) & 2358 & 1180 & $749(33.7 \%)$ & 0.3 \\
Sf - kCLUST & 2478 & 1362 & $862(38.8 \%)$ & $1 e-02$ \\
Sf - PSI-BLAST & 2155 & 1486 & $946(42.6 \%)$ & $1 e-05$ \\
Sf - DELTA-BLAST & 1925 & 1509 & $1036(46.7 \%)$ & $1 e-05$ \\
Sf - BLASTP & 2196 & 1535 & $\mathbf{1 0 5 1}(\mathbf{4 7 . 3 \% )}$ & $1 e-02$ \\
\hline
\end{tabular}

this table we can say that e.g. the AAS-STIRPC(0) discovered $44.56 \%$ of all the SCOP protein sequence groups, which included all the protein folds, superfamilies, families, domains and species appearing in the SCOP database. We can also say that the AAS-STIRPC(0) discovered $96.55 \%$ of the whole SCOP database (all protein sequence groups) with the $M C C$ greater than or equal 0.5. It is apparent that although e.g. the AAS-STIRPC $(0)$ is $12 \times$ faster than the DELTABLAST it still achieves better results. Likewise, it is seen that the STIRPC and 
AAS-STIRPC outperform the PSI-BLAST, BLASTP, DELTA-BLAST as well as kCLUST in overall accuracy.

\subsection{Discusion}

The protein sequence similarities as well as protein clusters discovered by our clustering algorithm were analyzed at all levels of the SCOP hierarchy (except class), representing fold (Fo), super-family (Sf), family (Fa), domain (Do) and species (Sp) groups (with respect to the SCOP tree representation - see Figure 2.6). We also tested the clustering algorithm for different sequence similarity thresholds since the similarity between two sequences takes values from interval $\langle 0 ; 1\rangle$, where a similarity of 1 means perfect sequence alignment and 0 stands for sequences that have no similar regions of alignments computed by our algorithm. The same approach was applied to the BLASTP, PSI-BLAST, DELTA-BLAST and kCLUST results except that the e-value was used as a threshold of similarity.

It is obvious that our sequence similarity approach is better in analyzing smaller protein sequences groups (the SCOP family, domain and species groups) whereas the PSI-BLAST and DELTA-BLAST perform better in the analyzing large protein sequences groups (fold and super-family groups). This can be seen in Table 6.1 and 6.2 and graphicaly presented in Figures with $R O C_{5}$ scores and a number of queries correspond to given score. It is also seen that the usage of the amino acid substitution matrix used in the AAS-STIRPC method improves the search sensitivity of the algorithm. When we analyze search results separately for each query with $R O C_{5}$ score then the STIRPC performs almost the same as the BLASTP in the case of smaller SCOP groups represented by SCOP domain and species groups. When we evaluate the search results of larger protein sequence groups which correspond to the SCOP families, super-family and fold groups, then the DELTA-BLAST as well as the PSI-BLAST outperform all the other presented algorithms.

Regarding experiments with the clustering of protein domain sequences, from the above Tables 6.3 and 6.4, it is obvious that the kCLUST and BLAST algorithms based clustering approaches can better detect larger protein sequence groups (fold and super-family SCOP groups) while our algorithm is much better 
in the detection of smaller protein sequence groups. It has also turned out that the modified suffix tree which uses the amino acid substitution matrix achieves better results than the classic suffix tree approach.

With respect to time complexity, kCLUST is the best among all, although it does not reach such a good accuracy as the STIRPC and the BLAST based methods. Our algorithm is faster than the PSI-BLAST, BLASTP and DELTABLAST based ones. The most difficult and important task for both STIRPC and BLAST algorithms is computing protein pairwise similarities. Time and memory requirements for calculating all 165,843 protein pairwise similarities and clustering for our algorithm and the PSI-BLAST, BLASTP, DELTA-BLAST and kCLUST is summarized in Table 6.6. Once the calculation of the similarities of protein sequences is done, the graph-based clustering step does not exceed 99 seconds for every method, not including the time needed to load the graph into memory. 
Table 6.4: $M C C$ for Protein Sequence Clusters

\begin{tabular}{|c|c|c|c|c|}
\hline SCOP & $\geq 0.5$ & $\geq 0.75$ & $=1.0$ & $t$ \\
\hline $\mathrm{Fa}-\mathrm{STIRPC}$ & 5442 & 2992 & $1944(40.2 \%)$ & 0.4 \\
\hline $\mathrm{Fa}-\mathrm{AAS}-\mathrm{STIRPC}(-1)$ & 5399 & 3036 & $1971(40.8 \%)$ & 0.3 \\
\hline Fa - AAS-STIRPC $(0)$ & 5365 & 3107 & $2034(42.1 \%)$ & 0.2 \\
\hline Fa - AAS-STIRPC(1) & 5363 & 3084 & $2005(41.5 \%)$ & 0.2 \\
\hline $\mathrm{Fa}-\mathrm{kCLUST}$ & 5133 & 3111 & $1984(41.0 \%)$ & $1 e-01$ \\
\hline $\mathrm{Fa}$ - PSI-BLAST & 3771 & 2782 & $1694(35.0 \%)$ & $1 e-05$ \\
\hline Fa - DELTA-BLAST & 3477 & 2395 & $1530(31.7 \%)$ & $1 e-30$ \\
\hline $\mathrm{Fa}-\mathrm{BLASTP}$ & 4230 & 3082 & $2015(47.7 \%)$ & $1 e-05$ \\
\hline Do - STIRPC & 12003 & 8407 & $6340(52.7 \%)$ & 0.5 \\
\hline Do - AAS-STIRPC(-1) & 11994 & 8438 & $6378(53.0 \%)$ & 0.5 \\
\hline Do - AAS-STIRPC(0) & 12063 & 8525 & $6481(56.9 \%)$ & 0.6 \\
\hline Do - AAS-STIRPC(1) & 12120 & 8520 & $6453(53.6 \%)$ & 0.6 \\
\hline Do - kCLUST & 10538 & 6985 & $5228(43.4 \%)$ & $1 e-40$ \\
\hline Do - PSI-BLAST & 8072 & 4153 & $3140(26.1 \%)$ & $1 e-70$ \\
\hline Do - DELTA-BLAST & 8015 & 3726 & $2929(24.3 \%)$ & $1 e-70$ \\
\hline Do - BLASTP & 9904 & 6430 & $4831(40.1 \%)$ & $1 e-50$ \\
\hline Sp - STIRPC & 19649 & 15380 & $12783(59.6 \%)$ & 0.7 \\
\hline Sp - AAS-STIRPC $(-1)$ & 19542 & 15412 & $12863(59.9 \%)$ & 0.7 \\
\hline Sp - AAS-STIRPC $(0)$ & 18884 & 15295 & $12960(60.4 \%)$ & 0.7 \\
\hline Sp - AAS-STIRPC (1) & 19191 & 15362 & $12936(60.3 \%)$ & 0.7 \\
\hline $\mathrm{Sp}-\mathrm{kCLUST}$ & 13912 & 9754 & $7623(35.5 \%)$ & $1 e-40$ \\
\hline Sp - PSI-BLAST & 14477 & 5611 & $4837(22.5 \%)$ & $1 e-100$ \\
\hline Sp - DELTA-BLAST & 14945 & 5276 & $4722(22.0 \%)$ & $1 e-100$ \\
\hline Sp - BLASTP & 15491 & 9404 & $7780(36.6 \%)$ & $1 e-80$ \\
\hline
\end{tabular}


Table 6.5: Overall $M C C$ accuracy for protein sequence clusters

\begin{tabular}{llll}
\hline Algorithm & $\geq 0.5$ & $\geq 0.75$ & $=1.0$ \\
\hline STIRPC & $97.45 \%$ & $60.67 \%$ & $43.23 \%$ \\
AAS-STIRPC(-1) & $97.44 \%$ & $61.15 \%$ & $43.70 \%$ \\
AAS-STIRPC(0) & $96.55 \%$ & $62.34 \%$ & $\mathbf{4 4 . 5 6 \%}$ \\
AAS-STIRPC(1) & $97.06 \%$ & $61.31 \%$ & $44.08 \%$ \\
kCLUST & $90.48 \%$ & $57.04 \%$ & $31.59 \%$ \\
PSI-BLAST & $80.29 \%$ & $49.63 \%$ & $32.99 \%$ \\
DELTA-BLAST & $76.22 \%$ & $47.54 \%$ & $33.63 \%$ \\
BLASTP & $87.41 \%$ & $59.10 \%$ & $41.70 \%$
\end{tabular}

Overall accuracy of the STIRPC, AAS-STIRPC, kCLUST and BLAST family algorithms with respect to the values of the Matthews correlation coefficient and SCOP classification. 
Table 6.6: Time and Memory Requirements

\begin{tabular}{lccc}
\hline Method & Time $(1$ thread $)$ & Time $(8$ threads $)$ & Memory \\
\hline STIRPC & $\approx 10 \mathrm{~h}(+10-99 \mathrm{~s})$ & $\approx 1.25 \mathrm{~h}(+10-99 \mathrm{~s})$ & $7.9 \mathrm{~GB}$ \\
AAS-STIRPC $(-1)$ & $\approx 12 \mathrm{~h}(+06-32 \mathrm{~s})$ & $\approx 1.5 \mathrm{~h}(+06-32 \mathrm{~s})$ & $8.6 \mathrm{~GB}$ \\
AAS-STIRPC $(0)$ & $\approx 12 \mathrm{~h}(+09-64 \mathrm{~s})$ & $\approx 1.5 \mathrm{~h}(+09-64 \mathrm{~s})$ & $8.7 \mathrm{~GB}$ \\
AAS-STIRPC $(1)$ & $\approx 12 \mathrm{~h}(+09-92 \mathrm{~s})$ & $\approx 1.5 \mathrm{~h}(+09-92 \mathrm{~s})$ & $8.6 \mathrm{~GB}$ \\
$\mathrm{kCLUST}$ & $\mathbf{5 m}-\mathbf{1 0 m}$ & - & $1.6 \mathrm{~GB}$ \\
BLASTP & $\approx 26 \mathrm{~h}(+10-57 \mathrm{~s})$ & $\approx 3.25 \mathrm{~h}(+10-57 \mathrm{~s})$ & $0.4 \mathrm{~GB}$ \\
PSI-BLAST & $\approx 109 \mathrm{~h}(+16-90 \mathrm{~s})$ & $\approx 13.5 \mathrm{~h}(+16-90 \mathrm{~s})$ & $0.5 \mathrm{~GB}$ \\
DELTA-BLAST & $\approx 148 \mathrm{~h}(+14-62 \mathrm{~s})$ & $\approx 18.5 \mathrm{~h}(+14-62 \mathrm{~s})$ & $0.5 \mathrm{~GB}$ \\
\hline
\end{tabular}

Time and memory requirements for STIRPC, AAS-STIRPC, kCLUST and for BLASTP, PSI-BLAST and DELTA-BLAST based methods. The details in brackets by the STIRPC and BLAST algorithms represent the clustering time. 
Part III

\section{Micro RNA Analysis}





\section{Chapter 7}

\section{Analysis of Micro RNA in Sarcoidosis}

In this part of the thesis we focus on the usage of bioinformatics tools and databases in the analysis of micro RNA (miRNA) and sarcoidosis disease. The data used for this research comes from a real clinical environment. It is a group of patients with sarcoidosis who we used to examine the relation of micro RNA expressions and the disease progress. We used the state-of-the-art technique Quantitative RealTime Polymerase Chain Reaction (RT-qPCR) [64] for measuring the expression of certain micro RNA molecules and then we used standard statistical methods, bioinformatics tools and databases for the subsequent analysis of micro RNAs and for finding biological signaling pathways that play a role in the progress of sarcoidosis [102].

\subsection{Sarcoidosis Disease and Micro RNA}

Recently, aberrantly expressed miRNAs were reported in lung tissue and peripheral blood cells obtained from sarcoidosis patients [19]. Sarcoidosis is a multisystem disorder of unknown etiology [54]. Inflammation mediated by lymphocytes of Th1 phenotype leads to the formation of non-caseating (non-necrotizing) granulomas, consisting of epithelioid and multinucleated giant cells [73]. In the majority of 
patients it affects lymph nodes and lungs, but all organs may be involved [54]. The overall prognosis is good and, in about $60 \%$ of all cases, the disease regresses spontaneously. In the rest of patients, sarcoidosis is a chronic disease, sometimes showing up with relapses $[33,75,95]$. In about $10-15 \%$ of people the disease slowly progresses to lung fibrosis, which is a major cause of death, affecting approximately $1 \%$ of patients in Europe and 5\% in North America [18]. Although the etiology of sarcoidosis is unknown, it is generally acknowledged that the disease develops in genetically predisposed subjects who were exposed to unidentified antigen(s) that are able to persist in the intracellular milieu of macrophages, stimulating them to produce cytokines responsible for transformation of Th0 to Th1 cells [117]. In response, lymphocytes produce a variety of cytokines which conversely stimulate macrophages and induce their transformation to granuloma cells. The ability to eliminate the antigen from the intracellular environment therefore seems to be a crucial precondition of complete and definitive remission [35]. Although mechanisms regulating these processes are not known, they are critical for understanding the pathogenesis of persistent and progressive sarcoidosis.

According to recent studies, miRNAs are possibly involved in the pathogenesis of sarcoidosis. Crouser et al. performed the first study on miRNA profiling in sarcoidosis lung tissues and peripheral blood mononuclear cells (PBMCs) and revealed differentially expressed (DE)-miRNAs, with distinct pattern of DE-miRNA expression identified in both lung tissue and PBMCs of sarcoidosis patients [19]. A subgroup of DE-miRNAs common to lung and lymph node tissues were predicted to target transforming growth factor (TGF $\beta$ )-regulated pathways. Likewise, the DE-miRNAs identified in PBMCs of sarcoidosis patients were predicted to target the TGF $\beta$-regulated "wingless and integrase-1" (WNT) pathway [19]. Another study by Maertzdorf et al. revealed similarity in miRNA expression signatures of tuberculosis with that of sarcoidosis, confirming the suggested link for etiopathogenesis of both diseases [66]. The most recent study by Jazwa et al. detected a significantly increased level of miR-34a in PBMCs isolated from sarcoidosis patients [56]. Moreover, significantly up-regulated levels of interferon IFN- $\gamma$ inducible protein (IP-10) and vascular endothelial growth factor were detected in the sera of sarcoidosis patients when compared to healthy subjects [56]. Nevertheless, no information exists to date about the miRNA profile in broncho-alveolar lavage 
(BAL) cells in sarcoidosis patients and their potential mRNA targets. Additionally, no information is available on miRNA profiles in the various stages (remission/progression) of sarcoidosis.

\subsection{Dataset description}

Based on the previous research and information from literature we investigate expression of 25 candidate miRNAs. The selected miRNAs are: miR-21, miR24, miR-25, miR-92, miR-125a, miR-126, miR-133a, miR-146a, miR-148a, miR150, miR-155, miR-181a, miR-199a, miR-202, miR-204, miR-206, miR-212, miR214, miR-222, miR-223, miR-302c, miR-424, miR-503, miR-let-7c, miR-let-7d) in unseparated BAL cells obtained from 48 sarcoidosis patients and 14 control subjects using quantitative RT-PCR [102].

In addition, we divided the group of 48 sarcoidosis patients into two subgroups. The first subgroup of 28 patients consists of those with a remitting of the disease and the second subgroup of 20 patients represent those with progressing sarcoidosis. We examined the progress of the disease by these patients after two years of observation. With both groups we focused on miRNA expression profiles and compared results with a values of initial profiles (before 2 years) [102].

\subsection{Experiments and Evaluation}

In this section we describe the experiments with micro RNA expression profiles obtained from patients with sarcoidosis with the usage of quantitative real time PCR. We divided the experiment into two different parts. The first part is targeted to the identification of significant miRNAs of both dataset groups. In the next part of the research we focused on finding target messenger RNA (mRNA) which are regulated by these miRNA and on the identification of biological signaling pathways in which target mRNA are included and are linked to sarcoidosis. 


\subsubsection{Identification of Significant miRNA}

In this part of the experiment we identify miRNA molecules which are significant in the group of miRNA we are targeting. At first we identified the miRNA which are significant for the group containing patients with sarcoidosis and control individuals which do not have the disease. Next we identify significant miRNA which play an important role in the distribution of sarcoidosis remission and regression. For this purpose we use the well-known statistical Mann-Whitney U test also called Mann-Whitney-Wilcoxon or Wilcoxon rank-sum test. This test tells us that two data samples are independent if they come from distinct populations and the samples do not affect each other. With the usage of this test we compute $p$-value for each miRNA in our dataset, which is used in the context of null hypothesis testing to quantify the idea of the statistical significance of evidence. The significance level is traditionally set to $5 \%$ which corresponds to $p-$ value $=0.05$.

Table 7.1 summarizes $p$-values calculated for two examined groups. The first group consists of patients with sarcoidosis and healthy control individuals and the second group contains only patients with sarcoidosis but which is divided into two subgroups, patients with remitting and patients with progressing sarcoidosis. From Table 7.1 we can see that we identified five miRNAs molecules, that are significant in the distribution of healthy and ill patients and two miRNAs which are significant between remitting and progressing sarcoidosis [102].

From Figures 7.1 and 7.5 we can see down-regulated miR-214 and miR-204 expression in sarcoidosis patients when compared to control subjects. Figures 7.2, 7.3, 7.4 show up-regulated expression of miR-150, miR-25 and miR-146a when comparing patients with sarcoidosis and healthy individuals. These figures represent box-plot graphs with strip-charts of relative expression of given miRNA. In descriptive statistics the box-plot, box graph or box diagram is the one of the visualization methods of numerical data with the usage of their quartiles. The middle part of the diagram (a box) is upper-bounded by the 3rd quartile and lower-bounded by the 1st quartile and the line in the box represents a median value of data (the 2nd quartile). The dashed vertical lines leading up and down from the box margins represent a variability of data below the first quartile and above the 3 rd quartile. The outliers in the data are represented by empty circles. 
Table 7.1: $p$-values for Patient vs. Control Group and Remission vs. Progression Group

\begin{tabular}{|c|c|c|c|c|}
\hline \multirow[b]{2}{*}{ Rank } & \multicolumn{2}{|c|}{ Patient vs. Control } & \multicolumn{2}{|c|}{ Remission vs. Progression } \\
\hline & miRNA & $p-$ value & miRNA & $p-$ value \\
\hline 1 & miR-214 & $1.614 \mathrm{e}-08$ & miR-92 & 0.0188 \\
\hline 2 & miR-150 & $3.203 \mathrm{e}-05$ & miR-let.7c & 0.0404 \\
\hline 3 & $\operatorname{miR}-25$ & 0.0018 & miR-let.7d & 0.0737 \\
\hline 4 & $\operatorname{miR}-146 a$ & 0.0056 & $\operatorname{miR}-155$ & 0.0985 \\
\hline 5 & miR-204 & 0.0349 & $\operatorname{miR}-503$ & 0.1237 \\
\hline 6 & miR-202 & 0.0538 & miR-25 & 0.2057 \\
\hline 7 & miR-222 & 0.0560 & miR-24 & 0.3005 \\
\hline 8 & $\operatorname{miR}-424$ & 0.0797 & miR-146a & 0.3360 \\
\hline 9 & $\operatorname{miR}-212$ & 0.1384 & miR-21 & 0.3797 \\
\hline 10 & miR-133a & 0.2221 & $\operatorname{miR}-214$ & 0.4452 \\
\hline 11 & miR-181a & 0.2557 & miR-148a & 0.4641 \\
\hline 12 & miR-let.7c & 0.2557 & miR-125a & 0.4706 \\
\hline 13 & miR-let.7d & 0.2593 & miR-202 & 0.5235 \\
\hline 14 & miR-223 & 0.2701 & miR-133a & 0.5302 \\
\hline 15 & miR-148a & 0.3414 & miR-206 & 0.5981 \\
\hline 16 & $\operatorname{miR}-24$ & 0.4141 & miR-212 & 0.6156 \\
\hline 17 & miR-302c & 0.4205 & miR-222 & 0.6681 \\
\hline 18 & miR-503 & 0.4264 & $\operatorname{miR}-424$ & 0.7303 \\
\hline 19 & miR-155 & 0.5556 & miR-223 & 0.8261 \\
\hline 20 & miR-199a & 0.7121 & miR-199a & 0.8777 \\
\hline
\end{tabular}




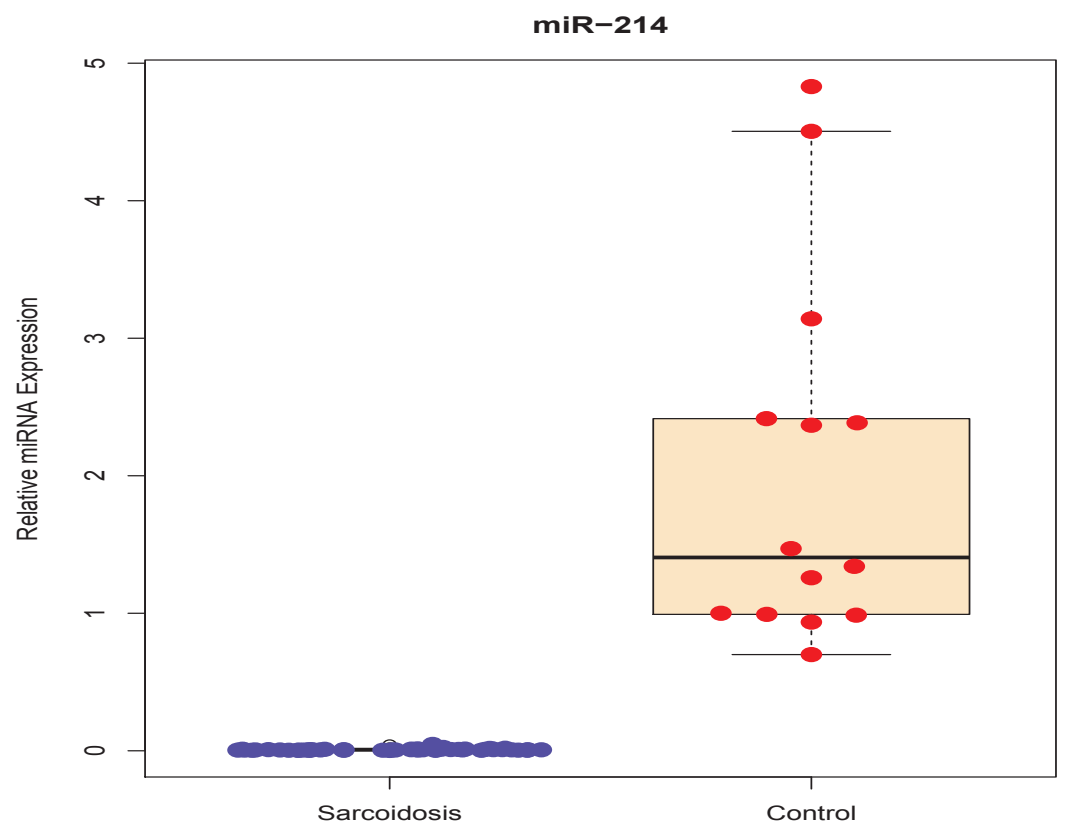

Figure 7.1: Relative expression of miR-214 - patients and controls.

The points in box plot graphs (strip-chart) represent the relative expression of the given miRNA of a concrete subject (patient or control).

When we compare only patients with remitting or progressing sarcoidosis we discovered two miRNA as significant in the distribution of two group samples. These are micro RNA molecules which are marked miR-92 and miR-let-7c. In this comparison a higher number of miR-92 and miR-let-7c transcripts was detected in patients with progressing sarcoidosis. These two up-regulated (in the progression state of disease) miRNAs and their box-plot graph with strip-charts are presented in Figure 7.6 and 7.7.

\subsubsection{Classification and Clustering of Subjects}

One of the important factors in clinical environment plays a classification of patients into predefined classes. Moreover the automation of the classification process helps human experts like biologist or physicians make initial decisions about a course of treatment. The next important thing in analysis of biological data is 


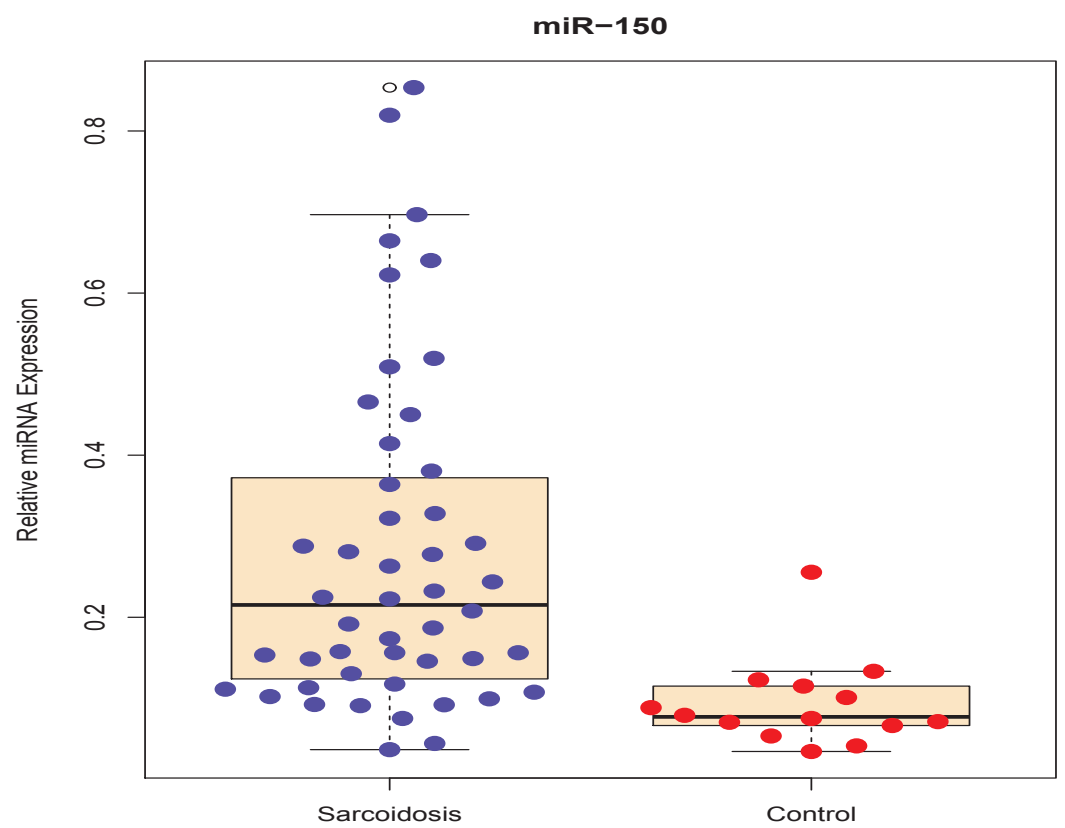

Figure 7.2: Relative expression of miR-150 - patients and controls. miR-25

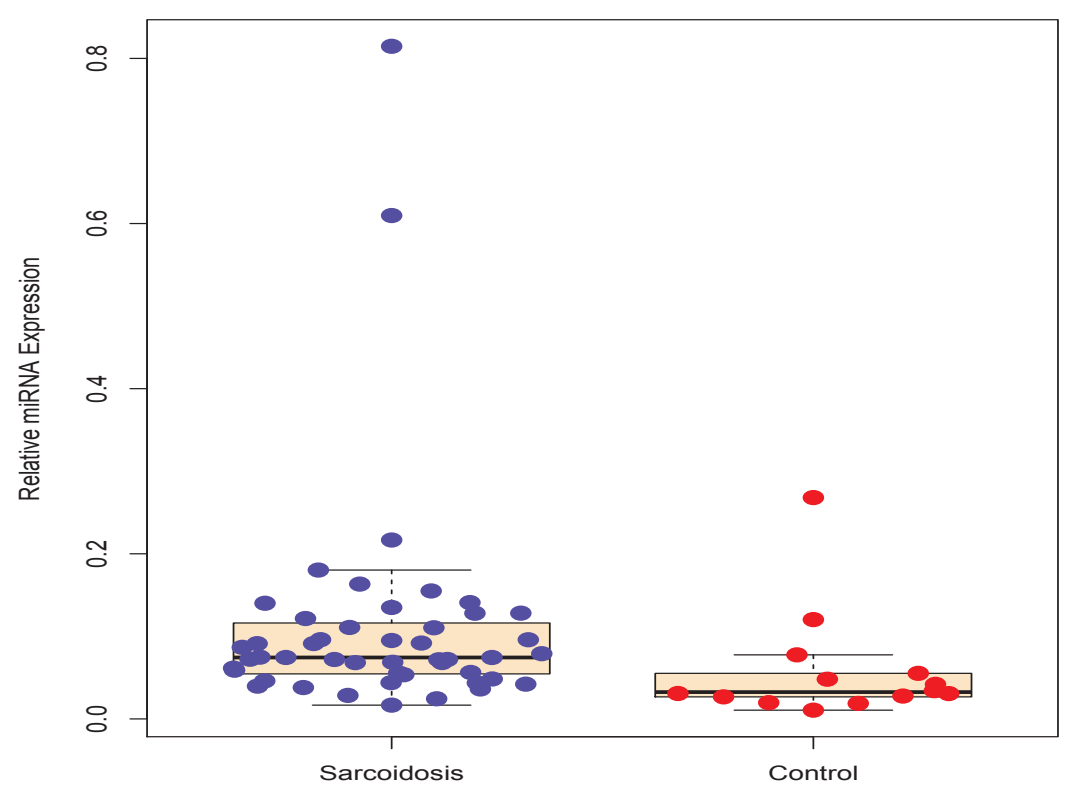

Figure 7.3: Relative expression of miR-25 - patients and controls. 


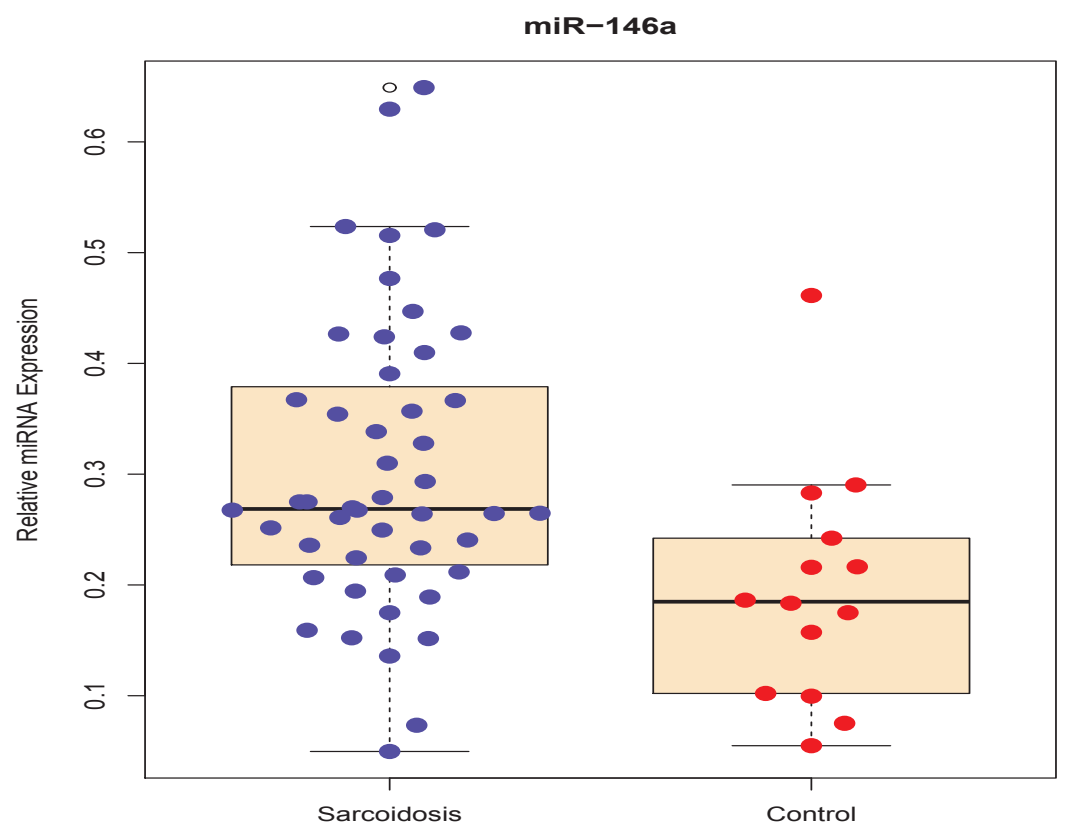

Figure 7.4: Relative expression of miR-146a - patients and controls. miR-204

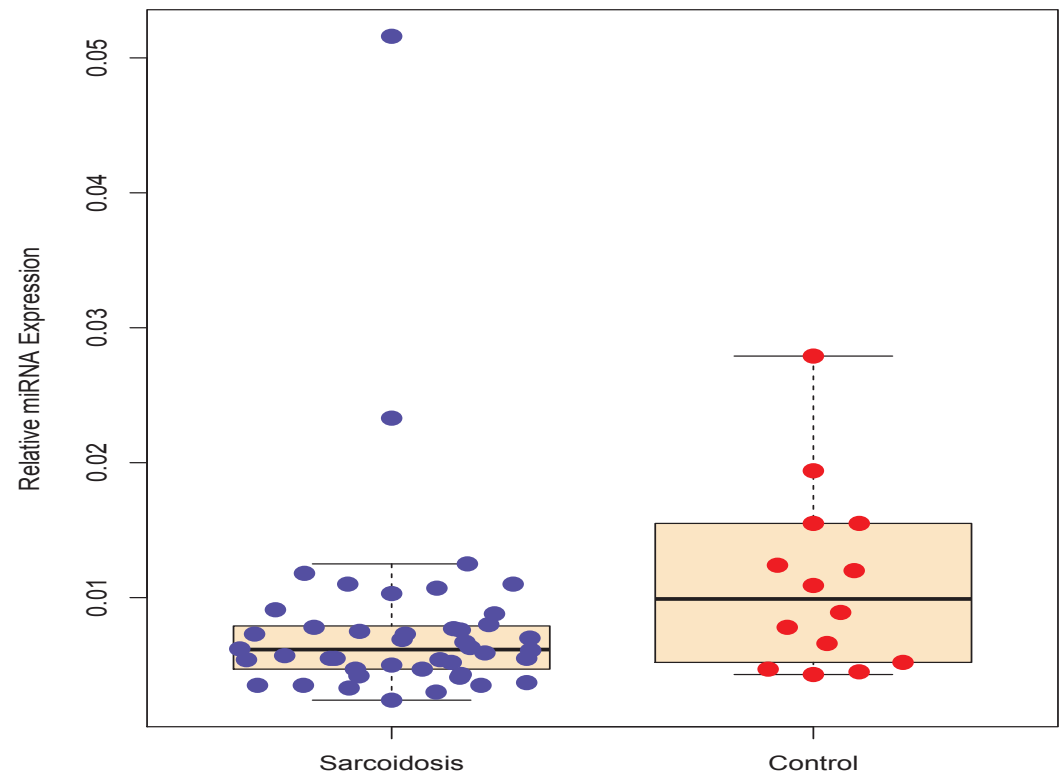

Figure 7.5: Relative expression of miR-204 - patients and controls. 


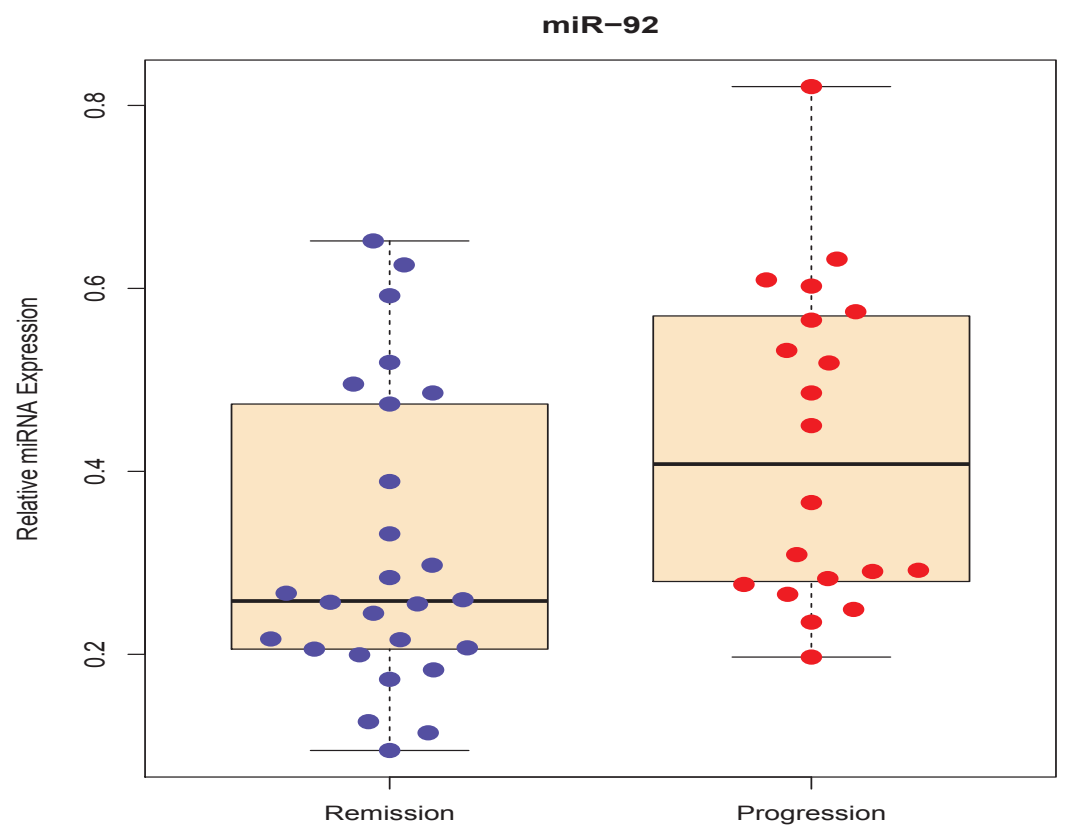

Figure 7.6: Relative expression of miR-92 - remission and progression subjects.

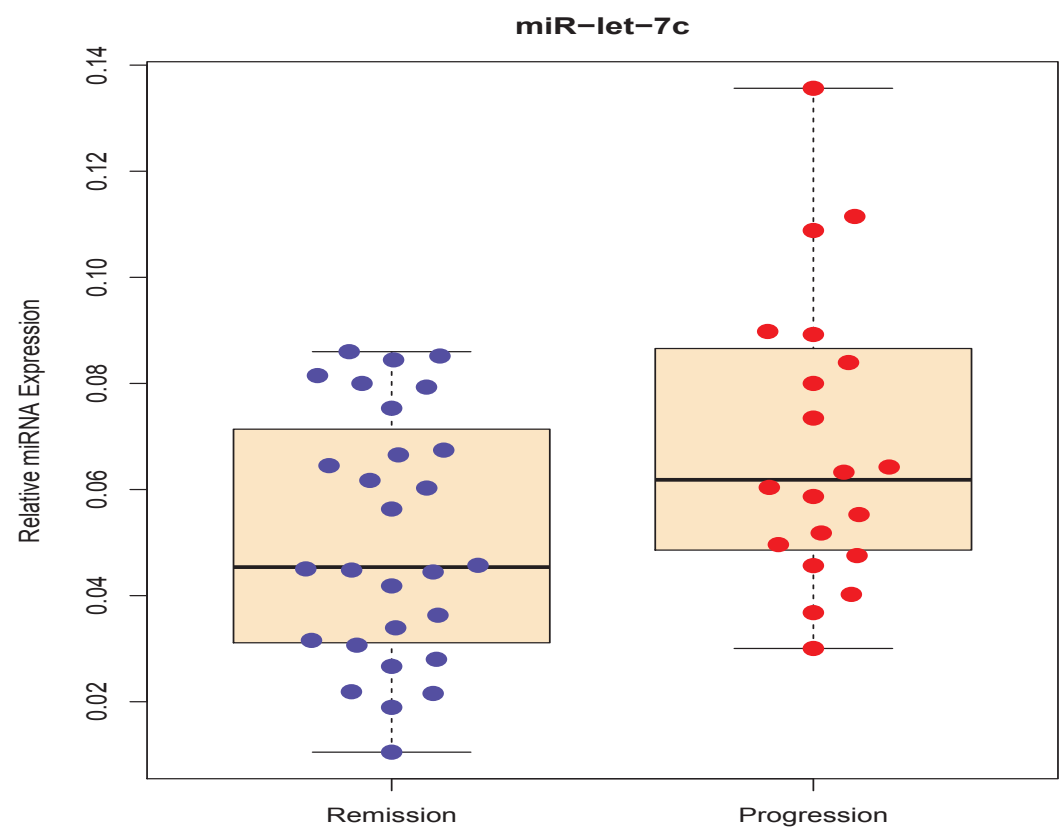

Figure 7.7: Relative expression of miR-let-7c - remission and progression subjects. 
clustering or grouping patients based on some common attributes. In our case the attributes represent the expressions of miRNA by observed patients witch sarcoidosis. In this part of the experiment we want to demonstrate the impact of analyzed significant miRNA to process of classification and prediction respectively and also for clustering. For the visualization of gene expression profiles or micro RNA expression profiles heatmaps with hierarchical agglomerative clustering are often used, since this kind of data is presented by a two dimensional vector space, where one dimension corresponds to subjects (patients) and second dimension represents expression of micro RNAs. Heatmap is traditionally two dimensional map and is a graphical representation of data in which every value appearing in the data is represented by color of certain continuous color spectrum. Heatmaps are often combined with agglomerative hierarchical clustering to show graphically display the clusters in the data. Figure 7.8 shows the heatmap for group of patients and control subject and all 25 miRNAs. Figure 7.9 represents the heatmap of the same group after selecting only 5 of the most significant miRNAs (see Table 7.1). As we can see from these two figures, the selection of significant miRNAs has influence on a quality of the clustering, since after clustering only significant miRNAs, the clusters forming patients and control subject are not mixed.

The heatmap in Figure 7.10 corresponds to the group with only patients with remitting or progressing sarcoidosis and all 25 examined miRNAs. The next heatmap displayed in Figure 7.11 corresponds to the same group but with only 5 the most significant miRNAs. We can see again that the quality of clusters is better with only significant miRNAs, although the clusters are not perfectly separated. This is caused by the profiles of miRNAs of remitting and progressing sarcoidosis being more closely related than in the case of patients with sarcoidosis and healthy control subjects.

We have also done the experiments with the classification of both groups patients vs controls and remission vs progression. For this experiment we chose a classifier called Random Forest. Random Forest is an ensemble learning algorithm for classification and regression that constructs a set of decision trees at the training stage and outputs the class that is the mode of the outputs (classifications) or the mean prediction (regression) of all the decision trees in the set. The decision tree learning method often has a habit of overfitting on training set and Random 


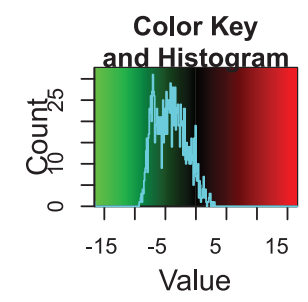

\section{Sarcoidosis \\ Patient vs. Control}
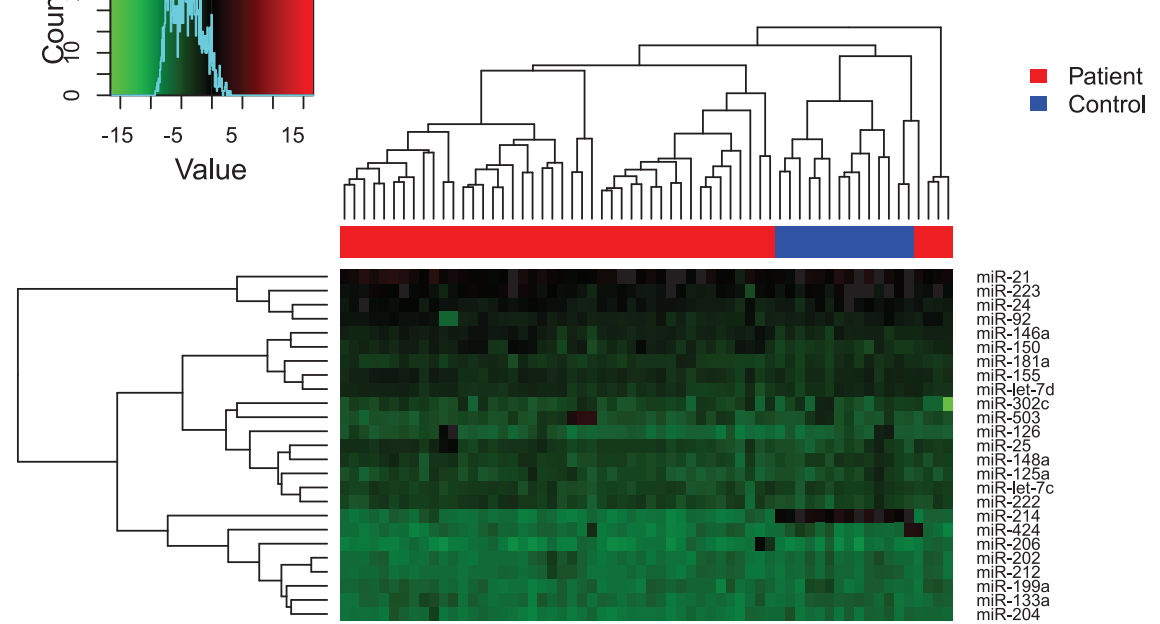

- Control
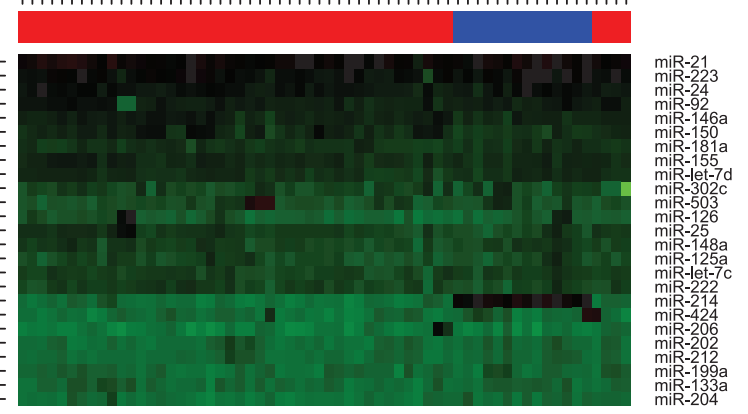

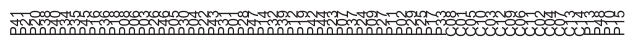

Figure 7.8: Heatmap of patients and controls - 25 miRNAs.

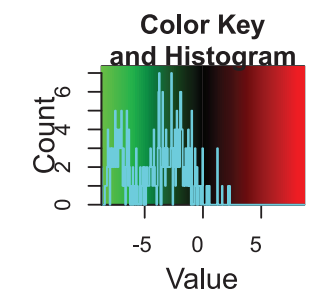

Sarcoidosis

Patient vs. Control
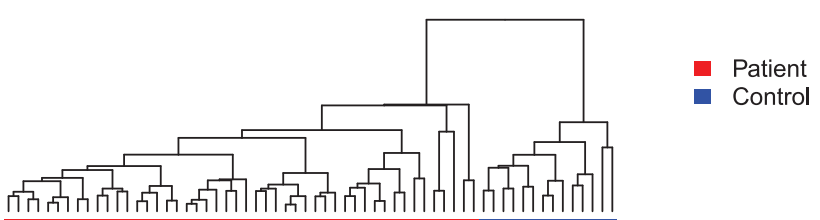

- Control

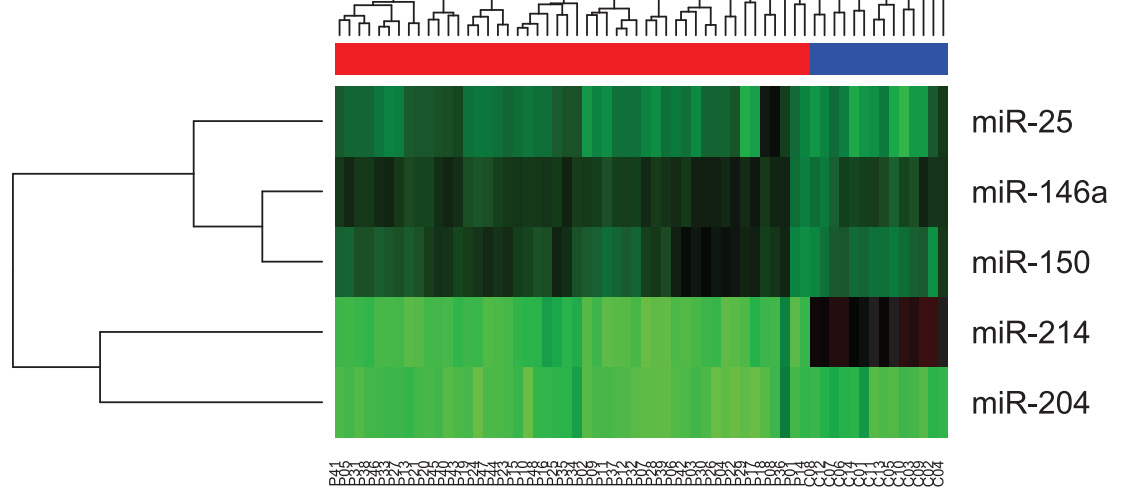

Figure 7.9: Heatmap of patients and controls - 5 the most significant miRNAs. 


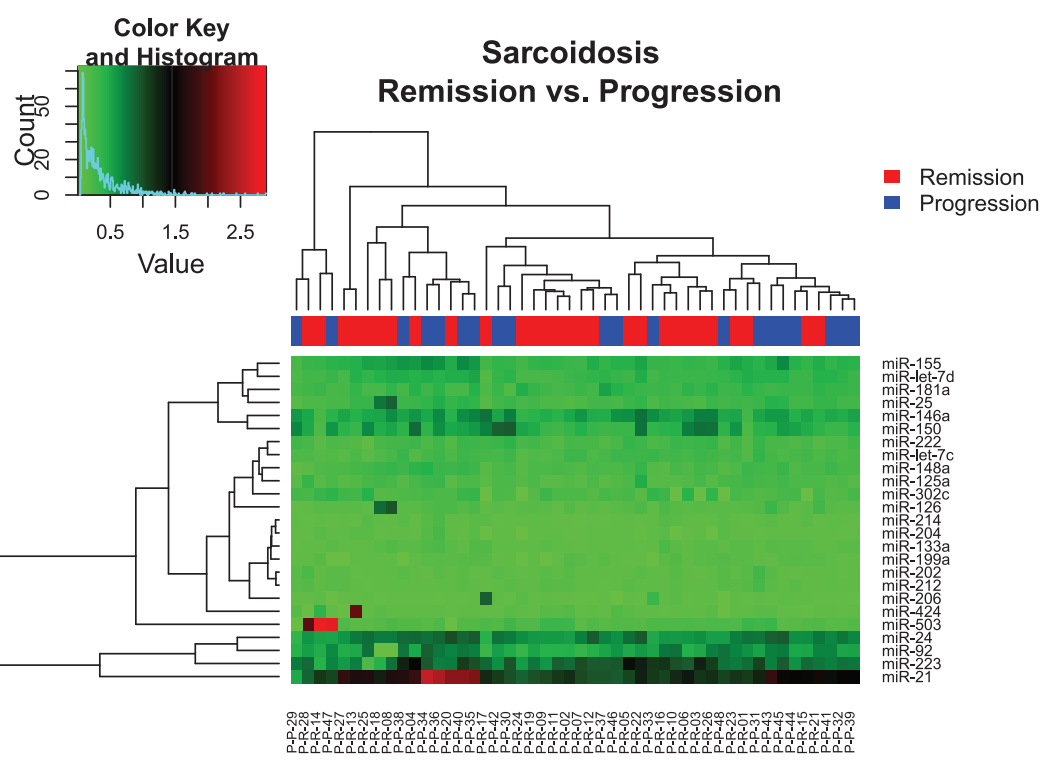

Figure 7.10: Heatmap of patients with remitting and progressing sarcoidosis - 25 miRNAs.
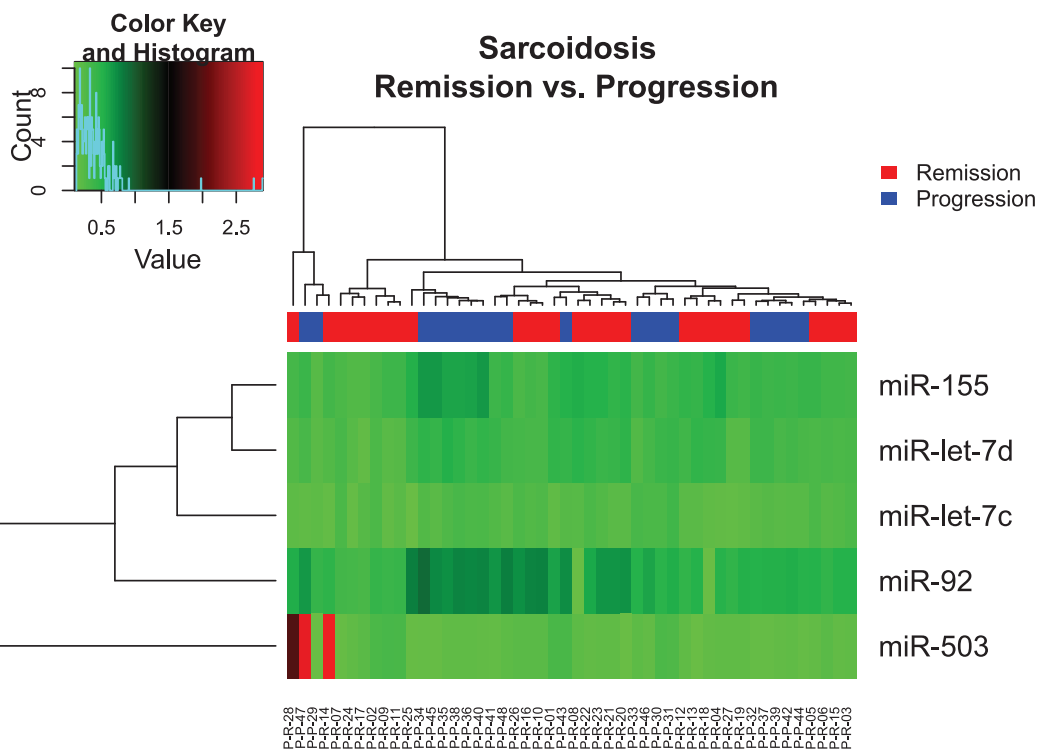

Figure 7.11: Heatmap of patients with remitting and progressing sarcoidosis - 5 the most significant miRNAs. 


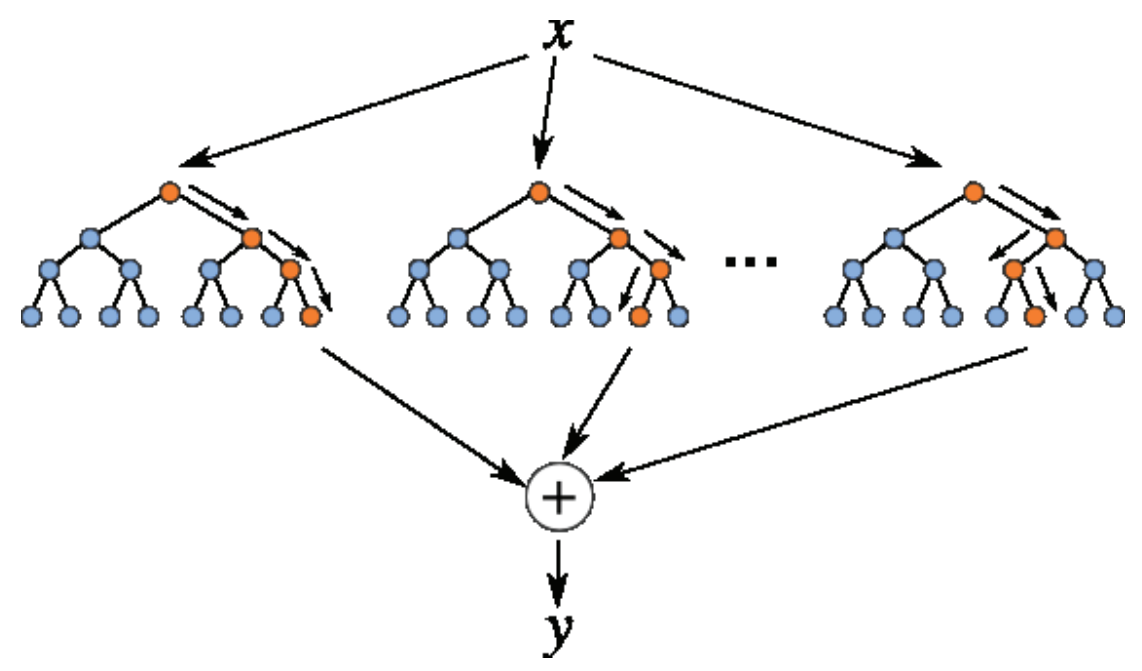

Figure 7.12: An idea of Random Forest algorithm.

Forest thanks to the ensemble of decision trees solving this issue. The first principles of the algorithm were introduced by Tim Kam Ho in 1995 and it was called Random Decision Forest [47]. The Random Forest algorithm was developed by Leo Breiman [13] and it combines Breiman's idea of "bagging" with random features selection to construct a group of decision trees with controlled variance. The selection of the random features groups is implemented by the random subspace method [48]. A basic idea of how the random forest algorithm works is shown in Figure 7.12 .

For our experiments we chose a Weka [41] implementation of the Random Forest algorithm. We used the same process as for heatmaps. We first tested all 25 miRNAs and then we tested only significant miRNAs. The experiment in this context is about the classification of examined subjects (patients and controls) into predefined classes. The first group consists of patients and control subjects and we classify individual cases into these two classes. The second case represents patients with remitting and progressing sarcoidosis respectively and we classify individual subjects into these two classes - remission and progression.

Table 7.2 presents the results of the classification of both groups of patients with all 25 miRNAs using the Random Forest classification algorithm. We evaluated the results of the classification using standard statistical measures: TPR - True 
Positive Rate and it is equal to Sensitivity or Recall, FPR - False Positive Rate also known as Fall-Out, Precision and combined score F-Measure which is a harmonic mean of precision and recall (TPR). We have also validated the classifier with 10-Fold cross validation to simulate a real environment with unseen test data. Column Correct corresponds to the number of correctly classified samples into a given group and Incorrect represents incorrectly classified ones. The next table 7.3, summarizes our experiments with classification using Random Forest with only selected significant miRNAs based on Table 7.1. From these two tables, 7.2 and 7.3, we can see that in the case of the group containing patients and a control subject, the influence of the selection of only significant miRNAs is not very big but, in the case of the group with remitting and progressing sarcoidosis patients, it is obvious that classification accuracy is significantly better. In both tables 7.2 and 7.3 a line with overall results represents a weighted average for TPR, FPR, Precision, F-Measure and for correct and incorrect reports it represents overall accuracy. The equations for statistical measures used for evaluation of experiments with the random forest is the following:

$$
\begin{gathered}
T P R=\text { Sensitivity }=\text { Recall }=\frac{T P}{T P+F N} \\
F P R=\text { FallOut }=\frac{F P}{F P+T N} \\
\text { Precision }=\frac{T P}{T P+F P} \\
F-\text { Measure }=2 \times \frac{\text { Precision } \times \text { Recall }}{\text { Precision }+ \text { Recall }}
\end{gathered}
$$

where TP,FP,TN and FN represents true, false positive and negative values in the context of classification.

\subsubsection{Identification of Signaling Pathways}

Cell response to external stimuli requires the integration and activation of a cascade of interdependent signals that travel along the cytosol to the cell nuclei. The interaction of signaling molecules with their surface receptors is pivotal in this 
Table 7.2: Random Forest for All 25 miRNAs

\begin{tabular}{cccccc|c}
\hline TPR & FPR & Precision & F-Measure & Correct & Incorrect & Class \\
\hline 1.0 & 0.143 & 0.96 & 0.98 & $48(100.0 \%)$ & $0(0.0 \%)$ & Patient \\
0.857 & 0.0 & 1.0 & 0.923 & $12(85.72 \%)$ & $2(14.28 \%)$ & Control \\
\hdashline 0.968 & 0.111 & 0.969 & 0.967 & $60(96.77 \%)$ & $2(3.225 \%)$ & Overall \\
\hline 0.75 & 0.7 & 0.6 & 0.667 & $21(75.0 \%)$ & $7(25.0 \%)$ & Remission \\
0.3 & 0.25 & 0.462 & 0.364 & $6(30 \%)$ & $14(70.0 \%)$ & Progression \\
\hline 0.563 & 0.513 & 0.542 & 0.54 & $27(56.25 \%)$ & $21(43.75 \%)$ & Overall \\
\hline
\end{tabular}

Table 7.3: Random Forest for significant miRNAs

\begin{tabular}{cccccc|c}
\hline TPR & FPR & Precision & F-Measure & Correct & Incorrect & Class \\
\hline 1.0 & 1.0 & 1.0 & 1.0 & $48(100.0 \%)$ & $0(0.0 \%)$ & Patient \\
1.0 & 0.0 & 1.0 & 1.0 & $14(100.0 \%)$ & $0(0.0 \%)$ & Control \\
& 0.0 & 1.0 & 1.0 & $62(100.0 \%)$ & $0(0.0 \%)$ & Overall \\
\hline 0.893 & 0.3 & 0.806 & 0.847 & $25(89.28 \%)$ & $3(10.72 \%)$ & Remission \\
0.3 & 0.25 & 0.462 & 0.364 & $14(70 \%)$ & $6(30.0 \%)$ & Progression \\
\hline 0.813 & 0.22 & 0.814 & 0.81 & $39(81.25 \%)$ & $9(18.75 \%)$ & Overall \\
\hline
\end{tabular}


signaling process, leading to the conversion of external stimuli into intracellular signals and the activation of intracellular pathways through phosphorylation of specific tyrosine residues of particular protein kinases [58]. The targets of such signaling pathways include transcription factors that function to regulate the gene expression of a number of molecules involved in various cellular processes, such as proliferation, differentiation, and cell death [58].

The regulation of cellular processes occurs through these signaling networks, primarily by proteins that mediate the internalization of receptor-ligand complexes, dephosphorylation of kinases and their substrates, as well as transcriptional repression [4]. Recent studies have reported the role of micro RNAs, posttranscriptional regulators that control mRNA stability, as key modulators of signal propagation $[67,110,9]$. By targeting specific molecules involved in signaling pathways, miRNAs can regulate numerous physiological processes, and their abnormal expression may lead to pathological processes and the development of various diseases, including pulmonary diseases [103].

In this work, we aimed to investigate miRNA expression profiles and to identify molecular pathways potentially altered by miRNA in patients with sarcoidosis and in patient subgroups with remitting and progressing sarcoidosis. We used DIANAmirPath [106], a web-based bioinformatics computational tool to predict potential miRNA target genes and related signaling pathways. As was mentioned above, our analysis revealed down-regulated miR-214 and miR-204 and up-regulated miR146a and miR-150 expression in sarcoidosis patients when compared to control subjects. These deregulated miRNAs were predicted to target TGF- $\beta$ and related WNT pathways (Figures 7.13 and 7.14. When comparing progressing to remitting sarcoidosis, a higher number of miR-92, miR-let-7c and miR-let-7d transcripts was detected in patients with progressing sarcoidosis (Figures 7.6 and 7.7). These up-regulated miRNAs were identified to target JAK/STAT signaling pathway (Figure 7.15) and the interaction between Cytokine-Cytokine receptors involved in processes leading to disease progression (Figure 7.16) [102]. 


\subsection{Discussion}

In this chapter we presented the results of our research regarding the analysis of micro RNA molecules which control the process of regulation of RNA and subsequently genes. We targeted patients with sarcoidosis and used statistical and computer science methods for the identification of significant micro RNAs involved in the progression or remission of the disease. Our dataset is composed of the miRNA profiles of patients collected in a real clinical environment. For the identification of significant miRNAs which have influence on the separation of patients with sarcoidosis and health control individuals or patients with remitting or progressing sarcoidosis we used the Mann-Whitney U-Test. With this test we identified significant miRNA molecules as is described in Table 7.1. By this observation we used all and significant miRNAs for experiments with clustering and classification. We showed the impact of the selection of only significant miRNAs in the clustering and classification process. For demonstration of clustering, we used the hierarchical agglomerative clustering algorithm combined with heatmaps and for classification we used the effective classification algorithm Random Forest. It has proved that using only significant miRNAs has a great impact on the accuracy of a classification algorithm mainly for the group of patients with remitting and progressing sarcoidosis. In the case of the group that consists of patients and health control subjects we are able to classify the subjects to predefined classes with 100\% accuracy checked with the 10-Fold cross validation. When we talk about the group consisting only from patients with sarcoidosis (remitting or progressing) we can properly classify $82 \%$ of all subjects also validated with the 10-Fold cross validation. With the usage of bioinformatics tool DIANA for the prediction of biological signaling pathways, we found four signaling pathways - JAK-STAT, TFG- $\beta$, WNT and Cytokine-Cytokine interactions. These biological pathways play roles in the progression or remission of the disease and we can study in more detail which genes included in these pathways may lead to a better identification of the disease and subsequently its treatment. 


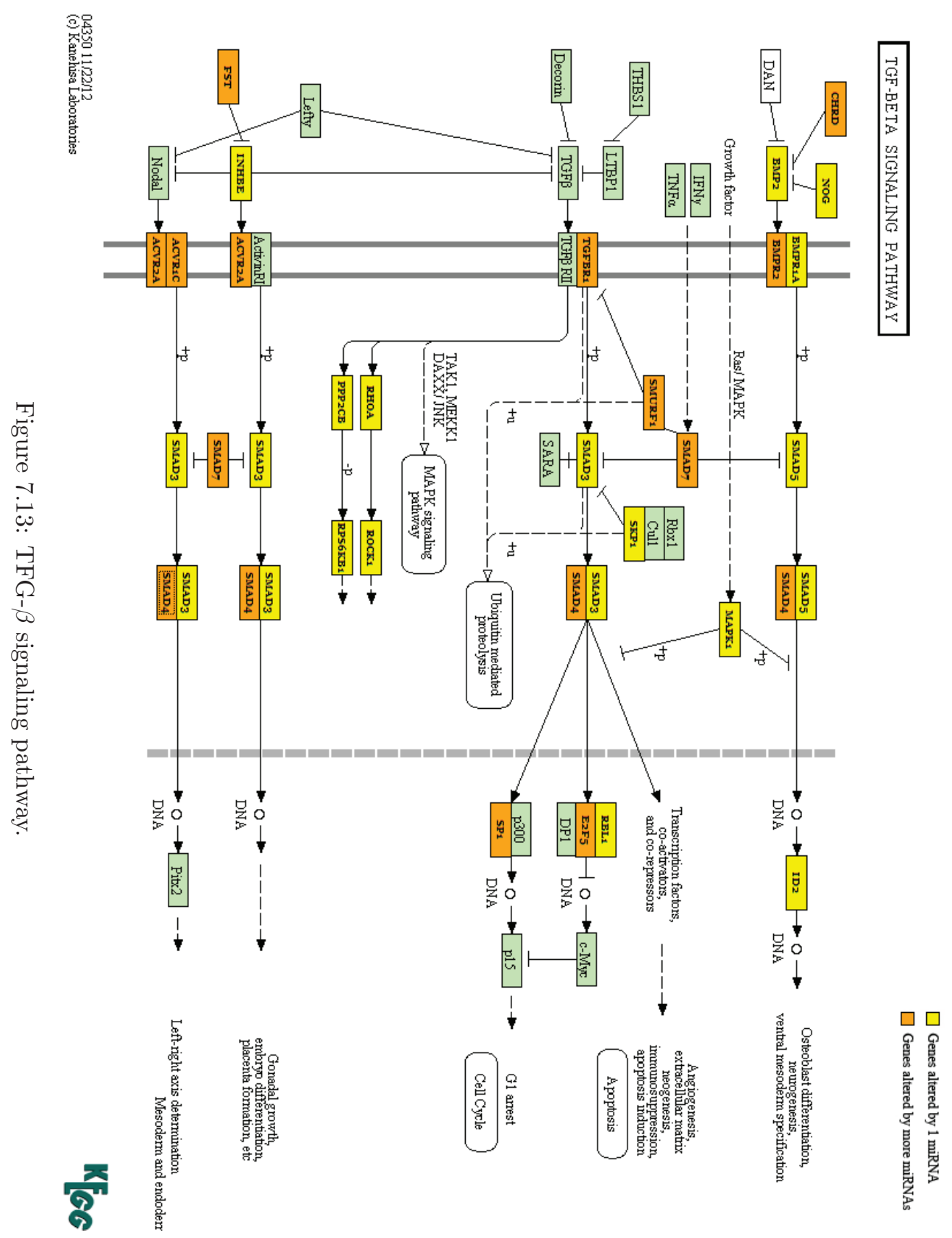




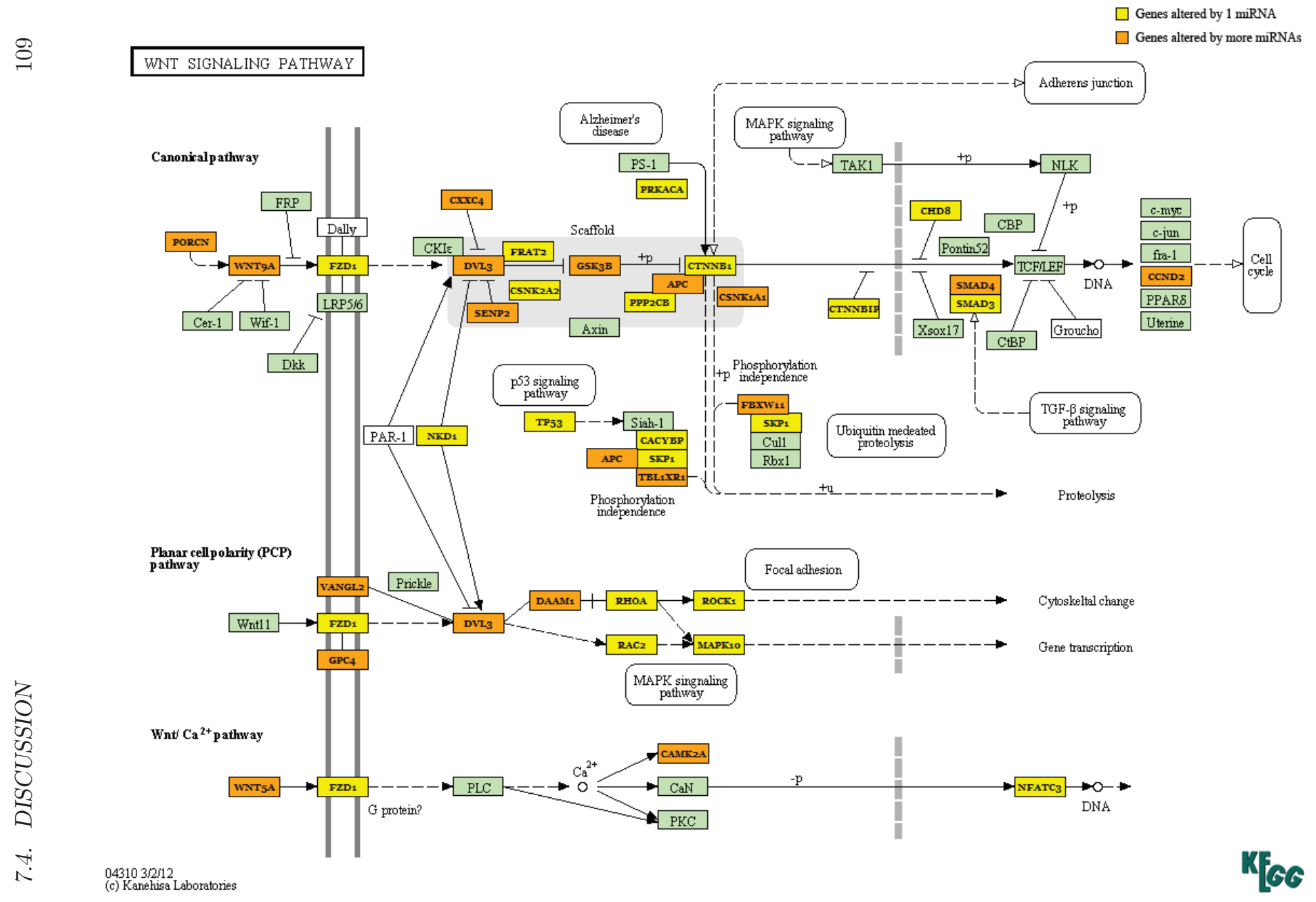

Figure 7.14: WNT signaling pathway. 


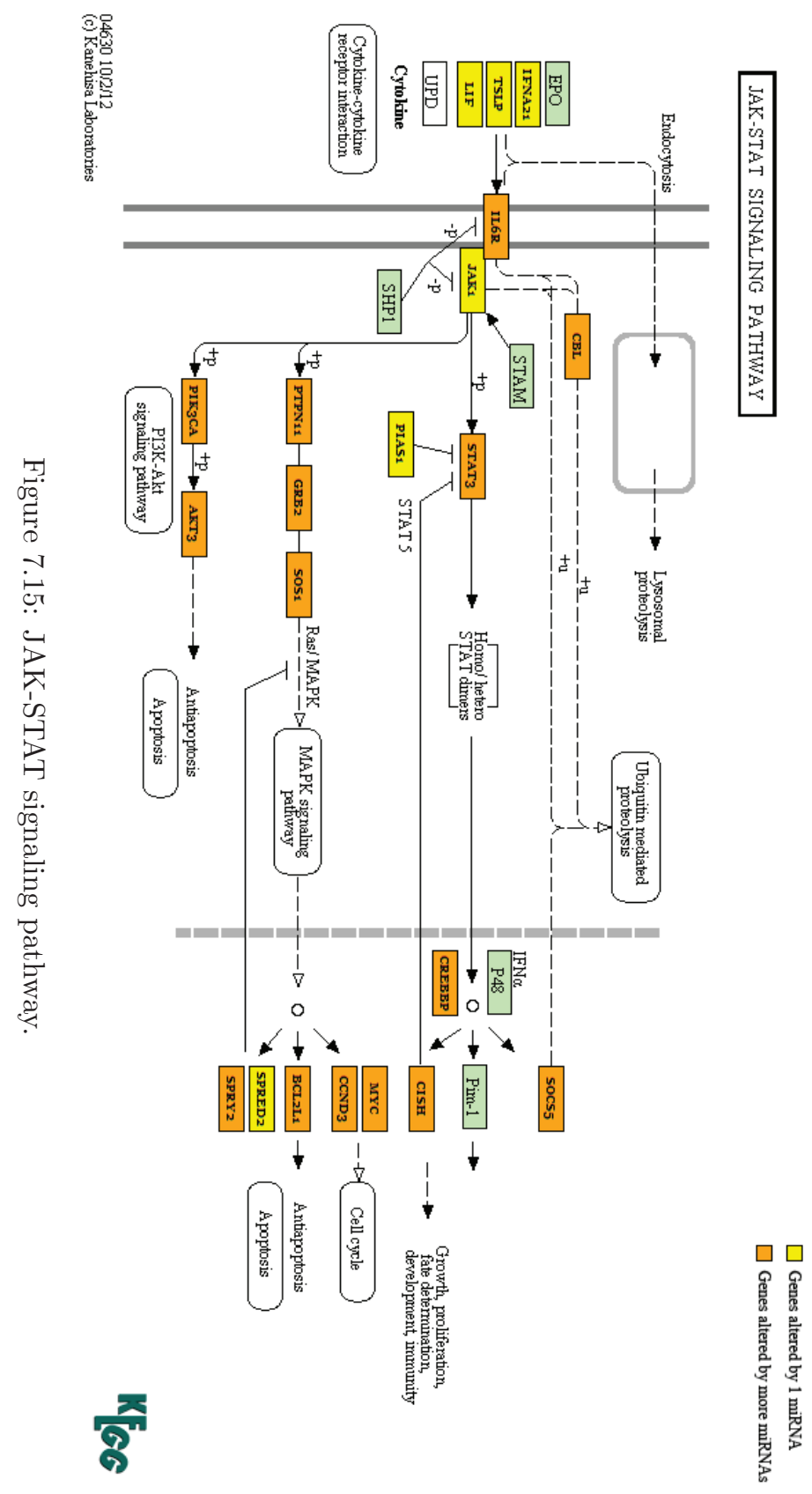




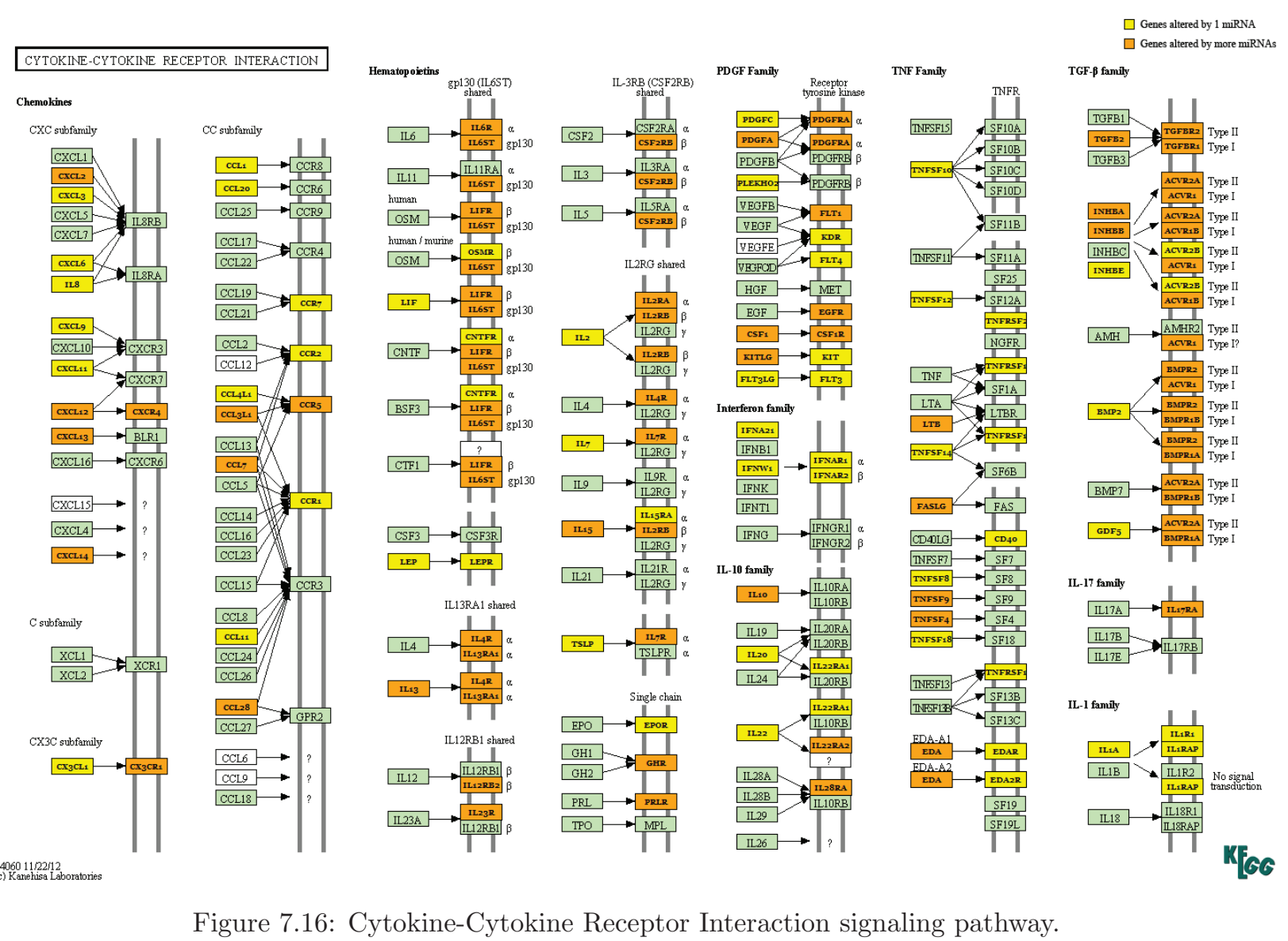


Part IV

\section{Conclusions}





\section{Chapter 8}

\section{Conclusions}

The objective of this thesis was the analysis of biological data focused mainly on protein molecules. Proteins are large molecules which control most of the actions in every cell of living organisms and thus the computer analysis of these molecules represents one of the main stream in modern bioinformatics. Since the proteins are products of transcription of DNA information into a mRNA which is subsequently translated into proteins, we also focused on small non-coding micro RNA molecules which have an influence on the regulation of proteins creation. In this thesis we targeted development of algorithms for the analysis of protein three dimensional - tertiary - structures as well as on protein sequences which represent the protein primary structure. In the context of micro RNA analysis, we focused on the usage of statistical methods, bioinformatics tools and machine learning approaches.

In the first part of the thesis we described the theoretical background needed to briefly understand the next parts of this work. We focused on the description of basic biological properties of protein molecules, mainly on the description of different protein structures (primary, tertiary, etc.). We have also presented protein databases from which we created datasets for our analysis and experiments. A brief description of micro RNA molecules is presented as well.

The analysis of protein molecules is presented in part II of this thesis. At first we propose an algorithm for the calculation of similarities between protein 3D structures which is based on a vector space model and a suffix tree data structure. 
We also introduced a method for the encoding of protein 3D structure into a sequence of encoded dihedral angles which represent a relation between consecutive amino acid residues which create a protein molecule. The results of this analysis were compared to the human crafted biological database SCOP and show that this method is effective in comparison with this database. Based on this work we developed a new algorithm for the comparison of protein sequences which is commonly known as protein primary structure. The algorithm also takes advantage of the vector space model and suffix tree data structure. Our aim was to develop a fast algorithm for the calculation of protein sequence similarities since these days "gold-standard" algorithms such as DELTA-BLAST or PSI-BLAST, which are traditionally used by biologists, require large amount of times and thus they are not so suitable for large scale analysis. For the evaluation of our method we targeted on the whole SCOP v2.03 database which consists of about 170,000 protein sequences. Our algorithm is e.g. 15x faster than the newest and accurate DELTA-BLAST algorithm and gives comparable or better results. Lastly we developed a fast graph-based clustering algorithm and showed the efficiency of this algorithm on the SCOP database which is represented as a tree structure and thus it forms clusters as well. Our graph-based clustering algorithm can detect a significant amount of clusters absolutely the same as is defined in the SCOP database. The results presented in this thesis proved the efficiency of the usage of information retrieval models, methods and structures in the area of the analysis of biological data.

The last part of this work deals with the analysis of micro RNA molecules which play an important role in regulation of protein molecules creation. Our analysis is focused on patients with sarcoidosis which is a disease with an unknown etiology. The data for this research was collected from a clinical environment from patients suffering from this disease. Based on previous research and literature sources, we selected 25 micro RNA candidate molecules. With usage of commonly used statistical analysis we identified the significant micro RNAs which have influence on the differentiation of groups of patients with and without sarcoidosis and the group with patients with remitting or progressing disease. Based on this we used agglomerative hierarchical clustering algorithm in connection with heatmaps for a graphical representation of the data. Subsequently we demonstrated the impor- 
tance of the selection of significant miRNAs on classification tasks with the usage of the Random Forest classifier. Using the Random Forest classifier we are able to classify healthy and ill patients with $100 \%$ accuracy. For the classification of patients with a remitting or progressing state of the disease we reached $82 \%$ accuracy using the random forest classifier. Both classification tasks were validated using a 10-Fold cross validation scheme for the assurance of the statistical significance of the results. Lastly we used the bioinformatics web service called DIANA, which is a web server used for the prediction of target genes affected by miRNAs and cell signaling pathways. Thanks to this tool we identified 4 biological cell signaling pathways which have an impact on the progress of the disease and can be used for further research regarding sarcoidosis. 


\section{References}

[1] Altschul,S.F., Madden,T.L., Schaffer,A.A., Zhang,J., Zhang,Z., Miller,W. and Lipman,D.J.: Gapped blast and psi-blast: a new generation of protein database search programs, Nucleic Acids Res., 25, 3389-3402, 1997.

[2] Andreeva,A., Howorth,D., Brenner,S.E., Hubbard,T.J.P., Chothia,C., Murzin,A.G.: SCOP database in 2004: refinements integrate structure and sequence family data. Nucl. Acid Res., 32(D), 226-229, 2004.

[3] Andreeva,A., Howorth,D., Chandonia,J.M., Brenner,S.E., Hubbard,T.J.P., Chothia,C., Murzin,A.G.: Data growth and its impact on the SCOP database: new developments. Nucl. Acids Res., 36(D), 419-425, 2008.

[4] Avraham,R., Yarden,Y.: Regulation of signalling by microRNAs, Biochem Soc Trans, 40(1), 26-30, 2012.

[5] Baeza-Yates,R., Ribeiro-Neto,B.: Modern Information Retrieval., 1st edn. Adison Wesley, Boston, 1999.

[6] Bartel,D.P.: MicroRNAs: genomics, biogenesis, mechanism, and function, Cell, 116, 281-97, 2004.

[7] Bolten,E., Schliep,A., Schneckener,S., Schomburg,D., Schrader,R.: Clustering protein sequences - structure prediction by transitive homology, Bioinformatics, 17(10), 935-941, 2001.

[8] Brodersen,P., Voinnet,O.: Revisiting the principles of microRNA target recognition and mode of action, Nat Rev Mol Cell Biol, 10, 141-148, 2009. 
[9] Brosh,R., Shalgi,R., Liran,A., Landan,G., Korotayev,K., Nguyen,G.H., Enerly,E., Johnsen,H., Buganim,Y., Solomon,H., et al.: p53-repressed miRNAs are involved with E2F in a feed-forward loop promoting proliferation, Mol Syst Biol, 4(1), 229, 2008.

[10] Bünger, A.T.: X-PLOR, Version 3.1. A System for X-ray Crystallography and NMR. Yale University Press, New Haven, USA, 1992.

[11] Boratyn,G.M., Schaffer,A.A., Agarwala,R., Altschul,S.F., Lipman,D.J., Madden,T.L.: Domain enhanced lookup time accelerated BLAST, Biol. Direct, 7(1), 12,2012 .

[12] Bowie,J.U., Luthy,R., Eisenberg,D.: A method to identify protein sequences that fold into a known three-dimensional structure, Science, 253(5016), 164$170,1991$.

[13] Breiman,L.: Random forests, Machine learning, 45(1), 5-32, 2001.

[14] Brenner,S.E., Chothia,C., Hubbard,T.J.: Assessing sequence comparison methods with reliable structurally identified distant evolutionary relationships, Proc. Natl Acad. Sci. USA 95, 6073-6078, 1995.

[15] Chandonia,J.M., Hon,G., Walker,N.S., Lo Conte,L., Koehl,P., Levitt,M., Brenner,S.E.: The ASTRAL compendium in 2004, Nucleic Acids Research, 32(D), 189-192, 2004.

[16] Chew,L.P., Huttenlocher,D., Kedem,K., Kleinberg,J.: Fast Detection of Common Geometric Substructure in Proteins, Journal of Computational Biology, 6(3/4), 313-326, 1999.

[17] Chothia,C., Lesk,A.M.: The relation between the divergence of sequence and structure in proteins, EMBO J., 5, 823-826, 1986.

[18] Coker,R.K.: Management strategies for pulmonary sarcoidosis, Ther Clin Risk Manag, 5, 575-584, 2009.

[19] Crouser,E.D., Julian,M.W., Crawford,M., Shao,G., Yu,L., Planck,S.R., Rosenbaum,J.T., Nana-Sinkam,S.P.: Differential Expression of MicroRNA and 
Predicted Targets in Pulmonary Sarcoidosis, Biochem Biophys Res Commun, 417(2), 886-891, 2012.

[20] Day,R., Beck,D.A., Armen,R.S., Daggett,V.: A consensus view of fold space: Combining SCOP, CATH, and the Dali Domain Dictionary, Protein Sci., 12(10), 2150-2160, 2003.

[21] Dayhoff,M.O., Schwartz,R.M.: A model of evolutionary change in proteins, Atlas of protein sequence and structure, 5(3), 345-358, 1978.

[22] Dennis C.: The brave new world of RNA. Nature, 418(6894), 122-124, 2002.

[23] Dongen,S.: Graph clustering by flow simulation. PhD Thesis, University of Utrecht, Utrecht, Netherlands, 2000.

[24] Dráždilová, P., Dvorský, J., Martinovič, J., Snášel, V.: Search in Documents based on Topical Development, AWIC, Springer Berlin Heidelberg, 155-166, 2010 .

[25] Ehrenfeucht,A., Haussler,D.: A new distance metric on strings computable in linear time, Discrete Applied Math, 20(3), 191-203, 1988.

[26] Edgar,R.C.: Search and clustering orders of magnitude faster than BLAST, Bioinformatics, 26(19), 2460-2461, 2010.

[27] Enright,A.J., Dongen,S., Ouzounis,C.A.: An efficient algorithm for large-scale detection of protein families, Nucl. Acids Res., 30(7), 1575-1584, 2002.

[28] Fawcett,T.: An Introduction to ROC Analysis, Pattern Recognition Letters, $\mathbf{2 7}(8), 861-874,2006$.

[29] Fogarty,J., Baker,R.S., Hudson,S.E.: Case studies in the use of ROC curve analysis for sensor-based estimates in human computer interaction, In Proceedings of Graphics Interface 2005, 129-136, 2005.

[30] Fox, N.K., Brenner, S.E., Chandonia, J.M.: SCOPe: Structural Classification of Proteins-extended, integrating SCOP and ASTRAL data and classification of new structures, Nucleic acids research, 42(D1), 304-309, 2014. 
[31] Fu,L. et al.: CD-HIT: accelerated for clustering the next-generation sequencing data, Bioinformatics, 28(23), 3150-3152, 2012.

[32] Gao,F., Zaki,M.J.: PSIST: Indexing Protein Structures using Suffix Trees, Proc. IEEE Computational Systems Bioinformatics Conference (CSB), 212$222,2005$.

[33] Gottlieb,J.E., Israel,H.L., Steiner,R.M., Triolo,J., Patrick,H.: Outcome in sarcoidosis. The relationship of relapse to corticosteroid therapy, Chest, 111(3), 623-631, 1997.

[34] Gribskov,M., Robinson,N.L.: Use of receiver operating characteristic (ROC) analysis to evaluate sequence matching, Comput Chem, 20, 25-33, 1996.

[35] Grunewald,J., Brynedal,B., Darlington,P., Nisell,M., Cederlund,K., Hillert,J., Eklund,A.: Different HLA-DRB1 allele distribution in distinct clinical subgroups of sarcoidosis patients, Respiratory Research, 11(1), 25, 2010.

[36] Guo,H., Ingolia,N.T., Weissman,J.S., Bartel, D.P.: Mammalian micro-RNAs predominantly act to decrease target mRNA levels, Nature, 466, 835-840, 2010.

[37] Gusfield,D.: Algorithms on Strings, Trees and Sequences: Computer Science and Computational Biology, 1st edn. Cambridge University Press, Melbourne, 1997.

[38] Guzzo,A.V.: Influence of Amino-Acid Sequence on Protein Structure, Biophys. J., 5(6), 809-822, 1965.

[39] Habib T., Zhang C., Yang J.Y., Yang M.Q., Deng Y.: Supervised learning method for the prediction of subcellular localization of proteins using amino acid and amino acid pair composition. BMC Genomics, 9(Suppl 1: S16), 2008.

[40] Hadley,C., Jones,D.T.: A systematic comparison of protein structure classifications: SCOP, CATH and FSSP, Structure, 7(9), 1099-1112, 1999.

[41] Hall,M., Frank,E., Holmes,G., Pfahringer,B., Reutemann,P., Witten,I.H.: The WEKA Data Mining Software: An Update, SIGKDD Explorations, 11(1), 2009 . 
[42] Hauser,M., Mayer,C.E., Söding,J.: kClust: fast and sensitive clustering of large protein sequence databases, BMC Bioinformatics, 14(1), 248, 2013.

[43] Hecker J., Yang J.Y., Cheng J.: Protein disorder prediction at multiple levels of sensitivity and specificity. BMC Genomics, 9(Suppl 1: S9), 2008.

[44] Henikoff,S., Henikoff,J.G.: Amino acid substitution matrices from protein blocks. Proceedings of the National Academy of Sciences, 89(22), 10915-10919, 1992.

[45] Hobohm,U., Scharf,M., Schneider,R., Sander,C.: Selection of representative protein data sets. Protein Science, 1(3), 409-417, 1992.

[46] Hruška,P., Martinovič,J., Dvorský,J., and Snášel,V.: XML Compression Improvements Based on the Clustering of Elements, CISIM, Poland, 2010.

[47] Ho,T.K.: Random decision forests, Document Analysis and Recognition, IEEE, 1, 278-282, 1995.

[48] Ho,T.K. The Random Subspace Method for Constructing Decision Forests, IEEE Transactions on Pattern Analysis and Machine Intelligence, 20(8), 832844, 1998.

[49] Holm,L., Rosenström,P.: Dali server: conservation mapping in 3D, Nucl. Acids Res., 38, 545-549, 2010.

[50] Holm,L., Sander,C.: Protein structure comparison by alignment of distance matrices, J. Mol. Biol., 233, 123-138, 1993.

[51] Holm,L., Sander,C.T.: DALI: A network tool for protein structure comparison, Trends in biochemical sciences, 20(11), 478-480, 1995.

[52] Holm,L., Sander,C.T.: The FSSP database: Fold classification based on structure-structure alignment of proteins, Nucleic Acids Res., 24(1), 206-209, 1996.

[53] Hopcroft,J., Tarjan,R.: Efficient algorithms for graph manipulation, Communications of the ACM, 16(6), 372-378, 1973. 
[54] Hunninghake,G.W., Costabel,U., Ando,M. et al.: ATS/ERS/WASOG statement on sarcoidosis. American Thoracic Society/European Respiratory Society/World Association of Sarcoidosis and other Granulomatous Disorders, Sarcoidosis Vasc Diffuse Lung Dis, 16, 149-173, 1999.

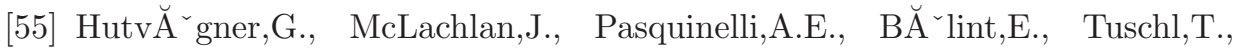
Zamore,P.D.: A cellular function for the RNA-interference enzyme Dicer in the maturation of the let-7 small temporal RNA, Science, 293, 834-838, 2001.

[56] Jazwa,A., et al.: Differential Inflammatory MicroRNA and Cytokine Expression in Pulmonary Sarcoidosis. Archivum immunologiae et therapiae experimentalis, 1-8 2014

[57] Jiang,Q., Wang,Y., Hao,Y. et al: miR2Disease: a manually curated database for microRNA deregulation in human disease, Nucleic Acids Res, 37, D98-104, 2009.

[58] Jordan,J.D., Landau,E.M., Iyengar,R.: Signaling Networks: The Origins of Cellular Multitasking, Cell, 103(2), 193-200, 2000. (2), 193-200, 2000.

[59] Kim,V.N.: MicroRNA biogenesis: coordinated cropping and dicing. Nat Rev Mol Cell Biol, 6, 376-385, 2005.

[60] Lee,D.L., Chuang,H., Seamons,K.E.: Document ranking and the vector-space model, IEEE Software, 14(2), 67-75, 1997.

[61] Lesk A.M.: Introduction to Bioinformatics, Oxford University Press, USA, 2008.

[62] Lo Conte,L., Brenner,S.E., Hubbard,T.J.P., Chothia,C., Murzin,A.: SCOP database in 2002: refinements accommodate structural genomics, Nucl. Acid Res., 30(1), 264-267, 2002.

[63] Lodish, H., Berk, A., Matsudaira, P., Kaiser, A. C., Krieger, M., Scott, P. M., Zipursky, L., Darnell, J.: Molecular Cell Biology. 6th Edition, W. H. Freeman, 2007. 
[64] Logan,J., Edwards,K., Saunders,N.: Real-Time PCR: Current Technology and Applications, Caister Academic Press, 2009.

[65] Manning,C.D., Raghavan,P., Schütze,H.: Introduction to Information Retrieval, 1st edn. Cambridge University Press, New York, 2008.

[66] Maertzdorf,J., et al.: Common patterns and disease-related signatures in tuberculosis and sarcoidosis, Proceedings of the National Academy of Sciences, $\mathbf{1 0 9}(20), 7853-7858,2012$.

[67] Marson,A., Levine,S.S., Cole,M.F., Frampton,G.M., Brambrink,T., Johnstone,S., Guenther,M.G., Johnston,W.K., Wernig,M., Newman,J., et al.: Connecting microRNA genes to the core transcriptional regulatory circuitry of embryonic stem cells, Cell, 134, 521-533, 2008.

[68] Martinovič, J., Snášel, V., Novosád, T.: Využití sufixových stromů pro vylepšení vektorového dotazu, Znalosti, Hradec Králové, 2006.

[69] Martinovič,J., Novosád,T., Snášel V.: Vector Model Improvement Using Suffix Trees, International Journal of Computational Intelligence Research, 5(1), 31-40, 2009.

[70] Martinovič, J., Novosád, T., Scherer, P., Snášel, V., Šebesta, R., Klement, P.: Clustering the mobile phone positions based on suffix tree and Self-Organizing Maps, Neural Network Word, 4(12), 371-386, 2012.

[71] Matthews,B.W.: Comparison of the predicted and observed secondary structure of T4 phage lysozyme, Biochim. Biophys Acta, 405(2), 442-451, 1975.

[72] McCreight,E.: A space-economical suffix tree construction algorithm, Journal of the ACM, 23, 262-272, 1976.

[73] Mizuno,K., Okamoto,H., Horio,T.: Heightened ability of monocytes from sarcoidosis patients to form multi-nucleated giant cells in vitro by supernatants of concanavalin A-stimulated mononuclear cells, Clin Exp Immunol, 126(1), 151156, 2001. 
[74] Murzin,A.G., Brenner,S.E., Hubbard,T., Chothia,C.: SCOP: a structural classification of proteins database for the investigation of sequences and structures. J. Mol. Biol., 247, 536-540, 1995.

[75] Neville,E., Walker,A.N., James,D.G.: Prognostic factors predicting outcome of sarcoidosis: an analysis of 818 patients, Quarterly Journal of Medicine, 52(208), 525-533, 1983.

[76] Novosád, T., Snášel, V., Abraham, A., Yang, J.Y. Prosima: Protein similarity algorithm, World congress on Nature $\&$ Biologically Inspired Computin, IEEE, 84-91, 2009.

[77] Novosád, T., Snášel, V., Abraham, A., Yang, J.Y. YAPS: Yet Another Protein Similarity, Soft Computing and Pattern Recognition, International Conference of. IEEE, 497-504, 2009.

[78] Novosád, T., Snášel, V., Abraham, A., Yang, J.Y: Discovering 3D Protein Structures for Optimal Structure Alignment, In Book Algorithmic and AI Methods for Protein Bioinformatics, Willey, 2013.

[79] Novosád, T., Snášel, V., Abraham A. and Yang, J.: Searching Protein 3-D Structures for Optimal Structure Alignment Using Intelligent Algorithms and Data Structures, IEEE Transactions on Information Technology in Biomedicine, 14(6), 1378-1386. 2010.

[80] Novosád, T., Martinovič, J., Scherer, P., Snášel, V., Šebesta, R., Klement, P.: Mobile Phone Positioning in GSM Networks Based on Information Retrieval Methods and Data Structures, Digital Information Processing and Communications, Springer Berlin Heidelberg, 349-363, 2011.

[81] Murzin,A.G., Brenner,S.E., Hubbard,T.J.P., Chothia,C.: SCOP: a structural classification of proteins database for the investigation of sequences and structures, J. Mol. Biol., 247, 536-540, 1995.

[82] Orengo,,C.A., Michie,A.D., Jones,S., Jones,D.T., Swindells,M.B., Thornton,J.M.: CATH-a hierarchic classification of protein domain structures, Structure, 5(8), 1093-1108, 1997. 
[83] Pauling L., Corey, R.B., Branson, H.R.: The structure of proteins; two hydrogen-bonded helical configurations of the polypeptide chain, Proc Natl Acad Sci USA37(4), 205-211, 1951.

[84] Pipenbacher,P., Schliep,A., Schneckener,S., Schönhuth,A., Schomburg,D., Schrader,R.: ProClust: improved clustering of protein sequences with an extended graph-based approach, Bioinformatics, 18(suppl. 2), 182-191, 2002.

[85] Rijsbergen,C.J.: Information Retrieval, 2nd edn. Butterworths, London, 1979 .

[86] Robinson R.: Genetics-Encyclopedias, Volume 3, Macmillan Reference USA, 2003.

[87] Rodeh,M., Pratt,V.R., Even, S.: Linear algorithm for data compression via string matching, Journal of the ACM, 28(1), 16-24, 1981.

[88] Rost,B.: Twilight zone of protein sequence alignments, Protein Eng., 12 , 85-94, 1999.

[89] RCSB Protein Databank - PDB, http://www.pdb.org.

[90] Salton,G.: The SMART Retrieval System - Experiments in Automatic Document Processing, Prentice Hall Inc., Englewood Cliffs, NJ, 1971.

[91] Salton,G., Lesk,M.E.: Computer evaluation of indexing and text processing, Journal of the ACM, 15(1), 8-36, 1968.

[92] Salton,G., Wong,A., Yang,C.S.: A vector space model for automatic indexing, Communications of the ACM, 18(11), 1975.

[93] Salton,G., Buckley,C.: Term-weighting approaches in automatic text retrieval, Information Processing and Management, 24(5), 513-523, 1988.

[94] Sarkar,I.N.: A vector space model approach to identify genetically related diseases, J Am Med Inform Assoc, amiajnl-2011, 2012.

[95] Scadding,J.: Prognosis of intrathoracic sarcoidosis in England. A review of 136 patients after 5 years observations, British Medical Journal, 2(5261), 1165$1172,1961$. 
[96] Shibuya,T.: Geometric Suffix Tree: A new index structure for protein 3D structures. Combinatorial Pattern Matching(LNCS 4009), 84-93, 2006.

[97] Schäffer,A.A., Aravind,L., Madden,T.L., Shavirin,S., Spouge,J.L., Wolf,Y.I., Koonin,E.V., Altschul,S.F.: Improving the accuracy of PSI-BLAST protein database searches with composition-based statistics and other refinements, $\mathrm{Nu}$ cleic Acids Res, 29, 2994-3005, 2001.

[98] Sillitoe,I., Cuff,A.L., Dessailly,B.H., Dawson,N.L., Furnham,N., Lee,D., Lees,J.G., Lewis,T.E., Studer,R.A., Rentzsch,R., Yeats,C., Thornton,J.M., Orengo,C.A.: New functional families (FunFams) in CATH to improve the mapping of conserved functional sites to 3D structures, Nucleic Acids Res., 41, 490-498, 2013.

[99] Slaninová, K., Martinovič, J., Novosád, T., Draždilová, P., Vojáček, L., Snášel, V.: Web Site Community Analysis Based on Suffix Tree and Clustering Algorithm, Web Intelligence and Intelligent Agent Technology (WI-IAT), 2011 IEEE/WIC/ACM International Conference on. Vol. 3. IEEE, 2011.

[100] Sonkoly,E., Pivarcsi,A.: Advances in microRNAs: implications for immunity and inflammatory diseases. J Cell Mol Med, 13, 24-38, 2009.

[101] Styczynski,M.P., Jensen,K.L., Rigoutsos,I., Stephanopoulos,G.: BLOSUM62 miscalculations improve search performance. Nature biotechnology, 26(3), 274-275, 2008.

[102] Tománková,T., Novosád,T., Žurková,M., Kolek,V., Kriegová,E.: Do deregulated miRNAs in sarcoidosis target key pathways towards progressing disease? In IMMUNOLOGY (Vol. 140), pp. 161-162. WILEY-BLACKWELL, 2013.

[103] Tománková,T., Petřek,M., Kriegová,E.: Involvement of microRNAs in physiological and pathological processes in the lung, Respir Res, 11(1), 159-169, 2010 .

[104] Ukkonen,E.: On-line construction of suffix trees, Algorithmica, 14(3), 249260, 1995. 
[105] Vichetra,S., Tai,C.H., Garnier,J., Gibrat,J.F., Lee,B., Munson,P.J.: Towards an automatic classification of protein structural domains based on structural similarity, BMC Bioinformatics, 9(74), doi:10.1186/1471-2105-9-74, 2008.

[106] Vlachos,I.S., Kostoulas,N., Vergoulis,T., Georgakilas,G., Reczko,M., Maragkakis,M., Paraskevopoulou,M.D., Prionidis,K., Dalamagas,T., Hatzigeorgiou,A.G.: DIANA miRPath v.2.0: investigating the combinatorial effect of microRNAs in pathways, Nucleic Acids Research, 40(W1), W498-W504, 2012.

[107] Wang,X., Wang,G., Shen,C., Li, L., Wang,X., Mooney,S.D., Edenberg,H.J., Sanford,J.R., Liu,Y.: Using RNase sequence specificity to refine the identification of RNA-protein binding regions. BMC Genomics, 9(Suppl 1: S17), 2008.

[108] Wang,Y., Stricker,H.M., Gou,D., Liu,L.: MicroRNA: past and present. Front Biosci, 12, 2316-2329, 2007.

[109] Weiner,P.: Linear pattern matching algorithms, Proceedings of the 14th Annual Symposium on Foundations of Computer Science, 1-11, 1973.

[110] Woods,K., Thomson,J.M., Hammond,S.M.: Direct regulation of an oncogenic micro-RNA cluster by E2F transcription factors, J Biol Chem, 282, 2130$2134,2007$.

[111] Zamir,O.: Clustering web documents: A phrase-based method for grouping search engine results. PhD Thesis, University of Washington, Washington, USA, 1999.

[112] Yang J.Y., Yang M.Q., Dunker A.K., Deng Y., Huang X: Investigation of transmembrane proteins using a computational approach. BMC Genomics 9(Suppl 1: S9), 2008.

[113] Ye et al.: Pairwise protein structure alignment based on an orientationindependent backbone representation, Journal of Bioinformatics and Computational Biology, 2, 699-718, 2004.

[114] Zamir,O., Etzioni,O.: Web document clustering: A feasibility demonstration. Proceedings of the 21st annual international ACM SIGIR conference on Research and development in information retrieval, 46-54, 1998. 
[115] Zhang,Y.: Progress and challenges in protein structure prediction, Curr Opin Struct Biol, 18(3), 342-350, 2008.

[116] Zhang,Y. and Skolnick,J.: The protein structure prediction problem could be solved using the current PDB library, Proc. Natl. Acad. Sci. USA, 102(4), 1029-34, 2005.

[117] Ziegenhagen,M.W., MĂĽller-Quernheim,J.: The cytokine network in sarcoidosis and its clinical relevance, Journal of Internal Medicine, 253(1), 18-30, 2003. 


\section{Appendix A}

\section{List of Author's Publications}

\section{Journal Articles}

- Martinovič, J., Snášel, V., Novosád, T.: Vector Model Improvement Using Suffix Trees, International Journal of Computational Intelligence Research, 5(1), 31-40, 2009.

- Novosád, T., Snášel, V., Abraham A. and Yang, J.: Searching Protein 3-D Structures for Optimal Structure Alignment Using Intelligent Algorithms and Data Structures, IEEE Transactions on Information Technology in Biomedicine, 14(6), 1378-1386. 2010.

- Martinovič, J., Novosád, T., Scherer, P., Snášel, V., Šebesta, R., Klement, P.: Clustering the mobile phone positions based on suffix tree and SelfOrganizing Maps, Neural Network Word, 4(12), 371-386, 2012.

- Tomanková, T., Novosád, T., T., Žurková, M., Kolek, V., Kriegová, E.: Do deregulated miRNAs in sarcoidosis target key pathways towards progressing disease?, IMMUNOLOGY, WILEY-BLACKWELL, 140, 161-162, 2013. 


\section{Book Chapters}

- Novosád, T., Snášel, V., Abraham, A., Yang, J.Y: Discovering 3D Protein Structures for Optimal Structure Alignment, Algorithmic and AI Methods for Protein Bioinformatics, Willey, 2013.

\section{Conference Papers}

- Martinovič, J., Snášel, V., Novosád, T.: Využití sufixových stromů pro vylepšení vektorového dotazu, Znalosti, Hradec Králové, 2006.

- Martinovič, J., Snášel, V., Novosád, T.: Vector model improvement using suffix trees, 2nd International Conference on Digital Information Management, IEEE, 1, 180-187, 2007.

- Novosád, T., Snášel, V., Abraham, A., Yang, J.Y. YAPS: Yet Another Protein Similarity, Soft Computing and Pattern Recognition, International Conference of. IEEE, 497-504, 2009 .

- Novosád, T., Snášel, V., Abraham, A., Yang, J.Y. Prosima: Protein similarity algorithm, World congress on Nature $\&$ Biologically Inspired Computin, IEEE, 84-91, 2009.

- Novosád, T., Martinovič, J., Scherer, P., Snášel, V., Šebesta, R., Klement, P.: Mobile Phone Positioning in GSM Networks Based on Information Retrieval Methods and Data Structures, Digital Information Processing and Communications, Springer Berlin Heidelberg, 349-363, 2011.

- Slaninová, K., Martinovič, J., Novosád, T., Draždilová, P., Vojáček, L., Snášel, V.: Web Site Community Analysis Based on Suffix Tree and Clustering Algorithm, International Conference on Web Intelligence and Intelligent Agent Technology IEEE/WIC/ACM, 3, 110-113, 2011. 


\section{Other Conference Papers}

- Novosád, T., Platoš, J., Snášel, V. and Abraham, A.: Fast Intrusion Detection System based on Flexible Neural Tree, Sixth International Conference on Information Assurance and Security (IAS), IEEE, 142-147, 2010.

- Novosád, T., Platoš, J., Snášel, V., Abraham, A., Fiala, P.: Heavy Facilities Tension Prediction Using Flexible Neural Trees, Soft Computing and Pattern Recognition, IEEE, 396-401, 2011.

- Prokop, L., Mišák, S., Novosád, T., Krömer, P., Platoš, J., Snášel, V.: Photovoltaic power plant output estimation by neural networks and fuzzy inference, Intelligent Data Engineering and Automated Learning-IDEAL, Springer Berlin Heidelberg, 810-817, 2012.

- Prokop, L., Mišák, S., Novosád, T., Krömer, P., Platoš, J., Snášel, V.: Artificially evolved soft computing models for photovoltaic power plant output estimation, International Conference on Systems, Man, and Cybernetics (SMC), IEEE, 1011-1016, 2012.

- Krömer, P., Novosád, T., Snášel, V., Vera, V., Hernando, B., Hernandez, L.G., Pardo, H.Q., Corchado, E., Redondo, R., Sedano, J., Garcia, A.E.: Prediction of Dental Milling Time-Error by Flexible Neural Trees and Fuzzy Rules, Intelligent Data Engineering and Automated Learning-IDEAL, Springer Berlin Heidelberg, 842-849, 2012.

- Krömer, P., Novosád, T., Snášel, V., Vera, V., Hernando, B., Hernandez, L.G., Pardo, H.Q., Corchado, E., Redondo, R., Sedano, J., Garcia, A.E.: Evaluation of Novel Soft Computing Methods for the Prediction of the Dental Milling Time-error Parameter, Soft Computing Models in Industrial and Environmental Applications, Springer Berlin Heidelberg, 163-172, 2013. 